\title{
The WOCE-Era 3-D Pacific Ocean Circulation and Heat Budget
}

A. M. Macdonald ${ }^{a *}$, S. Mecking ${ }^{b}$, J. M. Toole ${ }^{a}$, P. E. Robbins ${ }^{a}$, G. C. Johnson ${ }^{c}$, S. E. Wijffels ${ }^{d}$, L. Talley ${ }^{e}$ and M. Cook ${ }^{a}$

${ }^{a}$ WHOI,Clark 3, MS 21, 360 Woods Hole Rd., Woods Hole, MA 02563

${ }^{b}$ APL, Box 355640, Univ. of Washington, Seattle, WA 98105-6698

${ }^{c}$ DOC/NOAA/PMEL/OCRD, 7600 Sand Point Way NE, Bldg. 3, Seattle WA 98115-6349

${ }^{d}$ CSIRO, Marine Research, GPO 1538, Hobart Tas 7000 Australia

e SIO/UCSD,9500 Gilman Dr., La Jolla, CA 92093-0230

* Corresponding author: phone: 508-833-3560, fax: 508-457-2181

Email addresses:

amacdonald@whoi.edu, smecking@apl.washington.edu, jtoole@whoi.edu, probbins@whoi.edu, Gregory.C.Johnson@noaa.gov, Susan.Wijffels@csiro.au, lynne@gyre.ucsd.edu, mcook@whoi.edu

Submitted to Progress in Oceanography 


\section{Abstract}

To address questions concerning the intensity and spatial structure of the 3 -dimensional circulation within the Pacific Ocean and the associated advective and diffusive property flux divergences, data from approximately 3000 high-quality hydrographic stations collected on 40 zonal and meridional cruises have been merged into a physically consistent model. The majority of the stations were occupied as part of the World Ocean Circulation Experiment (WOCE), which took place in the 1990s. These data are supplemented by a few pre-WOCE surveys of similar quality, and time-averaged direct-velocity and historical hydrographic measurements about the equator.

An inverse box model formalism is employed to estimate the absolute along-isopycnal velocity field, the magnitude and spatial distribution of the associated diapycnal flow and the corresponding diapycnal advective and diffusive property flux divergences. The resulting large-scale WOCE Pacific circulation can be described as two shallow overturning cells at mid - to low latitudes, one in each hemisphere, and a single deep cell which brings abyssal waters from the Southern Ocean into the Pacific where they upwell across isopycnals and are returned south as deep waters. Upwelling is seen to occur throughout most of the basin with generally larger dianeutral transport and greater mixing occurring at depth. The derived pattern of ocean heat transport divergence is compared to published results based on air-sea flux estimates. The synthesis suggests a strongly east/west oriented pattern of air-sea heat flux with heat loss to the atmosphere throughout most of the western basins, and a gain of heat throughout the tropics extending poleward through the eastern basins. The calculated meridional heat transport agrees well with previous hydrographic estimates. Consistent with many of the climatologies at a variety of latitudes as well, our meridional heat transport estimates tend toward lower values in both hemispheres. 


\section{ASFA Keywords:}

- Pacific

- Ocean Circulation

- Overturn

- Vertical Advection

- Vertical Mixing

- Heat Transport

- Heat Budget 


\section{Contents}

1 Introduction $\quad 5$

$\begin{array}{lll}2 & \text { Observations and Methods } & 7\end{array}$

$\begin{array}{lll}2.1 & \text { The Data } & 7\end{array}$

2.2 Data Preparation in the Tropics 9

2.3 The Model 11

$3 \quad$ An Estimate of the Pacific 3-D Circulation 17

3.1 Horizontal Circulation $\quad 19$

3.2 Overturn 36

3.3 Dianeutral Circulation 38

3.4 Heat 44

$4 \quad$ Discussion and ECCO-GODAE Comparison $\quad 54$

$\begin{array}{lll}\text { A Appendix: Model Uncertainty } & 61\end{array}$

A.1 Calculation of initial estimates of data covariance 62

A.2 How well are the constraints applied to the inverse model met? 64

$\begin{array}{lll}\text { B Appendix: Velocity Field Initial Assumptions } & 67\end{array}$ 


\section{Introduction}

A primary goal of the one-time World Ocean Circulation Experiment (WOCE) global hydrographic survey, completed in 1998, was to procure data capable of providing a basic description of the ocean's general circulation. The first global estimate of the general circulation resulting from the WOCE survey was that of Ganachaud (1999), which refined several prior global analyses (Macdonald, 1998; Macdonald and Wunsch, 1996; Schmitz, 1995; Broecker, 1991, 1987; Gordon, 1986) with quantitative estimates based on a data set that spanned only 11 years (virtually synoptic in comparison to previous standards). Due to the enormity of the data set and complex nature of the system, global syntheses of the ocean circulation based on the WOCE-era observations such as Ganachaud's have chiefly used zonal lines between land boundaries and thus describe mainly the meridional ocean circulation. The present study contributes to the task of describing the WOCEperiod global circulation in finer detail by using both zonal and meridional transects, but concentrating on the Pacific Ocean.

There exists a prodigious variety of data that have been used to describe particular regions and oceanic phenomena within the Pacific. Investigations based on many of these observations will be described later as the foundation against which results from this work are compared. The present synthesis builds upon the wealth of accumulated knowledge by using the high resolution WOCE-era data to combine regional circulation patterns with the basin scale circulation in a physically consistent fashion. Formally, this is done through development and analysis of a multiple box inverse model for the Pacific circulation. The questions we look to answer here are:

(1) Is it possible to combine the Pacific WOCE one-time survey hydrographic observations (Figs. 1a, a data set that, when combined with some sections taken prior to WOCE, 
spans a time interval of 13 years) into a physically consistent depiction of the threedimensional, time--averaged Pacific Ocean circulation?

(2) Starting with an initial estimate of the circulation (based on geostrophic reference surfaces deduced from water property distributions and estimates of the surface Ekman transports) that may not balance mass locally within estimated errors, what adjustments to that initial circulation does the model invoke to achieve mass balance within uncertainties. Are there areas where mass balance is not achieved within the uncertainties?

(3) What do the results indicate about combining data sets spanning many years and the assumption of "steady state?" What does the synthesis suggest about future surveys?

Given that a consistent flow field is indeed obtained:

(1) What is the model's pattern of isopycnal and diapycnal flow? In what ways is the deduced general circulation similar to and different from previous findings?

(2) What are the model circulation's diapycnal advective and diffusive property fluxes and flux divergences? How do they compare to previous analyses?

(3) What are the derived distributions of net air-sea heat flux? How do they compare to flux climatologies based on atmospheric data?

The paper is laid out as follows. In the next section the inverse model and the observations it uses are described. Section 3 contains a discussion of the resulting estimate of the Pacific Ocean general circulation, beginning first with a presentation of the horizontal (isopycnal) flow field followed by an analysis of the model derived diapycnal "overturning" circulation. A discussion of the model estimates of net air-sea heat exchange constitutes Section 4. The work concludes with a discussion of the results and a comparison to a $1^{\circ}$ ocean state estimate (Stammer et al., 2002, 2003; Wunsch and Heimbach, 2006) which assimilated many of these same observations. It is complemented by Appendix A which dis- 
cusses the model's strengths and weaknesses, including the error analysis and Appendix B which outlines the initial velocity fields chosen prior to inversion.

\section{Observations and Methods}

\subsection{The Data}

The geographical design and implementation of the WOCE Pacific hydrographic survey with its long meridional and zonal lines (Fig. 1a) naturally lends itself to a box model analysis. Our Pacific synthesis inverse model is comprised of 52 "small" boxes (Fig. 1b) bracketed by 44 WOCE and pre-WOCE sections comprised of 3072 hydrographic stations (Fig. 1a, Table 1) which span the basin from $72^{\circ} \mathrm{S}$ to $59^{\circ} \mathrm{N}$ and from $125^{\circ} \mathrm{E}$ to $63^{\circ} \mathrm{W}\left(297^{\circ} \mathrm{E}\right)$, and the land masses within and surrounding the Pacific Ocean (Fig 1c). The model simultaneously analyzes the flow within and between several "large" boxes formed by basin-spanning sections (Fig. 1b), some of which have been previously investigated (Macdonald, 1998; Macdonald and Wunsch, 1996; Ganachaud, 2003b).

All of the hydrographic stations used here span the full ocean depth with temperature and salinity observations processed to $2 \mathrm{db}$ resolution. The vast majority of the stations also returned water samples at up to 36 levels in the vertical that were analyzed for the concentration of dissolved oxygen, silicic acid, phosphate, and nitrate. Details about the sampling conducted on the individual cruises and subsequent data processing are documented on the WOCE Hydrographic Program (WHP) Office website (now known as the CCHDO: CLIVAR and Carbon Hydrographic Data Office) (CCHDO, 2009). All of the data sets are available through the CCHDO. Vertical sections of all of the properties along each of the WOCE and pre-WOCE sections are available in the WOCE Hydrographic Program Atlas, as well as maps of most properties on neutral density and standard depth surfaces (Talley, 2007). 
The model makes use of temperature, salinity, dissolved oxygen, silicic acid and phosphate data along all of the sections. The water sample data about the intersections of the hydrographic lines were used to adjust the data calibrations to minimize in a least squares sense differences among nearby stations in water properties on potential temperature surfaces (Johnson et al., 2001). These adjusted water sample oxygen and nutrient data were subsequently interpolated vertically in neutral density space onto the CTD $2 \mathrm{db}$ levels using a local spline procedure. Missing data were filled using a multi-parameter linear regression technique that makes use of surrounding data (Holfort et al., 1998; Macdonald et al., 2003). This analyzed data set has been submitted to the CCHDO, and is also available through the authors.

At the hydrographic line intersections, the stations that define the geostrophic velocities at the box vertices were carefully chosen to minimize differences in surface dynamic height in an attempt to mitigate aliasing errors caused, for example, by an eddy being sampled on one section and not on another, or other temporal changes in the circulation such as shifts in intensity or position of a front. The choice of a different set of stations for the crossover pairs would have provided different transport estimates at the crossovers. However, the effect of this difference on the overall model or even on a small box should be negligible unless some very large transient feature were included.

Using 16 neutral density $\left(\gamma^{n}\right)$ interfaces, the data were partitioned in the vertical into 15 layers (Fig. 2, Table 2). Some of the lighter layers only exist in the tropics and the densest layer only exists in the southern hemisphere. The interfaces are chosen to broadly distinguish the major Pacific water masses (Table 3 and Fig. 2). Estimates of mass, and water property transports are made within each layer between pairs of adjacent stations. Layer boundaries in the vertical for station pairs are specified by the average depth of the bounding neutral density surfaces of the two stations forming a pair. In turn, layeraveraged properties (property transports) for each station pair are estimated by integrating 
the horizontally averaged water properties (product of the horizontally averaged water properties and velocity) over these depth intervals.

\subsection{Data Preparation in the Tropics}

The steady inverse box model we developed is based on the assumption that the synoptic hydrographic sections are representative of the long-term mean fields. One region where this is particularly suspect is the tropics where massive redistributions of water occur on 2-10 year time scales associated with ENSO (El Niño/Southern Oscillation). To lessen model errors in the tropics due to time variability, the synoptic temperature and salinity profiles obtained on the meridional WHP sections crossing the equator were replaced by estimates of the time-mean fields based on CTD stations archived in the Pacific Marine Environmental Laboratory data base which included the synoptic WHP sections and data from many other sources (Johnson and McPhaden, 1999).

Following their study, historical potential temperature and salinity values on selected neutral density surfaces spanning the water column were averaged about each WHP station site within an averaging window that was $550 \mathrm{~km}$ wide zonally and $110 \mathrm{~km}$ meridionally. The raw profiles were smoothed vertically with an $11 \mathrm{db}$ Hanning filter before use. The mean temperature and salinity on the average depths of the selected isopycnals were subsequently interpolated to $2 \mathrm{db}$ uniformly incrementing pressure series using a local spline procedure. The depth of the surface mixed layer in each raw station was taken as the point at which the density exceeded the upper-10 m-averaged density by $0.05 \mathrm{~kg} \mathrm{~m}^{-3}$. A homogeneous surface layer with thickness equal to the ensemble mixed layer mean was defined at the top of each mean profile. Mean values between the averaged mixed layer depth and the shallowest isopycnal used in the interior averaging process were derived by interpolation. 
Mean station profiles were constructed for each WHP station location between the P04 (nominally along $10^{\circ} \mathrm{N}$ ) and P21 (nominally along $17^{\circ} \mathrm{S}$ ) zonal lines. Dissolved oxygen and nutrient data from each of the WHP stations were then interpolated on isopycnals and mapped onto the mean station density profiles. Lastly, a manual procedure was adopted to identify the latitudes at which each model meridional section would transition between the synoptic realization of the water properties and the average profiles. The fundamental criterion used in the decision was minimization of upper-ocean dynamic height jumps at the transitions. Typically, the transition was made near the latitudes of the two bounding zonal sections. In similar spirit, the time--mean representation of the P04 section at the strongly variable western boundary discussed by Wijffels et al. (1995) was incorporated into the model.

One shortcoming of the historical hydrographic data base is its uneven depth coverage. The number of stations contributing to each mean profile fell off markedly and unevenly at depths below $1000 \mathrm{~m}$. Due to this irregular sampling, the meridional density gradients based on the mean profiles contained spurious structure that, particularly near equatorial latitudes, resulted in large and unrealistic initial-guess zonal geostrophic velocity profiles. There was as well the question of how to estimate the flow at the equator. These issues were both addressed by replacing the relative geostrophic velocity fields and reference velocity unknowns within $200 \mathrm{~km}$ of the equator with initial-guess velocity profiles from directly measured estimates of the mean across-section flows. These profiles were averages of repeated Acoustic Doppler Current Profiler (ADCP) sections individually processed following Johnson et al. (2000, 2002).

Each synoptic ADCP section was objectively mapped to a latitude-pressure grid using $1.18^{\circ}$ latitude by 30 dbar pressure de-correlation length scales assuming Gaussian covariance and a noise to signal energy of 0.01. For simplicity, the mapping was done on pressure surfaces, not isopycnals. The ADCP data analyzed were primarily collected during 
cruises servicing the TAO moored array (McPhaden et al., 1998): $95^{\circ} \mathrm{W}, 110^{\circ} \mathrm{W}, 125^{\circ} \mathrm{W}$, $140^{\circ} \mathrm{W}, 155^{\circ} \mathrm{W}, 170^{\circ} \mathrm{W}, 180^{\circ}, 165^{\circ} \mathrm{E}, 156^{\circ} \mathrm{E}$, and $142^{\circ} \mathrm{E}$. Hence the sections were separated by zonal location into bins centered at these longitudes and then averaged. The ADCP averages closest to each meridional WOCE section crossing the equator were used for that section. One drawback to the directly measured velocities is that they are available only for the upper $\sim 400 \mathrm{~m}$ of the water column. Lacking any additional information, the deep initial-guess velocities in the equatorial strip below $400 \mathrm{~m}$ were simply zeroed.

ADCP velocities are estimates of the absolute velocity field. Therefore, no explicit Ekman component of the velocity was included in the initial guess for the equatorial station pairs. Nor was any unknown associated with the Ekman component for these station pairs. However, owing to the uncertainties in the initial-guess velocity field and proximity to the equator (where the thermal-wind relationship breaks down), the inverse model permitted depth varying adjustments to the initial-guess velocities about the equator (one velocity adjustment allowed per model layer per station pair, see below).

\subsection{The Model}

The inverse box model we developed is based upon the method introduced to the physical oceanographic community by Wunsch (1978) and described in greater detail in Wunsch (1996). A steady hydrostatic geostrophic balance is assumed below the surface layer (and away from the equator) so that the thermal wind equations apply there. Ekman dynamics are assumed in the surface layer. Estimates of diapycnal exchanges and depthindependent velocity adjustments to an initial-guess circulation based on a priori estimates of the geostrophic flow relative to the velocity on specified references surfaces and Ekman transports in the surface mixed layer (Table 4) are sought under a set of constraining conservation equations for properties within individual boxes as a whole, and within individual layer sets. As noted above, depth varying velocity adjustments are derived under constrain- 
ing conservation equations about the equator. How well any particular unknown is resolved by the inverse system is determined by the constraints, weights and uncertainties.

For our model implementation, the general equation describing conservation of a property in a neutral density layer or set of layers has the form:

$$
\begin{array}{r}
\sum_{m} \sum_{i} \sum_{j=U}^{L} \rho_{m i j} a_{i j} \mathbf{v}_{m i i_{R}} C_{m i j}-\sum_{m} \mathbf{E}_{m} \sum_{i} \sum_{k} \rho_{m i k} a_{m i k} C_{m i k} v_{m i k_{E}}-\mathbf{w}_{U} \alpha_{U} C_{U}+\mathbf{w}_{L} \alpha_{L} C_{L} \\
+\mathbf{k}_{\mathbf{z}_{\mathbf{U}}} \alpha_{U}\left(\partial C_{U} / \partial z\right)-\mathbf{k}_{\mathbf{z}_{\mathbf{L}}} \alpha_{L}\left(\partial C_{L} / \partial z\right)+V \mathbf{J} \\
\approx-\sum_{m} \sum_{i} \sum_{j} \rho_{m i j} a_{m i j} v_{m i j_{G}} C_{m i j}-\sum_{m} \sum_{i} \sum_{k} \rho_{m i k} a_{m i k} C_{m i k} v_{m i k_{E}}
\end{array}
$$

where for this equation alone, for clarity, the unknown values are in boldface type and

$i \quad$ are indices to the station pairs;

j are indices to the 2 dbar levels within each layer;

$k \quad$ are indices to the 2 dbar levels in the portion of the mixed layer contained within the layer of interest;

$m \quad$ are indices to each segment (i.e. box side or portion of a side);

$\rho \quad$ is in situ density;

$\mathrm{v}_{G} \quad$ are known geostrophic velocities relative to the reference surface;

$\mathbf{v}_{\mathbf{R}} \quad$ are unknown reference surface velocity adjustments;

$\mathrm{v}_{E} \quad$ are initial Ekman velocity estimates;

$\mathrm{C}_{i \text { or } k} \quad$ are 2 dbar average property concentrations;

$\mathrm{C}_{U}$ or $L \quad$ are average interface property concentrations;

a are vertical layer areas (between station pairs and interfaces);

$\alpha \quad$ are horizontal interface areas (across a box);

$\mathbf{E}_{\mathbf{m}} \quad$ are unknown multiplicative Ekman component correction factors;

$\mathbf{w}, \mathbf{k}_{\mathbf{z}} \quad$ are unknown dianeutral velocity and diffusivity terms;

$\mathrm{U}, \mathrm{L} \quad$ are indices to the upper and lower interfaces bounding the layer;

J are unknown source/sink terms within a layer or set of layers, and

$\mathrm{V} \quad$ is the layer volume. 
These equations are combined to form the by now familiar constraint set $\mathbf{A b}+\mathbf{n}=\mathbf{y}$, where the elements of the $\mathbf{A}$ matrix are $\mathbf{A}_{i j}=\int_{B}^{T} \rho_{i j} \mathbf{a}_{i j} \mathbf{C}_{i j} d p$ and are constructed from the hydrographic station data. $T$ and $B$ are top and bottom neutral densities, respectively, of the layer or sets of layers used in an individual constraint. The vector $\mathbf{b}$ represents unknown adjustments to initial estimates of reference surface velocities, $\mathrm{v}_{R}$ (see Appendix B), dianeutral advection terms $(\mathbf{w})$, dianeutral diffusion coefficients $\left(\mathbf{k}_{\mathrm{z}}\right)$ and air-sea exchange of certain properties (e.g. heat, oxygen, etc.), sources and sinks (e.g. production, remineralization, respiration etc.) at depth $(\mathbf{J})$ of certain properties, and adjustments to the magnitude of the Ekman transport across the box sides. The right-hand side vector, $\mathbf{y}$ contains the derived, initial-guess velocity transports, $\mathbf{v}_{R}$, and can include the a priori estimates of the Ekman transport, freshwater inflow/outflow and other net transport estimates.

The structure of the equations in the near-equatorial region (Section 2.2) is similar except that the unknowns, rather than being corrections to a barotropic velocity at each station $\left(\mathrm{v}_{R}\right)$ and an Ekman component correction factor $\mathbf{E}_{m}$ for each box side, are corrections to the absolute velocity estimates provided by the repeat ADCP sections. There is one absolute velocity unknown for each layer, each value representing the flow within 2 degrees north and south of the equator, similar to Lux et al. (2001). Below the ADCP record $(400 \mathrm{~m})$ the initial guess for the average absolute velocity is zero. The initial estimate of the variance for these unknowns is based on the variance of the ADCP record and is set to $36 \mathrm{~cm}^{2} \mathrm{~s}^{2}$.

Conservation equations vertically integrated over the full water column are used in addition to individual layer property anomaly (see below) constraints (Table 5). Bulk constraints are also applied to outcropping layer sets within each box by including airsea exchange terms in the conservation equations. That is, all outcropping layers within a given box are treated by the model constraints as a single bulk layer. This approach avoids uncertainty associated with outcropping of layer-bounding isopycnal surfaces. The 
use of the outcropping layer constraints allows the model to solve for the air-sea exchange or regeneration/consumption of heat, fresh water, oxygen and nutrients. Deep boxes or portions of boxes that are separated or divided by the bathymetry are defined as distinct sub-boxes for which sets of layer conservation equations are also imposed.

During the course of our study, a variety of models and associated constraint equations were analyzed. Selected results from these runs will be mentioned throughout the discussion where relevant. For clarity of presentation, this manuscript focuses on one particular version of the model (designated "SR" for Small box Redfield model). Model SR imposes constraints (Table 5) on the 52 "small" boxes defined in Fig. 1b and simultaneously on 6 "large" boxes defined by basin-spanning sections. A similar model (Model LR) that uses only these large boxes was also run.

The original small boxes were labeled 1 through 81. As a number of these were combined $^{1}$, the labels provided in Fig. $1 \mathrm{~b}$ represent the combinations. The large boxes are defined by the zonal transoceanic transects at $47^{\circ} \mathrm{N}(\mathrm{P} 01), 24^{\circ} \mathrm{N}(\mathrm{P} 03), 10^{\circ} \mathrm{N}(\mathrm{P} 04)$, $17^{\circ} \mathrm{S}(\mathrm{P} 21)$ and $32^{\circ} \mathrm{S}(\mathrm{P} 06)$ (in conjunction with statements about the Indonesian and Bering Strait throughflows). They are labeled 10002-10007 (Fig. 1b). Note, however their numerical order does not match their north-south order, as 10002-10005 were intended as a comparison to the Ganachaud (1999) model, while 10006 and 10007 use P04, which Ganachaud did not include. In addition, mass conservation constraints are applied to a set of boxes defined by the meridional transects (shown in black (Fig 1b), but not specifically outlined). Three such boxes are defined by the data spanning the Indonesian Archipelago and the meridional transects at $137^{\circ} \mathrm{E}(\mathrm{P} 09), 149^{\circ} \mathrm{E}(\mathrm{P} 10)$ and $165^{\circ} \mathrm{E}(\mathrm{P} 13) ; 2$ boxes are defined by the Drake Passage section and the transects at $179^{\circ} \mathrm{E}(\mathrm{P} 14)$ and $165^{\circ} \mathrm{W}(\mathrm{P} 15)$.

\footnotetext{
$\overline{1}$ There are a number of reasons why the P02 line at $30^{\circ} \mathrm{N}$ is not used in the model. First, the data were not available until after the analysis had begun. Second, it was found that the multi-year, multi-ship P02 data set made the transect problematic for cross-over analysis. Third, $24^{\circ} \mathrm{N}$ and $30^{\circ} \mathrm{N}$ are close, therefore removal of one or other to avoid aliasing in the small boxes 14:19 and 26:31 was necessary.
} 
Finally, mass conservation is required across the meridional lines at $135^{\circ} \mathrm{W}(\mathrm{P} 17)$ and $103^{\circ} \mathrm{W}$ (P18), which are connected to the coast of South America using the zonal segment of P17.

For each Model SR box, conservation constraints are applied to total mass (integrated from surface to bottom), to total silicic acid (except in Southern Ocean boxes - see Ganachaud (1999)), and, within each non-outcropping layer and for the bulk surface outcropping layer, to the water volume and anomalies of salinity, heat, oxygen and phosphate. In addition, a number of local flux constraints such as total flow through Drake Passage and abyssal flow into specific bathymetric cul-de-sacs are stipulated (Tables 5 and 6). An initial estimate of the transport through Bering Strait from the literature is included across each of the zonal lines, and estimated average transport through the Indonesian Passages, also from the literature, is included in the net transport across P21 $\left(17^{\circ} \mathrm{S}\right)$ and P06 $\left(32^{\circ} \mathrm{S}\right)$ (Table 5).

In Model SR, as the name implies, the source/sink terms of phosphate (Jph) and oxygen (Jox) at depth (i.e. within the non-outcropping layers below the euphotic zone) are bound through Redfield ratios (Redfield et al., 1963) using the revised stoichiometric value of 1:-170 for Jph:Jox (Anderson and Sarmiento, 1994). This linkage between phosphate production and oxygen consumption at depth due to predominantly respiratory processes produces better consistency among the nutrient and oxygen transports in the model, and provides additional constraints on the flow fields derived from the inversion. Model nutrient and oxygen budgets will be discussed in a companion paper which builds upon a preliminary analysis of respiration rates resulting from the coupling of the biogeochemical source/sink terms in the model (Mecking et al., 2004).

Expressing layer constraints in terms of property anomalies greatly improves the signal to noise ratio of the tracer data by ameliorating the effects imposed by noise in 
the mass conservation equation (Wijffels, 1993; Ganachaud, 2003b). Within the present model the anomaly constraints are derived only for individual non-outcropping layers. Property anomaly transport, $T_{C}$ is defined as $T_{C}-T_{\bar{C}}$, where $T_{C}$ is the property transport through a station pair in a layer and $\mathrm{T}_{\overline{\mathrm{C}}}$ is the transport of the layer volume mean of the property concentration times the density, $\overline{\mathrm{C}}$. On the right hand side of Equation $1, \mathbf{y}$ therefore becomes $\mathbf{y}^{\prime}=\mathbf{y}-\sum_{i}\left[\left(a_{i} v_{i_{G}}\right)\left(\rho_{i} C_{i}-\overline{\mathrm{C}}\right)\right]$. The left hand side of Equation 1 for an anomaly constraint is derived similarly, with the layer volume mean concentrations also being subtracted from the diapycnal velocity terms. As the mixing terms depend on gradients not anomalies they remain unchanged.

How much noise from mass conservation we believe has been subtracted defines the uncertainty ascribed to the anomaly constraints. The anomaly conservation uncertainty is defined as the standard deviation of the property concentration around the edge of the box times the uncertainty in the associated mass conservation constraint (Ganachaud, 1999), which for individual box layers is set at $2 \times 10^{9} \mathrm{~kg} \mathrm{~s}^{-1}$.

Model LR (Large box Redfield model), is defined through the above set of constraints applied only to the 6 large boxes delineated by the zonal sections. This model is similar to the Pacific sector of the Ganachaud (2003b) model except that it also includes observations from the $10^{\circ} \mathrm{N}$ (P04) line. Model LR was run first. It used initial estimates of dianeutral velocity and diffusion coefficient magnitudes of $10^{-5} \mathrm{~cm} \mathrm{~s}^{-1}$ and $1 \mathrm{~cm}^{2} \mathrm{~s}^{-1}$, respectively. The resulting LR model estimates of dianeutral velocities and diffusion coefficients, as well as their uncertainties, are used as initial estimates for Model SR. Furthermore, to improve signal to noise, the sum of the dianeutral transports in the small boxes of Model SR are required to match the dianeutral transports in the associated large boxes that are also defined within Model SR. 
Model SR has 5064 unknowns that are estimated using 3108 constraints. Uncertainties, which are a priori estimates of data and solution covariance, are applied to each constraint and each unknown, respectively (see Table 7 and Appendix A). Lacking a priori estimates of the correlation among the constraints or unknowns, it was initially assumed that none exist. A solution to the set of simultaneous linear equations (i.e. the constraint equations) was found using a Gauss-Markov formulation (Wunsch, 1996; Macdonald, 1998; Ganachaud, 2003b), which provides, along with an estimate of each unknown, an estimate of its covariance with all other unknowns. This error estimate includes that part of the solution which is not resolved by the given set of constraints (i.e. the null space) and it is used to formulate an a posteriori estimate of the uncertainty in transport. Some of the model constraints are not met. This is an expected result as the uncertainty with which each of the equations is associated represents only a single standard deviation (see Appendix A for details). The solution is an estimate of the absolute circulation, the associated property fluxes and their uncertainties based on our a priori estimates of circulation and uncertainty. This estimate of the 3-dimensional Pacific circulation is described in the next section.

\section{An Estimate of the Pacific 3-D Circulation}

There has been a great deal of effort over the last half century to describe and understand the large-scale circulation of the Pacific Ocean. The works of K. Wyrtki, B. Taft, M. Tsuchiya, B. Warren, J. Reid, and W. Schmitz, as well as a host of others, have laid the groundwork both in broad brush strokes and in great detail for the synthesis we present here. The overall circulation and water masses are reviewed in Talley et al. (2009), among others. In particular, we make quantitative comparisons to the previous findings by the following authors: Schmitz (1996), a synthesis of the results of numerous regional analyses combined to produce a global estimate of ocean circulation; Talley (2003) and Talley et al. (2003) (henceforth T03 and TE03, respectively), which use the basin-wide velocity and 
transport analyses of J. Reid (Reid, 1994, 1997, 2003) to look at overturn within the World Ocean, and Ganachaud (2003b) and succeeding publications, which present a global inverse analysis of the zonal WOCE long lines. The multi-box inverse of Roemmich and McCallister (1989) based on pre-WOCE data from the North Pacific may be viewed as a precursor to the present work. Prior analyses of hydrographic long lines (Wijffels et al., 1995, 1998, 2001; Tsimplis et al., 1998; Bryden et al., 1991) have also been immensely useful.

In some regions, such as the tropics where much of what is known about subsurface flow is based on a single data set, and in this case a time series (TOGA-TAO), it has made sense to compare the present results with a detailed analysis of particular observations (in this case Johnson et al. (2002)). On the other hand, in the North Pacific, for instance, where a variety of previous data sets and associated analyses are available for comparison, our discussion is less one sided. Nevertheless, regardless of the availability of data sets or previous research, the goal is to present an estimate of the circulation consistent with the WOCE era observations, and to determine what previous results are consistent with this flow field. In general, we have not attempted to determine how one might reproduce specific results using the WOCE data set, nor have we sought to understand the full Pacific circulation through an analysis of different, sometimes inconsistent and sometimes incompatible previous results (as in Schmitz (1996)). Rather, the focus has been on combining the observations themselves. In bringing both the zonal and meridional, long transect observations of the one-time WOCE survey together with the supporting literature, we hope to clarify what is known about the general circulation within this largest ocean. In the following section we first present the Model SR horizontal circulation pattern, followed by an analysis of the diapycnal overturn. Throughout the text, unless otherwise indicated, positive values indicate northward, eastward and upward motion; negative values the opposite. 


\subsection{Horizontal Circulation}

We offer several depictions of the model circulation here including net transport across long lines (e.g. Fig. 3), overturn (Fig. 4), and following Roemmich and McCallister (1989) and others, net integrated transports across each small-box side (Fig. 5) to quantify the barotropic (e.g., vertically integrated) circulation. This representation is complemented (Figs. 6a-6h and $7 \mathrm{a}-7 \mathrm{e}$ ) by depictions of the spatial structure of the model horizontal circulation using the cumulative transport integrated along each of the long lines from west to east, and south to north. In the first case, an arrow is drawn each time the cumulative transport increases or decreases by $10 \times 10^{9} \mathrm{~kg} \mathrm{~s}^{-1}$. The arrow is positioned at the midpoint of each segment. Transport residuals (net convergence or divergence) are also reported for each small box. This format is also adopted to document the horizontal circulation within groups of model layers. To limit manuscript length and reduce repetition, integrated transports across multiple adjoining model layers having similar flow patterns are presented rather than the circulation on each of the 15 original layers. Transport fields for individual layers (Table 2) are available from the authors. Model estimates of the diapycnal mass transports into and out of the layer sets are also provided (Figs. $6 \mathrm{~b}-6 \mathrm{~h}$ ).

\subsubsection{The $A C C$}

The largest input of water to the Pacific Ocean is accomplished by the Antarctic Circumpolar Current (ACC) south of Australia. A comparably sized flow exits through Drake Passage, augmented by progressively order-of-magnitude-smaller exports through the Indonesian Archipelago and Bering Strait (Fig. 3, 6a-6h). Section S03 between Tasmania and Antarctica, our westernmost transect, yields an initial (before application of the inverse solution, i.e. relative to a zero reference surface at the bottom) net baroclinic transport estimate of $118 \times 10^{9} \mathrm{~kg} \mathrm{~s}^{-1}$. Continuity dictates that the net transport across S03 must exceed (within uncertainties) the transport through Drake Passage by the sum of the 
fluxes through the Indonesian Archipelago (PIT) and Bering Strait (BS). Model SR's net transport of $141 \pm 5 \times 10^{9} \mathrm{~kg} \mathrm{~s}^{-1}$ is consistent, but somewhat less than the imposed constraint of $149 \pm 12 \times 10^{9} \mathrm{~kg} \mathrm{~s}^{-1}$ (Drake Passage+PIT+BS) and estimated mean net volume transport south of Tasmania suggested by Rintoul and Sokolov (2001) of $147 \pm 10 \times 10^{6} \mathrm{~m}^{3} \mathrm{~s}^{-1}$.

The initial-guess velocity field on the Drake Passage section (S04A/A21) carries a net eastward geostrophic transport of $128 \times 10^{9} \mathrm{~kg} \mathrm{~s}^{-1}$ relative to the bottom. Greater than the initial Tasmania-Antarctica transport estimate, it is constrained to be $138.7 \pm 10.7 \times 10^{9} \mathrm{~kg} \mathrm{~s}^{-1}$ based on the analysis of current meter data by Whitworth and Peterson (1985). We note that the Whitworth and Peterson (1985) transport estimate is consistent with the flux determined from analysis of recent WOCE SR1 repeat hydrographic transects which suggests a mean (from 6 sections between 1993 and 2000) of $136.7 \pm 7.8 \times 10^{6} \mathrm{~m}^{3} \mathrm{~s}^{-1}$ relative to the bottom (Cunningham et al., 2003, 2002). In accordance with the Cunningham et al. (2003) results, Model SR used an initial zero velocity reference surface at the bottom and a variance on $\mathbf{v}_{\mathbf{R}}$ of order $100 \mathrm{~cm}^{2} \mathrm{~s}^{-2}$. The final Drake Passage mass flux estimate from the model is $133 \pm 5 \times 10^{9} \mathrm{~kg} \mathrm{~s}^{-1}$, which is again less than, but consistent with the constraint.

The waters of the Southern Ocean, comprised of deep waters originating in the North Atlantic and intermediate and bottom waters ventilated around Antarctica, circumnavigate the globe within the ACC (Figs. 3 and 6a). The ACC is thus the conduit through which exchanges of mass and properties occur among the three ocean basins. The boundary between the subtropics and the Southern Ocean is defined to be the Subtropical Front (STF) (Klink and Nowlin Jr., 2001; Orsi et al., 1995) which, circumnavigating the globe, is the transition zone between relatively cold and fresh $\left(<\sim 10^{\circ} \mathrm{C}, \sim 34.6\right.$, Subantarctic Surface Water, SASW) and warm and salty $\left(\sim 12^{\circ} \mathrm{C}, \sim 35\right.$, Subtropical Surface Water, STSW) upper waters (Fig. 6c). Within the Pacific a relatively cooler STF lies to the south of Tasmania and New Zealand in the west, and a relatively warmer version is found at $30^{\circ} \mathrm{S}$ in the east. 
The STF is not regarded as part of the ACC proper (Klink and Nowlin Jr., 2001); rather, the ACC is considered to be made up of three regions of strong horizontal density gradients and associated surface-intensified currents. These fronts, which are thought to be continuous throughout the ACC (Rintoul et al., 2001; Orsi et al., 1995), are the Subantarctic Front (SAF, a salinity minimum with temperature increasing northward $>4^{\circ} \mathrm{C}$ at $400 \mathrm{~m}$ ) the Polar Front $\left(\mathrm{PF}\right.$, minimum $\Theta$ at $200 \mathrm{~m}$ is less than $2^{\circ} \mathrm{C}$ ) and the Southern ACC Front (SACCF, $\Theta$ less then $0^{\circ} \mathrm{C}$ above $150 \mathrm{~m}$ ). Using these definitions (based at the Greenwich Meridian) and the spatial distribution provided by Orsi et al. (1995), through examination of the velocity field for strong currents and the property fields for the maxima in temperature and salinity gradients, we are able to identify the more northerly of these fronts $(\mathrm{SAF}, \mathrm{PF})$ in all of the meridional transects. The SACCF lies too far south to be seen in the P18 or P19 data sets.

Compared to the literature (in particular, Orsi et al. (1995) and Rintoul et al. (2001)), we see comparable focusing of the transport fields at these fronts as they pass between the Pacific-Antarctic Ridge and the New Zealand Plateau/Chatham Rise region (P14, P15), the northward excursion with the Pacific-Antarctic Ridge (P16, P17), the widening space between the fronts in the eastern basin with the dip to the south by the SACCF (P18, P19) and, lastly, the squeeze through Drake Passage (Fig. 6a). Model SR's circulation pattern in the west is consistent with previous estimates (see Rintoul et al. (2001), their figure 4.6.5), exhibiting in addition to the 3 fronts mentioned above (SAF $105 \times 10^{9} \mathrm{~kg} \mathrm{~s}^{-1}$ at $51.5^{\circ} \mathrm{S}$; PF $29 \times 10^{9} \mathrm{~kg} \mathrm{~s}^{-1}$ at $57^{\circ} \mathrm{S}$; SACCF $22 \times 10^{9} \mathrm{~kg} \mathrm{~s}^{-1}$ at $\left.63.3^{\circ} \mathrm{S}\right)$, a westward flow south of Tasmania $\left(13 \times 10^{9} \mathrm{~kg} \mathrm{~s}^{-1}, 44.4^{\circ} \mathrm{S}\right)$, an anticyclonic recirculation in the Subantarctic Zone $\left(38 \times 10^{9} \mathrm{~kg} \mathrm{~s}^{-1}, 47.3^{\circ} \mathrm{S}\right)$, and an Antarctic Slope Front $\left(0.7 \times 10^{9} \mathrm{~kg} \mathrm{~s}^{-1}, 65.5^{\circ} \mathrm{S}\right)$. These reported positions are the latitudes about which Model SR's velocity field was integrated to obtain transport estimates. 
In Model SR at Drake Passage, the bulk of the eastward transport occurs in the three jets associated with the SAF $\left(62 \times 10^{9} \mathrm{~kg} \mathrm{~s}^{-1}, 59.6^{\circ} \mathrm{S}\right)$, the PF $\left(44 \times 10^{9} \mathrm{~kg} \mathrm{~s}^{-1}, 61^{\circ} \mathrm{S}\right)$ and the SACCF $\left(30 \times 10^{9} \mathrm{~kg} \mathrm{~s}^{-1}, 63.9^{\circ} \mathrm{S}\right)$. Our estimate of SACCF transport is quite a bit higher than that suggested by Cunningham et al. (2002) $\left(9.3 \pm 2.4 \times 10^{6} \mathrm{~m}^{3} \mathrm{~s}^{-1}\right)$. This difference probably has less to do with temporal variations than it does with spatial differences as the SR1b transect is $\sim 12^{\circ}$ downstream of that used in the model.

Most of the meridional WHP sections in the Southern Ocean do not extend all the way to the Antarctic continent, complicating interpretation of the transport variations with eastward distance. For example, a reduction in net eastward transport poleward of $40^{\circ} \mathrm{S}$ across both P18 and P19 is derived. This decrease is attributable to the transport in the SACCF, which has shifted south of the S4 line at these longitudes. This shift is manifested along $\mathrm{S} 4$ at $67^{\circ} \mathrm{S}$ as strong southward flow between about $150^{\circ} \mathrm{W}$ and $100^{\circ} \mathrm{W}$ balanced by net northward transport across the $67^{\circ} \mathrm{S}$ line in boxes 77 and 78 just west of Drake Passage (Fig. 6a, see Fig. 1b for the location of the boxes). Not to be neglected is a net southward transport across the northern edge of box 78, mainly in the North Pacific Deep Water layers (Fig. 6f) which also contributes to the Drake Passage flow into the Atlantic as originally suggested by Reid (1986) (his Fig. 43).

We grouped the deep and abyssal waters into three layers for presentation: North Pacific Deep Water (NPDW) bounded by the $27.6 \gamma^{n}$ and $28 \gamma^{n}$ surfaces (model layers 11-12), an Upper Circumpolar Deep Water layer ( 28.0-28.1 $\gamma^{n}$, model layer 13) and a Lower Circumpolar Deep Water/Antarctic Bottom Water layer below 28.1 $\gamma^{n}$ (model layers 14-15). All of these layers contribute significantly to the ACC. Manifesting its equivalent barotropic character (shear, but little rotation of the velocity vectors with depth), the ACC flow patterns within these model layers are similar to the barotropic circulation (Figs. 6f-6h). However, the ACC flow in the deepest layer is much smaller relative to the eddy variability. Consequently, the transport distribution map for summed-layer 14-15 
exhibits many flow reversals. In addition to the general eastward ACC flow, a portion of the densest two layers peel off at the Campbell Plateau east of New Zealand to form the northward-directed Deep Western Boundary Current seen at the Tonga-Kermadec Ridge at $32^{\circ} \mathrm{S}$ (Whitworth et al., 1999) and in the Samoan Passage (Roemmich et al., 1996; Freeland, 2001). In the South Pacific, the expected southward return transport of deep waters appears largely between the Tonga-Kermadec Ridge north of New Zealand and $150^{\circ} \mathrm{W}$. The aforementioned southward flow of NPDW just west of S. America across the northern boundary of box 78 (Fig. 6f) also contributes. Farther east, the model has weak northward transport superimposed by eddy variability. These elements of the overturning circulation are more clearly documented in the following section.

The summed-layer 6-8 (26.2-27.1 $\left.\gamma^{n},\right)$ encompassing the Subantarctic Mode Water outcrops in the southern hemisphere in a band between about $30^{\circ} \mathrm{S}$ and $60^{\circ} \mathrm{S}$ (Fig. 6d). South of Australia the ACC carries $30-40 \times 10^{9} \mathrm{~kg} \mathrm{~s}^{-1}$ in this layer, but with distance east, the ACC transport in this density class falls off dramatically with only about $5 \times 10^{9} \mathrm{~kg} \mathrm{~s}^{-1}$ leaving the Pacific through Drake Passage. The bulk of this water mass transformation is accomplished by air-sea forcing. Because these layers outcrop, no layer property anomaly constraints are applied by the model and consequently, no diapycnal mass flux estimates from property anomaly equations are available. Vertical integration of the continuity equation was carried out to produce the cross-isopycnal mass transport estimates for the ACC boxes of summed layer $6-8$. These estimates suggest a strong upwelling $\left(7 \times 10^{6} \mathrm{~m}^{3} \mathrm{~s}^{-1}\right)$ across the $26.2 \gamma^{n}$ interface over the area of the southernmost large box, and a smaller $\left(2.4 \times 10^{6} \mathrm{~m}^{3} \mathrm{~s}^{-1}\right)$ downwelling to deeper layers across the $27.1 \gamma^{n}$ interface. The circulation in summed-layer 9-10 (27.1-27.6 $\gamma^{n}$, nominally the Antarctic Intermediate Water) is quite similar to that of layers $6-8$, though the downstream water mass transformation at these densities in the ACC is much less pronounced (Fig. 6e). 


\subsubsection{The South Pacific Subtropics}

Consistent with the pattern of wind stress and Sverdrup dynamics (Sverdrup, 1947), at southern subtropical latitudes an anticyclonic circulation in the South Pacific Ocean is produced by Model SR (Fig. 5). Eddy variability, particularly in the west, acts to obscure this simple pattern. The transport of the West Wind Drift and STF across the meridional transects between $32^{\circ} \mathrm{S}$ and the ACC meet the South American coast where these flows split north and south into the complex Peru-Chile Current System. To the north lies the westward flow of the South Equatorial Current. The subtropical circulation is closed by the East Australian Current (EAC) at the western boundary.

Within the South Pacific, previous studies of the zonal lines used here (Tsimplis et al., 1998) and earlier data sets (Stommel et al., 1973; Reid, 1973; Wunsch et al., 1983; Macdonald, 1998) have consistently found that there is zonally integrated northward abyssal flow, generally southward deep flow, northward flow of intermediate waters of Antarctic origin and southward, divergent surface flow. The vertically integrated model transport estimates representing the barotropic circulation show a generally northward flow along $32^{\circ} \mathrm{S}$ east of about $160^{\circ} \mathrm{W}$, with generally southward flow to west (Fig. 5). There are, however, regions of fairly strong $\left(10-20 \times 10^{9} \mathrm{~kg} \mathrm{~s}^{-1}\right)$ northward transport west of $\mathrm{P} 16\left(150^{\circ} \mathrm{W}\right)$ along the P21 $\left(17^{\circ} \mathrm{S}\right)$ transect where the balance is more strongly tied to the western boundary and along the Tonga-Kermadec ridge. No explicit model constraints are placed on these flows. Continuity dictates that the net mass transport across P6 $\left(32^{\circ} \mathrm{S}\right)$ and P21 (17 $\left.\mathrm{S}\right)$ balance the Indonesian Archipelago and Bering Strait transports. The model's net northward transports of $8.8 \pm 1.6$ and $10.0 \pm 1.8$ respectively, meet the constraints within the specified uncertainties (Table 5).

The model appears to represent the Peru-Chile Current System reasonably well for the season in which the measurements were taken. Published transport estimates are few 
(Strub et al., 1998; Hill et al., 1998). The Cape Horn Coastal Current and Undercurrent carries nearly $22 \times 10^{9} \mathrm{~kg} \mathrm{~s}^{-1}$ poleward across $\mathrm{P} 17$ where it turns eastward along $53^{\circ} \mathrm{S}$. At $32^{\circ} \mathrm{S}$ between $73-74^{\circ} \mathrm{W}$, the Peru Current carries $10.3 \times 10^{9} \mathrm{~kg} \mathrm{~s}^{-1}$ northward. The poleward Peru-Chile Counter Current $\left(-6 \times 10^{9} \mathrm{~kg} \mathrm{~s}^{-1}\right)$ is found to the east of this flow. In the easternmost $100 \mathrm{~km}$ strongly spatially variable flow integrates to a net southward transport, likely manifesting an eddy-filled realization of the Peru-Undercurrent and Chile Coastal Current (Strub et al., 1998). A similar pattern of alternating north-south flows is found at $17^{\circ} \mathrm{S}$

In the west, the EAC western boundary current transport is $-27 \pm 8 \times 10^{9} \mathrm{~kg} \mathrm{~s}^{-1}$ at $25^{\circ} \mathrm{S}(\mathrm{P} 21)$ and $-40 \pm 8 \times 10^{9} \mathrm{~kg} \mathrm{~s}^{-1}$ at $32^{\circ} \mathrm{S}(\mathrm{P} 6)$. The $25^{\circ} \mathrm{S}$ estimate is comparable to previous estimates of $-25 \pm 6 \times 10^{6} \mathrm{~m}^{3} \mathrm{~s}^{-1}$ from the same section (Ganachaud, 1999; Tsimplis et al., 1998). The $32^{\circ} \mathrm{S}$ EAC estimate also compares well to previous estimates (Wijffels et al., 2001; Ganachaud, 1999; Tsimplis et al., 1998), but is high compared to the 3-year PCM3 current meter record mean value $-22.1 \pm 4.6 \times 10^{6} \mathrm{~m}^{3} \mathrm{~s}^{-1}$ (Mata et al., 2000). The moored record had an root mean square (rms) variability of $30 \times 10^{6} \mathrm{~m}^{3} \mathrm{~s}^{-1}$ with a low of $-19 \times 10^{6} \mathrm{~m}^{3} \mathrm{~s}^{-1}$ and a high of $-63 \times 10^{6} \mathrm{~m}^{3} \mathrm{~s}^{-1}$. Nevertheless, the Mata et al. (2000) P6 estimate integrated to the same (array-spanning) longitude of $154.4^{\circ} \mathrm{E}$ suggested a similar low transport of $-20 \times 10^{6} \mathrm{~m}^{3} \mathrm{~s}^{-1}$ using both an absolute zero reference level of $2000 \mathrm{dbar}$ and one based on the mooring data. Our initial-guess zero-velocity reference surfaces are somewhat deeper, (the bottom near the coast, 2000 dbar just beyond the shelf and 3000 dbar for the 3 deepest station pairs included in the integration) and the model makes significant adjustments, i.e. EAC rms reference velocities of $4.9 \mathrm{~cm} \mathrm{~s}^{-1}$. Altimetric sea surface height data locate strong mesoscale current variability in exactly this region of the P6 transect (Bowen et al., 2005). Thus, the P6 transport uncertainty of $8 \times 10^{9} \mathrm{~kg} \mathrm{~s}^{-1}$ is likely too small as it is only a $1 \sigma$ uncertainty that does not include a direct estimate of mesoscale variability in the region. 
Part of the southward EAC transport turns east, crossing the P14 (172 $\left.{ }^{\circ} \mathrm{E}\right)$ section just north of New Zealand (Fig. 5). The rest either flows southward east of Tasmania, or turns east and then south to join the ACC west of the New Zealand's South Island. The EAC originates from the Coral Sea between $11^{\circ} \mathrm{S}$ and $19^{\circ} \mathrm{S}$ (Fig. 1c) as the southern branch of the South Equatorial Current (SEC) bifurcates into the North Vanuatu Jet and North Caledonian Jet (Gourdeau et al., 2008; Ganachaud et al., 2008).

Bottom waters enter the Pacific via the Southwest Pacific Basin east of New Zealand. As in Ganachaud (1999) at $32^{\circ} \mathrm{S} 17 \times 10^{9} \mathrm{~kg} \mathrm{~s}^{-1}$ moves northward in the deep western boundary current against the Tonga-Kermadec Ridge. This unconstrained DWBC estimate is surprisingly close to the time-averaged transport, $16 \pm 11.9 \times 10^{6} \mathrm{~m}^{3} \mathrm{~s}^{-1}$ from 22 months of current meter data in the PCM9 array (Whitworth et al., 1999).

Hydrography and current meter data in the Samoan Passage $\left(11^{\circ} \mathrm{S}\right)$, give a total mean northward bottom water $\left(\Theta<1^{\circ} \mathrm{C}\right.$ ) transport of $10.6 \pm 1.7 \times 10^{6} \mathrm{~m}^{3} \mathrm{~s}^{-1}$ (Roemmich et al., 1996). This transport they divide into: $7.8 \times 10^{6} \mathrm{~m}^{3} \mathrm{~s}^{-1}$ through the Samoan Passage $\left(169^{\circ}-170^{\circ} \mathrm{W}\right) ; 1.1 \times 10^{6} \mathrm{~m}^{3} \mathrm{~s}^{-1}$ through a gap in Robbie Ridge at approximately $175^{\circ} \mathrm{W}$; and $2.8 \times 10^{6} \mathrm{~m}^{3} \mathrm{~s}^{-1}$ along the eastern side of Manihiki Plateau $\left(160^{\circ}-161^{\circ} \mathrm{W}\right)$. Other recent estimates of the net deep inflow range between 8 and $13 \times 10^{6} \mathrm{~m}^{3} \mathrm{~s}^{-1}$ (Talley et al., 2003; Wijffels et al., 2001; Ganachaud, 2003b; Freeland, 2001; Tsimplis et al., 1998; Macdonald, 1998). Earlier estimates suggested lower values of $1-6 \times 10^{6} \mathrm{~m}^{3} \mathrm{~s}^{-1}$ (Rudnick, 1997; Johnson et al., 1994; Taft et al., 1991).

To match the Roemmich et al. (1996) estimate of mean abyssal inflow, Model SR includes a flux constraint in the lowest two layers of P21 $\left(17^{\circ} \mathrm{S}\right.$, the southern boundary of boxes 56 and 57) and in the lowest existing layer (whose upper interface corresponds to a potential temperature of $1.12^{\circ} \mathrm{C}$ ) across P31 (i.e. the northern boundary of boxes 56 and 57). The model produces a net transport in layers 14 and 15 of $10.0 \pm 0.9 \times 10^{9} \mathrm{~kg} \mathrm{~s}^{-1}$ 
across $32^{\circ} \mathrm{S}$, but a lower net transport of $5.5 \pm 1 \times 10^{9} \mathrm{~kg} \mathrm{~s}^{-1}$ across $17^{\circ} \mathrm{S}$. Although suggesting a larger overall convergence, these estimates are consistent with Ganachaud's (2003b) estimates of $8 \pm 2 \times 10^{6} \mathrm{~m}^{3} \mathrm{~s}^{-1}$ across $32^{\circ} \mathrm{S}$ and $7 \pm 1.3 \times 10^{6} \mathrm{~m}^{3} \mathrm{~s}^{-1}$ across $17^{\circ} \mathrm{S}$. Across the northern boundary of boxes 56 and 57 , we find $1.5 \pm 0.8 \times 10^{9} \mathrm{~kg} \mathrm{~s}^{-1}$ at Robbie Ridge and $5.3 \pm 2.8 \times 10^{9} \mathrm{~kg} \mathrm{~s}^{-1}$ through the Samoan Passage. The model does not realize northward transport on the eastern flank of the Manihiki Plateau, but does find balancing north/south flows in the gap in Manihiki Plateau at $165^{\circ} \mathrm{W}$, consistent with the suggestion by Roemmich et al. (1996) that this gap cannot support a large net transport of abyssal waters. Changes to the constraint weights and to the expected magnitude of the reference level velocities failed to significantly increase the northward flux of bottom water across $17^{\circ} \mathrm{S}$.

\subsubsection{The Tropics}

Within the Tropical Pacific 9 meridional hydrographic lines cross the equator (Fig. 1a), bounded at $10^{\circ} \mathrm{N}$ and $17^{\circ} \mathrm{S}$ by zonal hydrographic lines. Within $2^{\circ}$ of the equator, estimates of absolute mean flow based on CTD/ADCP repeat observations (see Section 2.2) at the 9 meridional lines include, but not exclusively, data from sections taken during maintenance of the TAO (Tropical-Ocean-Atmosphere) and TRITON (Triangle Trans-Ocean Buoy Network) moorings (Johnson et al., 2002) (hereafter JSKM). This combination of hydrography and direct measurements produces some substantial initial net mass imbalances within the boxes. The model reduces these box imbalances to a Sverdrup or less through a reduction in the eastward flow near the equator. The model solution enhances the South Equatorial Current (SEC) in the surface layer of the western basin and the North Equatorial Countercurrent (NECC) in the surface layer of the eastern basin, and increases westward flow at depth about the equator (below $\sigma_{0}=27.1$ ) where the model begins with no motion. The model also makes use of the strong spatial variability in the $10^{\circ} \mathrm{N}$ section to bring the equatorial boxes into balance. 
The zonal equatorial current system dominates the interior tropical circulation. Model SR's estimated barotropic circulation (Figs. 5 and 6a) about the equator is roughly consistent with Sverdrup balance, although with perhaps more spatial structure and stronger flows (Kessler et al., 2002). The band of generally westward transport between $2^{\circ} \mathrm{S}$ and $10^{\circ} \mathrm{S}$ depending on longitude, the eastward transport at and north of the equator to approximately $8^{\circ} \mathrm{N}$ and the westward transport farther north are the SEC, NECC and NEC (North Equatorial Current), respectively. As geostrophy breaks down at the equator, basin scale hydrographic inverse models have typically not included equatorial flows, the exception being the Atlantic studies of Mercier et al. (2003) and Lux et al. (2001). Here, the directly measured climatological velocity data of JSKM, allow us to harmonize estimates of the mean zonal equatorial flows with geostrophic circulation in the rest of the Pacific Ocean.

Sverdrup theory applied to ERS satellite scatterometer winds predicts a westward SEC transport of $20-25 \times 10^{9} \mathrm{~kg} \mathrm{~s}^{-1}$ between $120^{\circ} \mathrm{W}$ and the dateline with a weakening to the east (Kessler and Gourdeau, 2006). Here, local transport extrema of vertical integrals between meridional integration limits of $15^{\circ} \mathrm{N}$ and $10^{\circ} \mathrm{S}$, yield SEC transport estimates ranging from $-3 \times 10^{9} \mathrm{~kg} \mathrm{~s}^{-1}$ at $165^{\circ} \mathrm{E}$ (with a strong broad band of westward transport south of $10^{\circ} \mathrm{S}$ ), to $44 \times 10^{9} \mathrm{~kg} \mathrm{~s}^{-1}$ at $170^{\circ} \mathrm{W}$. SEC transport across $135^{\circ} \mathrm{W}$ and $152^{\circ} \mathrm{W}$ is around $20 \times 10^{9} \mathrm{~kg} \mathrm{~s}^{-1}$, and falls to about $15 \times 10^{9} \mathrm{~kg} \mathrm{~s}^{-1}$ farther east. Model NEC transport estimates range from a low $11 \times 10^{9} \mathrm{~kg} \mathrm{~s}^{-1}$ at $179^{\circ} \mathrm{E}$ (where there are numerous east/west flow reversals to the north of $3^{\circ} \mathrm{N}$ ), to $77 \times 10^{9} \mathrm{~kg} \mathrm{~s}^{-1}$ in the far west (where the New Guinea Coastal Current is included in the estimate). Eastward NECC transport estimates have a similar range with a maximum of $67 \times 10^{9} \mathrm{~kg} \mathrm{~s}^{-1}$ at $170^{\circ} \mathrm{W}$ balancing the strong SEC across this longitude, to a minimum of $15 \times 10^{9} \mathrm{~kg} \mathrm{~s}^{-1}$ in the far east.

Equatorial current transport estimates (Table 8) use the JSKM definitions to allow comparison (see their Fig. 17) as follows. Equatorial Undercurrent (EUC) transport estimates encompass all eastward flow between $2^{\circ} \mathrm{N}$ and $2^{\circ} \mathrm{S}, 23<\sigma_{\theta}<26.5 \mathrm{~kg} \mathrm{~m}^{-3}$. The 
reported NEC, NECC and SEC transports are for $\sigma_{\theta}<26.0 \mathrm{~kg} \mathrm{~m}^{-3}$. NECC transport derives from all eastward flow between $2^{\circ} \mathrm{N}$ and $8^{\circ} \mathrm{N}$. SEC $(\mathrm{N})$, the northern branch of the SEC includes all westward flow between the equator and $2^{\circ} \mathrm{N}$ while $\mathrm{SEC}(\mathrm{S})$, the southern branch of the SEC, is the sum of all westward flow between $8^{\circ} \mathrm{S}$ and the equator. Our own definition for NEC transport is all westward flow between $2^{\circ} \mathrm{N}$ and $15^{\circ} \mathrm{N}$.

As our initial estimates of these current transports derive in part from the data used by JSKM, differences between our results and theirs represent adjustments made by the model to bring the mean direct transport estimates into balance with the surrounding hydrographic, geostrophic flow field. Nearly all our mean equatorial current transport estimates fall within the seasonal ranges reported in JSKM. The SEC(S) transport estimates are within JSKM's error bars for the mean everywhere except at P14 $\left(179^{\circ} \mathrm{E}\right)$ where the model has reduced transport, and across P16 $\left(152^{\circ} \mathrm{W}\right)$, where it is larger. Across P16, the model has a compensating increased NECC eastward flow, but not at P14. A northern SEC branch is evident in the surface waters (summed layers 1-3) at some of the model's eastern meridional lines (Fig. 6b), but not west of $150^{\circ} \mathrm{W}$, where the SEC is found only south of the equator. Model SR's NECC transport estimates are similar to the JSKM's mean values, except at $170^{\circ} \mathrm{W}$ where our value is outside their seasonal range. Although well within JSKM's seasonal range, the model mean EUC transports are consistently lower than JSKM's means.

Off the Philippine coast at latitude $8^{\circ} \mathrm{N}$ is the Mindanao Current, an equatorward boundary current with a transport of $-33.6 \pm 11.2 \times 10^{9} \mathrm{~kg} \mathrm{~s}^{-1}\left(21.5 \times 10^{9} \mathrm{~kg} \mathrm{~s}^{-1}\right.$ above 26.2 $\left.\gamma^{n}\right)$. This transport is comparable to the $25 \times 10^{6} \mathrm{~m}^{3} \mathrm{~s}^{-1}$ found by Wijffels et al. (1996) for $\sigma_{\theta}<26.2$ and to Sverdrup theory (Wijffels et al., 1996; Trenberth et al., 1990). The maximum velocity of $1.1 \mathrm{~m} \mathrm{~s}^{-1}$, found at a depth of about $80 \mathrm{~m}$, is roughly consistent with the results of both Wijffels et al. (1996), using the same data as in this work and Kashino et al. (2005), using 3 years of mooring observations. Boxes 3233, 4445 and 4655 (Fig. 1b) 
define the entrance to the Indonesian Archipelago. The present observations suggest that at least $80 \%$ of the Indonesian Passage Throughflow $\left(-10.4 \pm 1.4 \times 10^{9} \mathrm{~kg} \mathrm{~s}^{-1}\right)$ comes from the Mindanao Current. There is also a strong $\left(16.5 \pm 11.1 \times 10^{9} \mathrm{~kg} \mathrm{~s}^{-1}\right)$ eastward transport just north of the equator contributing to both the NECC and NEC.

The P04 $\left(10^{\circ} \mathrm{N}\right)$ section is notable for its spatial variability; alternating bands of northward and southward transport with amplitudes of 10 to $50 \times 10^{9} \mathrm{~kg} \mathrm{~s}^{-1}$ (Fig. 6a). Strong spatial variability in the $13^{\circ} \mathrm{C}$, intermediate and deep waters along this line were first illustrated by Wijffels et al. (1996) and ascribed to intense geostrophic eddies. Large barotropic transport variations are also obtained with the initial guess velocity field, which was based on deep zero velocity surfaces guided by the water property distributions.

In the abyss, the derived flow of LCDW and AABW is reminiscent of Figure 10 of Johnson and Toole (1993). In particular, the westward bottom flow along the equator west of $160^{\circ} \mathrm{W}$ turning north at the Solomon Rise and Caroline Islands is well depicted in Model SR. This flow emerges from the model chiefly through continuity. The initial guess velocity at depth about the equator was zero and independent velocity adjustments were allowed within each layer at these latitudes. Agreement with the Johnson and Toole schematic east of $160^{\circ} \mathrm{W}$ is poor; eddy noise along $10^{\circ} \mathrm{N}$ masks the net circulation there.

\subsubsection{The North Pacific Subtropics}

The Model SR circulation estimate quantifies elements of the North Pacific anticyclonic subtropical circulation (Fig. 6a). The northern extension of the NEC flows westward between $10^{\circ} \mathrm{N}$ and $24^{\circ} \mathrm{N}$ across all of the meridional sections west of $120^{\circ} \mathrm{W}$. Consistent with the literature (Reid, 1997), this flow is supplied by northward flow across $10^{\circ} \mathrm{N}$ as well as southward flow across $24^{\circ} \mathrm{N}$. At the western boundary, NEC waters bifurcate some flowing southward within the Mindanao Current (discussed above) and some northward within the Kuroshio system. 
Theoretically, the poleward flow of the Kuroshio current balances the equatorward interior Sverdrup circulation. Sverdrup theory suggests a western boundary current carrying greater than $50 \times 10^{6} \mathrm{~m}^{3} \mathrm{~s}^{-1}$ (Tomczak and Godfrey, 1994) south of Japan. The Model SR Kuroshio transport estimate is $31 \pm 2 \times 10^{9} \mathrm{~kg} \mathrm{~s}^{-1}$ northeastward across the western end of the P03 $\left(24^{\circ} \mathrm{N}\right)$ transect (Table 9, Figs. 5, 6a and 7b). This result is not directly constrained and is similar to the $32 \times 10^{6} \mathrm{~m}^{3} \mathrm{~s}^{-1}$ suggested by Roemmich and McCallister (1989) who use both the same $198524^{\circ} \mathrm{N}$ data set and an earlier (1981) section at $137^{\circ} \mathrm{E}$. Our value is also consistent with, though somewhat greater than, other estimates of $24-27 \times 10^{6} \mathrm{~m}^{3} \mathrm{~s}^{-1}$ in the East China Sea (Bingham and Talley, 1991; Chen et al., 1992; Ichikawa and Beardsley, 1993), including the $28 \times 10^{6} \mathrm{~m}^{3} \mathrm{~s}^{-1}$ estimated from the $198524^{\circ} \mathrm{N}$ data set alone (Bryden et al., 1991). Meridional lines constrain the solution to match the larger downstream Kuroshio transports (also noted by Roemmich and McCallister (1989)). Additional northward model transport across P03 just east of the Okinawa Islands has previously been observed as a strongly varying current of -10 to $30 \times 10^{6} \mathrm{~m}^{3} \mathrm{~s}^{-1}$ comprised of mesoscale eddies (Zhu et al., 2003, 2004). The observations and Model SR may have captured the current itself or a strong transient eddy.

The Kuroshio (Table 9) hugs the coast as it crosses P09 at $\sim 31^{\circ} \mathrm{N}, 137^{\circ} \mathrm{E}$, carrying $79 \times 10^{9} \mathrm{~kg} \mathrm{~s}^{-1}$, increasing to $88 \times 10^{9} \mathrm{~kg} \mathrm{~s}^{-1}$ across P10 at $\sim 143^{\circ} \mathrm{E}$ around the same latitude. Prior estimates made to the south of Japan are similar: $80 \times 10^{6} \mathrm{~m}^{3} \mathrm{~s}^{-1}$ (Worthington and Kawai, 1972); and a 7 year (1992-1999) altimetric mean of $57 \times 10^{6} \mathrm{~m}^{3} \mathrm{~s}^{-1}$ with a range of $27-85 \times 10^{6} \mathrm{~m}^{3} \mathrm{~s}^{-1}$ (Imawaki et al., 2001). A large array of echo sounders and current meters (1993-1995) in the region of the P09 line produced a mean Kuroshio mass transport estimate slightly less than but consistent with ours, $65 \pm 4 \times 10^{6} \mathrm{~m}^{3} \mathrm{~s}^{-1}$ with a standard deviation of $\pm 20 \times 10^{6} \mathrm{~m}^{3} \mathrm{~s}^{-1}$ (Book et al., 2002). Our estimate is much less than one study which used the same P10 hydrographic section, but combined it with synoptic direct velocity measurements (Wijffels et al., 1998) (henceforth W98) and found substantial deep 
flow. It would be of interest to see how the model would handle a constraint requiring this larger (W98) $143 \times 10^{6} \mathrm{~m}^{3} \mathrm{~s}^{-1}$ estimate of Kuroshio transport across the $149^{\circ} \mathrm{E}$ section.

Although most of the model Kuroshio transport is carried in the upper waters (layers 8 and above, $<750$ dbar) the northeastward current signature of the Kuroshio is evident near the bottom on all of these lines, with an abyssal countercurrent in the lowest layer of order $1 \times 10^{9} \mathrm{~kg} \mathrm{~s}^{-1}$ (Fig. 6h). This deep flow is consistent across the sections, but not significantly different from zero. As suggested by Sainz-Trapaga et al. (2001), the Model SR Kuroshio Extension bifurcates to the east of P13 $\left(165^{\circ} \mathrm{E}\right)$ and its flow spreads north and south.

In the deep northwest Pacific, the P10 analysis of W98 suggests an energetic circulation, and the present synthesis supports the view of a complex system of gyres and recirculation in the deep northwest. Both the W98 flow schematics and our Figs. 6f-6g show a general pattern of agreement with westward flow in the tropics, and eastward return in the subtropics and along the northwest boundary. The "upper" deep circulation of W98 would be best described by our layers 10-12 (800-2600 dbar), while the "lower" deep corresponds to our layers 13-14.

In the upper deep layers 10-12 within the Caroline Basin to the north of PapuaNew Guinea (P10, Fig 1c), we find a gyre-like circulation as suggested by W98, but in the opposite sense, i.e. eastward flow $\left(10 \pm 5.5 \times 10^{9} \mathrm{~kg} \mathrm{~s}^{-1}\right)$ to the north of Papua-new Guinea and westward $\left(6.6 \pm 6.3 \times 10^{9} \mathrm{~kg} \mathrm{~s}^{-1}\right)$ to the south of the Caroline Islands which lie at about $7^{\circ} \mathrm{N}$ (Fig. 8). The values quoted here are based on the maximum transport integrated from south to north, whereas Fig. 8 shows the values integrated across box sides. Another obvious difference between our results and those of W98 is the presence of a deep, strong southeastward flow along the boundary within the northern tropics. Model SR confirms the existence of the deep westward flow against the northern coast of Papua-New Guinea (W98 
their Fig. 9), but it is small $\mathrm{O}\left(1 \times 10^{9} \mathrm{~kg} \mathrm{~s}^{-1}\right)$ and confined to layer $11(\sim 1100-1600 \mathrm{dbar})$. Differences between our results and W98 may be due the inclusion of surrounding data in Model SR, but are also likely due to the particular methods (direct vs. indirect) of referencing the hydrography. W98 note that the deep water transports in the region are sensitive to referencing choices.

According to Kawabe et al. (2003) the waters that pass through the Samoan Passage divide into an "eastern branch" that flows through the Central Pacific Basin to the east of the Marshall Seamount Chain to eventually enter the Northwest Pacific Basin having passed through the Wake Island Passage, and a "western branch" that flows to the southwest of the Marshall Seamounts and to the north of the Caroline Islands, in particular, mainly westward flow between 2000-3000 to the east and north of the Papua-New Guinea. In the abyss, layer 13 (> 2600 dbar) carries westward flow $\left(9 \times 10^{9} \mathrm{~kg} \mathrm{~s}^{-1}\right)$ to the north of the Caroline Islands (Fig. 8b and W98, LCDW their Fig. 10), a pattern consistent with the deep 'western branch' of Kawabe et al. (2003).

To the north of the Caroline Basin, our flow patterns agree well with those of W98. In the upper deep waters (layer 10-12) there are: $-14.8 \times 10^{9} \mathrm{~kg} \mathrm{~s}^{-1}$ moving westward to the north of $10^{\circ} \mathrm{N} ; 18.0 \times 10^{9} \mathrm{~kg} \mathrm{~s}^{-1}$ returning eastward in the subtropics; and westward flow of $-16.6 \times 10^{9} \mathrm{~kg} \mathrm{~s}^{-1}$, centered on $30^{\circ} \mathrm{N}$ within the Kuroshio recirculation which in these layers carries $17.2 \times 10^{9} \mathrm{~kg} \mathrm{~s}^{-1}$ northward. Missing from the W98 schematic (and analysis) of upper deep waters are the strong north/south exchanges $\mathrm{O}\left(10 \times 10^{9} \mathrm{~kg} \mathrm{~s}^{-1}\right)$ seen across the P04 section in Model SR to the west of the P10 $\left(149^{\circ} \mathrm{E}\right)$ line. Note, these are also are obscured in our figures by the basin-wide layer choices.

The Model SR results in the lower deep waters also agree well with the pattern described by W98 (their Fig. 10). One difference is that we find northward flow of LCDW to west of the Marianas Ridge (P9, $137^{\circ} \mathrm{E}$, Figs. 1a-1c, 8b). 
Further east, the deep current meter moorings of Kawabe et al. (2005) at $18.2^{\circ} \mathrm{N}$, $168.5^{\circ} \mathrm{E}$ and $169.5^{\circ} \mathrm{E}$, indicate mean northward transport of abyssal waters $\left(3.6 \pm 1.3 \times 10^{6} \mathrm{~m}^{3} \mathrm{~s}^{-1}\right.$ with a range of -5.3 to $14.8 \times 10^{6} \mathrm{~m}^{3} \mathrm{~s}^{-1}$ ) through Wake Island Passage and the smaller passages to the west $\left(18^{\circ} \mathrm{N}, \sim 164-170^{\circ} \mathrm{E}\right)$. Just to the south of Wake Island Passage, Uchida et al. (2007) have estimated the Eastern Branch transport at 1.4 to $4 \times 10^{6} \mathrm{~m}^{3} \mathrm{~s}^{-1}$ depending on the referencing scheme. At $10^{\circ} \mathrm{N}$, Model SR finds northward abyssal transport to both the east and west of P14 at $179^{\circ} \mathrm{E}$ (net of $\sim 5 \times 10^{9} \mathrm{~kg} \mathrm{~s}^{-1}$ between $165^{\circ} \mathrm{E}-170^{\circ} \mathrm{W}$ ). Some of these waters turn east across $\mathrm{P} 15\left(165^{\circ} \mathrm{W}\right)$ between $10-24^{\circ} \mathrm{N}$ (Fig. 6h), and some continue northward across P03 $\left(25^{\circ} \mathrm{N}\right)$. Consistent with the Kawabe et al. (2005) and Uchida et al. (2007) estimates of flow in the Eastern Branch and through Wake Island Passage, Model SR finds a net $\sim 2.5 \times 10^{9} \mathrm{~kg} \mathrm{~s}^{-1}$ crossing P03 to east of $165^{\circ} \mathrm{E}$ in the two deepest model layers $\left(>28.1 \gamma^{n}\right)$.

\subsubsection{Subarctic North Pacific}

Adjusted steric height maps (Reid, 1997) evince a North Pacific cyclonic subpolar gyre extending down to about $1500 \mathrm{~m}$ with little variation of the gyre center with depth. Hence, the subpolar gyre is clear in the SR model's vertically integrated transport estimate (Fig 6a).

Westerly winds in the North Pacific drive an Ekman divergence and northward interior Sverdrup flow north of $40^{\circ}-45^{\circ} \mathrm{N}$. In Model SR, this interior northward flux occurs mainly between the dateline and $\sim 150^{\circ} \mathrm{W}$, and is balanced by southward flow within the eastern boundary and the interior west of the dateline. The Kuroshio Extension, discussed in the previous section, flows eastward and broadens to become the North Pacific Current, evident from $170^{\circ}$ to $135^{\circ} \mathrm{W}$. This flow bifurcates at the North American coast. The southern component forms the California Current crossing P03 at about $30^{\circ} \mathrm{N}$, while the northern component contributes to the Alaska Current and Gyre (Fig. 6a) which cuts across P17 
$\left(135^{\circ} \mathrm{W}\right)$ to the north of P01 at $47^{\circ} \mathrm{N}$, forming a rather broad Alaskan Gyre with the southwestward flow of the Alaskan Stream along the Aleutian Islands carrying $10 \times 10^{9} \mathrm{~kg} \mathrm{~s}^{-1}$ across P15 $\left(170^{\circ} \mathrm{W}\right)$.

The Oyashio/Kuroshio mixed water region is characterized by an alternating flow pattern at the far western end of $\mathrm{P} 01\left(47^{\circ} \mathrm{N}\right)$ as shown in the original velocity observations from this section (Talley et al., 1991). Across P13 at $165^{\circ} \mathrm{E}$, the flow pattern agrees at least qualitatively with that of Kawabe and Taira (1995). We find a southwestward transport of $10 \times 10^{9} \mathrm{~kg} \mathrm{~s}^{-1}$ off the coast of Kamchatka and strong $\left(\mathrm{O}\left(25 \times 10^{9} \mathrm{~kg} \mathrm{~s}^{-1}\right)\right)$ east/west flows south of the coastal current and north of P01. Beneath this flow, a deep (layers 12-14, see Table 10) northeastward transport over the slope is reminiscent of the northern boundary current observed at $170^{\circ} \mathrm{W}$ (Warren and Owens, 1985,1988 ) and $180^{\circ} \mathrm{W}$ (Onishi and Ohtani, 1999). A small non-significant southwestward transport along the inshore side of the Kuril Trench is paired with a larger, but still uncertain northeastward flow on the offshore side (Johnson, 1998).

In the deep northwest Pacific off the coast of northern Japan, an analysis of two years of current meter observations at $2000 \mathrm{~m}$ and below (Owens and Warren, 2001) suggested a mean circulation that included a deep southwestward flow over the slope $\left(\mathrm{O}\left(4 \times 10^{6} \mathrm{~m}^{3} \mathrm{~s}^{-1}\right)\right)$ and opposing flows within the trenches that combined produced a net northeastward transport of $10-20 \times 10^{6} \mathrm{~m}^{3} \mathrm{~s}^{-1}$ (Fig. 8). Integrating out from the coast, focusing on maxima in transport in the deep layers 12-14 at each of our North Pacific sections which cross systems, we obtain a similar circulation pattern (Table 10). Not all our numbers are significantly different from zero, but across P01 $\left(42^{\circ} \mathrm{N}\right), \mathrm{P} 10\left(34^{\circ} \mathrm{N}\right)$ and P03 $\left(25^{\circ} \mathrm{N}, 144^{\circ} \mathrm{E}\right)$ we find, as did Owens and Warren (2001), small $\left(2-3 \times 10^{9} \mathrm{~kg} \mathrm{~s}^{-1}\right)$ southward transport over the slope region and opposing flows over the trenches. However, we see strong recirculation beyond the trench system (Fig. 8), and the boundary currents represent only a portion of this northward flow of deep and bottom water. The deep northward transport seen at the far western 
end of P03 $\left(24^{\circ} \mathrm{N}\right)$ is recirculated to the south of the Izu-Ogasawara trench/ridge system (Fig. 8) and little bottom water makes it north of P03 west of P9 (137 E). Nevertheless, our estimate of $13.6 \pm 6.7 \times 10^{9} \mathrm{~kg} \mathrm{~s}^{-1}$ bottom water (layers $13-14$ ) moving northeastward across the northern sector of P01 is consistent with the $10-20 \times 10^{6} \mathrm{~m}^{3} \mathrm{~s}^{-1}$ suggested by Owens and Warren (2001). Overall, abyssal waters move into the region from the east both in the tropics and in the subtropics, recirculate to the east, and flow to the north and east off Kamchatka.

\subsection{Overturn}

The Pacific Ocean has a shallow overturning circulation in each hemisphere with a deep cross-equatorial cell below (Fig. 4). Model SR's overturning circulation is revealed by horizontal integration of layer transport estimates. Because the model layers are defined in terms of neutral density surfaces, what results is the estimated diapycnal overturning circulation, which relates to interior turbulent mixing and air-sea buoyancy fluxes.

In the southern hemisphere, the shallow overturn in made up of northward subsurface flow and a warmer southward return. Laterally, this is the southward flowing East Australian Current (EAC) in the west (Table 9, Figs. 6a, 7d and 7e) balanced by a generally northward flow within the interior. Here, the core of the shallow cell, which reaches upward of $16 \times 10^{9} \mathrm{~kg} \mathrm{~s}^{-1}$, is centered at $17^{\circ} \mathrm{S}$ at less than $100 \mathrm{dbar}\left(24.0 \gamma^{n}\right)$. It deepens to the south. Part of this southern overturning cell extends across the equator, underlying the northern shallow overturn at $10^{\circ} \mathrm{N}$, with northward flow downwelling through the intermediate water layer (Table 2) to 1000 dbar.

The northern hemisphere shallow overturning cell is slightly weaker, but still substantial, carrying $8 \times 10^{9} \mathrm{~kg} \mathrm{~s}^{-1}$ at $10^{\circ} \mathrm{N}$ (core above $22.4 \gamma^{n}$ ) and strengthening to $12 \times 10^{9} \mathrm{~kg} \mathrm{~s}^{-1}$ at $24^{\circ} \mathrm{N}$ (core at about $24.6 \gamma^{n}$ ). In the tropical surface waters, there is a generally north- 
ward flow east of the Mindanao Current (Fig. 7c) which results in a small, net northward transport in the uppermost layer of the model, but a southward transport across the basin below (layers $2-5,22.4 \gamma^{n}$ to $26.2 \gamma^{n}$ ). In the subtropics, the overturn is accomplished laterally by the northward flow in the Kuroshio and an interior southward return (Fig. 7b) occurring mainly at densities just greater than the lightest layers.

This picture of the shallow Pacific subtropical overturn is similar to, though not quite the same as, that described by TE03 using the Reid data set (see TE03 Figs. 2cd). The TE03 cells are weaker and the locations of the cores are different. The weaker cells arise from the lack of resolution of the shallower isopycnal layers in TE03 compared with here. The different core location is due of the exclusion of the tropical sections from the TE03 diagram because of concerns about error arising from the large tropical Ekman transports, that were included differently in TE03 than here. In addition, different data sets were used. Here, we have relied mainly on WOCE-era data whereas the earlier Reid (1997) study made use of pre-WOCE sections in the South Pacific. Geostrophic velocities are referenced differently, although mass is balanced in both treatments, and Ekman flow is included differently.

Similar to previous analyses, Model SR has an abyssal--deep overturning cell that is largely distinct from the shallow cells (Talley et al., 2003; Wijffels et al., 1996; Bryden et al., 1991). Net northward transports in layers 14 and 15 across $32^{\circ} \mathrm{S}$ are $10 \pm 1.1 \times 10^{9} \mathrm{~kg} \mathrm{~s}^{-1}$ and at $17^{\circ} \mathrm{S} 5.5 \pm 1 \times 10^{9} \mathrm{~kg} \mathrm{~s}^{-1}$, chiefly in layer 14 . This flux in the model falls to about $4 \times 10^{9} \mathrm{~kg} \mathrm{~s}^{-1}$ at $10^{\circ} \mathrm{N}$ (layer 14) and $2 \times 10^{9} \mathrm{~kg} \mathrm{~s}^{-1}$ by $24^{\circ} \mathrm{N}$ (partitioned between layers 13 and 14). The compensating southward return flow is chiefly confined to model layers 11 and 12. This upwelling of bottom waters into deep waters is comparable to that in TE03 in each of these cells and each of these longitude ranges. 
In the North Pacific, however, the character of the overturn differs substantially from TE03 which includes downwelling of around $8 \times 10^{6} \mathrm{~m}^{3} \mathrm{~s}^{-1}$ in the deep waters north of $35^{\circ} \mathrm{N}$. The $35^{\circ} \mathrm{N}$ Pacific transect, which is the main source of the deep overturn in T03 and TE03, was not used in our model as it was occupied long before WOCE and was incomplete. (The CTD data were lost in the early 1980s.) The P02 WOCE data set at $30^{\circ} \mathrm{N}$ was also not used here (see Section 2.3). Neither our results at $47^{\circ} \mathrm{N}$ nor at $10^{\circ} \mathrm{N}$ (not included in TE03 because of problems with treatment of the large Ekman transport) show this strong deep circulation feature. Instead, we see only a weak southward transport in the deepest 2 layers across $47^{\circ} \mathrm{N}\left(-0.3 \pm 1.5,-1.3 \pm 1.4 \times 10^{9} \mathrm{~kg} \mathrm{~s}^{-1}\right)$, about half the strength of that in TE03, and similar to that reported by Roemmich and McCallister (1989) and Macdonald (1998) both of whom analyzed this same $47^{\circ} \mathrm{N}$ section. Bottom waters are not formed from surface waters in the northern North Pacific, However, TE03 argued that a deep downwelling cell in the boundary region north of $47^{\circ} \mathrm{N}$ could be driven by deep diffusivity that decreases with height above the bathymetry.

\subsection{Dianeutral Circulation}

Abyssal waters flow north in the Pacific, upwell and return south as deep waters. Here, we use the model to explore upwelling and diffusion associated with this circulation. As mentioned in Section 2.3, the initial estimates of dianeutral velocity (w) and diffusion coefficients $\left(\mathbf{k}_{\mathrm{z}}\right)$ throughout most of the large box model were $0 \pm 2 \times 10^{-5} \mathrm{~cm} \mathrm{~s}^{-1}$ and $1 \pm 1 \mathrm{~cm}^{2} \mathrm{~s}^{-1}$, respectively. The exception was a non-zero initial $\mathbf{w}$ estimate $\left(2 \pm 2 \times 10^{-5} \mathrm{~cm} \mathrm{~s}^{-1}\right)$ for the deepest interfaces of the Central Pacific boxes (10003, 10006 \& 10007) allowed specifically to accommodate the upwelling of bottom waters entering from the Southern Ocean. The large box model (LR) solutions and uncertainty estimates for these variables were used as the initial estimates for the small box model (SR), which was further constrained to have the sum of the dianeutral mass transport in the small boxes match those of the 
associated large boxes. The reader is reminded that Model LR contains only large boxes, while Model SR contains both large and small boxes. Unless otherwise indicated, Model SR results are reported here as these are considered the best estimate. In the following discussion, the terms vertical and dianeutral (meaning across $\gamma^{n}$, neutral density surfaces) are used interchangeably as over broad regions of the Pacific the density surfaces are essentially horizontal. Estimates of $\mathbf{w}$ and $\mathbf{k}_{\mathrm{z}}$ were computed only across the non-outcropping model $\gamma^{n}$ surfaces.

\subsubsection{Dianeutral Advection}

In general, the magnitudes of the estimated vertical velocities (the solution) are consistent with the initial estimates, i.e. w estimates of $0.8-1.6 \times 10^{-5} \mathrm{~cm} \mathrm{~s}^{-1}$ for those with a non-zero initial estimate, and $-0.5-1.2 \times 10^{-5} \mathrm{~cm} \mathrm{~s}^{-1}$ for those with a zero initial estimate. No constraint was imposed on the sign of the solution. However, the dianeutral velocities computed by the model suggest that there is ubiquitous upwelling across density surfaces throughout both the North and South Pacific Oceans (Figs. 9, 10 and 12a-12e), consistent with a Munk (1966)/Stommel and Arons (1960a,b) view of the abyssal ocean. Likewise, diapycnal mixing inferred from the model estimates of $\mathbf{k}_{\mathbf{z}}$ indicate an overall mixing down of heat. Larger values of $\mathbf{w}$ tend to occur near the bottom, although only the three Central Pacific boxes had non-zero initial estimates. The largest values of $\mathbf{w}$ occur in the abyss in the subtropics of both hemispheres and the most vigorous deep and intermediate upwelling occurs in the tropics. In the Central Pacific (boxes 10006 and 10007) there is slightly stronger upwelling across the uppermost non-outcropping interfaces, whereas in the subtropics (boxes 10002, 10006 and 10004) there is tendency toward downwelling across the upper interfaces and a hint of a mid-depth minimum in w (Fig. 9 e.g boxes 1527, 39 and 63). The stronger upwelling in the upper central basin was also suggested by TE03 and Ganachaud (2003b). 
In a number of cases there appears to be a minimum in $\mathbf{w}$ across the deepest interface. This feature is likely an artifact of the relatively small horizontal area through which these deepest w's act. The small area produces a small coefficient in the constraint matrix, which results in a less well resolved unknown, i.e. a solution that is similar to the initial guess.

The estimated w's across the large box density interfaces translate to mass transports of 1 to $3 \times 10^{9} \mathrm{~kg} \mathrm{~s}^{-1}$ with upwelling of northward flowing bottom waters (Fig. 10). There are several differences between our dianeutral transport results and those from the inverse box model of Ganachaud (2003b) whose three Pacific boxes were defined by transoceanic sections at $32^{\circ} \mathrm{S}, 17^{\circ} \mathrm{S}, 24^{\circ} \mathrm{N}$ and $47^{\circ} \mathrm{N}$. 1) The Ganachaud estimates (Table 11) are generally larger than ours, reaching upward of $45 \times 10^{6} \mathrm{~m}^{3} \mathrm{~s}^{-1}$ in the upper Central Pacific. However, our study does not provide values to compare to these very large estimates as we do not estimate $\mathbf{w}$ across the outcropping interfaces. 2) Except in the $32^{\circ} \mathrm{S}-17^{\circ} \mathrm{S}$ box, Ganachaud's results did not suggest increased dianeutral transport at depth. 3) The Ganachaud estimates were not significantly different from zero except in the central basin above $500 \mathrm{~m}$ and below $2200 \mathrm{~m}$, and in the abyss in the southern subtropics. Most of our Model SR, small box $\mathbf{w}$ estimates are also not significantly different from zero. But, Model SR's large box w estimates are significantly different from zero in most regions (Fig. 10).

The inclusion of the small box constraints reduced the uncertainty in the dianeutral velocity estimates, changed their magnitude, and even changed their sign as compared to the large box model. In particular, across the two uppermost, large-box, non-outcropping interfaces, inclusion of the small box constraints reduced the $\mathbf{w}$ estimates on average by an order of magnitude. That is, across these interfaces, without the small box constraints, transports of order $10 \times 10^{9} \mathrm{~kg} \mathrm{~s}^{-1}$ were found in the Central Pacific, not as large, closer to the Ganachaud results. The magnitude of near-bottom $\mathbf{w}$ estimates were not so strongly affected. Model SR is much more strongly constrained by the observations and therefore, 
we take it as our best estimate, i.e. we believe these smaller $\mathbf{w}$ estimates to be more realistic than the large-box model estimates suggested by the zonal sections alone.

The dianeutral advection terms for the small boxes are less well resolved than the diffusion coefficients, $\mathbf{k}_{\mathrm{z}}$. For 1 representing a variable that is completely resolved, meaning the information is available to completely determine its value (as in a system with one equation, one unknown and no solution or constraint uncertainty), and 0 representing a variable that is completely unresolved (which would be the case if no equation constrained the unknown), the average resolution of $\mathbf{w}$ estimates is $0.15 \pm 0.25$ (where 0.25 is the standard deviation, and no value was less than zero). In contrast, the $\mathbf{k}_{\mathrm{z}}$ estimates have an average resolution of $0.35 \pm 0.22$. As mentioned earlier, how well any particular variable is resolved is determined by the constraints, weights and uncertainties. The calculation and interpretation of resolution matrices as they relate to oceanographic box inversions have been discussed previously (Rintoul, 1991; Macdonald, 1993; Wunsch, 1996).

\subsubsection{Dianeutral Mixing}

Dianeutral exchange of properties and closure of the overturning circulation occurs through mixing. Within the box model, vertical mixing is quantified by the dianeutral diffusion coefficients $\left(\mathbf{k}_{\mathrm{z}}\right)$. As previously mentioned, these variables were initially set at $1 \pm 1 \mathrm{~cm}^{2} \mathrm{~s}^{-1}$, similar to the $1.3 \mathrm{~cm}^{2} \mathrm{~s}^{-1}$ suggested over 40 years ago by Munk (1966) based

on the distribution of Pacific radiocarbon data. These values are a weighted average of weak interior values, $0.1 \mathrm{~cm}^{2} \mathrm{~s}^{-1}$ (Munk and Wunsch, 1998; Polzin et al., 1997), and much stronger mixing, 5 to $100 \mathrm{~cm}^{2} \mathrm{~s}^{-1}$, in particular regions such as those near rough topography (Polzin et al., 1997; Heywood et al., 2002; Naveira Garabato et al., 2004; Thurnherr, 2006).

Within Model LR the average estimated $\mathbf{k}_{\mathrm{z}}$ value and uncertainty is $0.5 \pm 0.4 \mathrm{~cm}^{2} \mathrm{~s}^{-1}$ with a general tendency for increased values $\left(0.7\right.$ to $\left.1.6 \mathrm{~cm}^{2} \mathrm{~s}^{-1}\right)$ for those interfaces intersecting large portions of the bottom topography (not shown). The tendency for stronger 
mixing to occur near the bottom and/or side boundaries is supported by recent literature (Muench, 2004; Polzin et al., 1997) and is consistent with the large box results of Ganachaud and Wunsch (2000). The diffusion coefficient estimate associated with the lowest interface is rarely negative, and in these cases, this lowest interface which exists along the southern edge of the box, either does not appear or only appears in a piecewise fashion along the northern edge, invalidating or, at least, weakening the conservation constraints associated with these terms. Except in the deep layers with the large $\mathbf{k}_{\mathrm{z}}$ values which are significantly different from zero, the magnitudes of the Model LR estimated $\mathbf{k}_{\mathrm{z}}$ uncertainties are similar to the estimates themselves.

Model SR, which used the Model LR results as its starting point, produces an average large box $\mathbf{k}_{\mathrm{z}}$ estimate of $0.7 \pm 0.2 \mathrm{~cm}^{2} \mathrm{~s}^{-1}$ (Fig. 11) suggesting that the inclusion of the small box constraints tends to increase the estimates of diffusivities overall, even though the maximum values in the large boxes of Model SR are slightly less than the initial estimates. The average small box SR estimate is $0.9 \pm 0.3 \mathrm{~cm}^{2} \mathrm{~s}^{-1}$ indicating a tendency for larger values in local regions. The SR constraint reduced the uncertainty to the point that virtually all the $\mathbf{k}_{\mathrm{z}}$ estimates are significantly different from zero. Also, all SR estimates are positive as the lowest interfaces were better defined by the small boxes. The greatest large box SR $\mathbf{k}_{\mathrm{z}}$ estimate $\left(1.5 \pm 0.2 \mathrm{~cm}^{2} \mathrm{~s}^{-1}\right)$ is associated with the $28.0 \gamma^{n}$ interface in the northern subtropical box, 10002. The maximum southern subtropical, 10004 , estimate $\left(1.1 \pm 0.5 \mathrm{~cm}^{2} \mathrm{~s}^{-1}\right)$ occurs at the same interface. Between $24^{\circ} \mathrm{N}$ and $17^{\circ} \mathrm{S}$, the maximum occurs at $28.1 \gamma^{n}$, and in the southern ocean box, 10005, largest $\mathbf{k}_{\mathrm{z}}$ estimate occurs at lowest interface, $28.2 \gamma^{n}$. As in Model LR, the SR estimates generally increase with depth and the maximum $\mathbf{k}_{\mathrm{z}}$ estimates in all boxes are $1.0 \mathrm{~cm}^{2} \mathrm{~s}^{-1}$ or greater.

Although many of these small box estimates are significantly different from zero, it is not possible in most instances to state that the $\mathbf{k}_{\mathrm{z}}$ estimates in one box are significantly different from those in another box. However, if we simply look at where the dozen largest 
values occur, we find them all to be deep and in approximate order from largest $(1.5 \pm 0.8)$ to smallest $(1.2 \pm 0.2)$ in boxes:

- 37 and 38 near Hawaii and Mid-Pacific Seamounts,

- 70 and 71 where the ACC crosses the East Pacific Rise,

- 78 to west of Drake Passage,

- 710 in the region of the Alaska Stream and a number of seamounts,

- 35 which includes the Magellan Seamounts and part of the Mariana Ridge system,

- 1224 where the Kuroshio flows to the South of Japan,

- 74 across the South Tasman Ridge,

- and 6667, 61 and 60 over ridge and island systems surrounding New Zealand.

Of the dozen smallest of these maximum deep values (all $\sim 1.0 \mathrm{~cm}^{2} \mathrm{~s}^{-1}$, i.e. not changed from the initial estimate) seven occur in the eastern basin in regions of smoother topography, however the other five occur in regions that include strong bathymetric features. In the vertical, the smallest and largest values, those most different from the initial estimates, occurred at or near the top and bottom of the water column where mixing is expected to be important.

The Ganachaud and Wunsch (2000) estimates of $\mathbf{k}_{\mathrm{z}}$ were generally upwards of an order of magnitude larger than those suggested by Model SR, as were the associated uncertainties. Which is to say, that although both efforts found that strong abyssal mixing was an integral part of the circulation and property distributions, the present results suggest that the very strong deep mixing (diffusivities of order $40 \mathrm{~cm}^{2} \mathrm{~s}^{-1}$ ) found by Ganachaud and Wunsch (2000) are not necessary to the solution on the scale of the small boxes.

The vertical heat fluxes suggested by these $\mathbf{k}_{\mathrm{z}}$ values (Figs. 12a-12e) have obvious maxima where we would expect, i.e. in the boxes surrounding the equator. Within the small boxes (not shown), the largest diffusive heat flux is located in the eastern basin, 
$0.3 \pm 0.1 \mathrm{PW}$ across the uppermost interface of Box 51. The mixing of heat in the boxes along the Californian and South American coasts is much less than what is seen further west at the same latitude. Almost everywhere within the basin heat is diffused from the surface down through the water column. The one exception is in the western Southern Ocean (boxes $74,6667,68,69$ and 70$)$, where there is a consistent pattern of weak $(<0.005 \mathrm{PW})$ upward diffusion of heat through the upper one or two model interfaces $\left(27.8 \gamma^{n}\right.$ and $\left.28.0 \gamma^{n}\right)$. In the far north, mixing appears to be stronger in the west (box 123) than in the east (boxes 710, 809 and 11). In the northern subtropics, there is less mixing in the west (box 1224, 1325), where the Kuroshio hugs the coast than farther east $(1426 \ldots)$, where its extension heads across the interior. Despite their small geographical size, there is reasonably strong mixing of heat through the upper interfaces of the boxes in the region of the Samoan Passage to the south of the SEC $(56,57)$. Abyssal temperatures cooler than surrounding waters on the same isopycnals are associated with the inflow of bottom water in this region (Fig 6h). These waters are warmer in the north than they are at the equator, while the opposite is true throughout the rest of the water column. In the next section, the vertical flux of heat will be discussed in light of the horizontal flow field.

\subsection{Heat}

The meridional transport of heat (energy) by the Pacific circulation is principally poleward. Unlike the North Atlantic where the northward meridional flux of heat arises from the poleward transport of warm western boundary surface waters and a southward return of waters which are on average colder and deeper, in the Pacific the virtual isolation of the upper level and deep water overturning circulations (Wijffels et al., 1996; Bryden et al., 1991), discussed in Section 3.2, means that the poleward heat flux is mainly achieved by a warm poleward surface transport and an only slightly cooler return flow within the thermocline(Talley, 2003). Another way to understand this is that the deep overturn in the 
North Pacific does not involve deep water formation from surface waters, so the temperature difference between northward and southward flowing abyssal waters is small, unlike in the North Atlantic. Heat transport within the North Pacific is thus thought to be more a result of the zonal relationship between temperature and velocity, than a vertical relationship (Bryden et al., 1991). Consistent with this view, Roemmich and McCallister (1989) suggested a strong flux of heat to the atmosphere in the western subtropics and weaker heat gain by the ocean to the east. The pattern of air-sea and meridional heat flux suggested by our model (Fig. 13) also supports this interpretation, but suggests some further details.

\subsubsection{Air-Sea Heat Flux}

Among the 52 small boxes that define the inverse model (Fig. 1b), there is a large range in estimates of time- mean $^{2}$ air/sea heat flux among climatologies created from the surface observations with bulk formulae, numerical models and assimilative models (Fig. 13). Consequently, within the calculated uncertainties of our model, it not difficult to find agreement with at least one climatological estimate in any particular box. Nevertheless, some features of the box model results stand out:

- as expected, a net loss of heat to the atmosphere (positive value) is obtained in the northern basin in the region of the Kuroshio, but a disagreement in magnitude is found with the climatologies in the northwest boxes (1224 and 1325);

- unlike Roemmich and McCallister (1989) in the northern basin north of $24^{\circ} \mathrm{N}$, the only heat gain occurs in the far eastern basin (boxes 1931, 710, 11);

- a net gain of heat (negative values) from the atmosphere over most of the basin is deduced, with the largest influx occurring near the equator. The strongest box-average gain per unit area occurs in the far eastern basin (boxes 4142 and 53), a pattern that agrees qualitatively with all of the climatologies, but with a general tendency toward larger

2 Here, we interpret the annual mean estimates from the climatologies as equivalent to the values suggested from the synthesis of these hydrographic data 
influxes than the climatologies over the central and western tropics and a comparatively smaller heat gain in box 52 ;

- similar to the northern basin, there is a net loss of heat in the southwestern subtropics and gain from the atmosphere in the southeastern subtropics;

- except in the far southeast (boxes 76-78), this pattern continues into the Pacific Southern Ocean with heat loss to the atmosphere in the west and gain in the east.

Summarizing, the Pacific WOCE synthesis suggests a strongly east/west oriented pattern in air-sea heat flux with heat loss to the atmosphere throughout most of the western basins (stretching across the basin north of $20^{\circ} \mathrm{N}$ following the path of the boundary currents and Kuroshio Extension), and a gain of heat from the atmosphere throughout the tropics $\left(20^{\circ} \mathrm{N}\right.$ to $20^{\circ} \mathrm{S}$ ) extending poleward in the eastern basins. Over the full basin, the inverse model finds a net heat gain from the atmosphere of $1.5 \pm 0.3 \mathrm{PW}$, with $1 \mathrm{PW}$ due to the influx between $10^{\circ} \mathrm{N}$ and $17^{\circ} \mathrm{S}$.

The box model pattern of air-sea heat flux agrees well with the adjusted SOC (Grist and Josey, 2003) estimates everywhere except in the southwestern basin. In $62 \%$ of the small boxes where data are available, the SOC flux estimates are within the $1 \sigma$ uncertainty of the box model results. Overall SOC suggests no net heat gain or loss over the Pacific within the boxes defined by the inverse model.

The stronger pattern of heat gain in the central and eastern tropics as well as in the southwest is similar in character to the OAFlux+ISCCP estimates (Yu and Weller, 2007; Rossow and Schiffer, 1999), but the magnitude of the equatorial heat gain is less than that suggested by this climatology. The OAFlux product (Yu and Weller, 2007), which estimates the latent and sensible heat flux components from in situ observations, has been combined with estimates of radiation from the ISCCP (International Satellite Cloud Climatology Program) to produce estimates of net air-sea heat exchange. This combined product shows 
a much larger input of heat in the tropics, particularly in the east, than the inverse model or any of the other climatologies we examined. This strong apparent flux into ocean may be caused by the bias in the ISCCP radiation values toward land-based estimates (L. Yu pers. comm.).

Although agreeing well in character with the box model air-sea exchange estimates, the COADS (da Silva et al., 1994) product has a small net loss of heat to the atmosphere. Compared to our results, an integrated difference over the basin of $1.8 \mathrm{PW}$ is found. This appears to be due to generally more heat loss in the northwest, loss instead of gain over a good portion of the subtropics in both hemispheres, and lower heat gain estimates in the tropics and southern ocean.

Keith's (1995) estimates, like the SOC product, suggest a balance rather than a net gain or loss of heat through air-sea exchange over the Pacific. Unlike SOC, however, the discrepancy appears to be the result of large differences in particular regions, e.g. in the northwest (boxes 1325,1426,1527,1628), in the southeast (box 73), in the southwest (box 7980) and, as with most of the products, in the eastern tropics.

Integrating over the Pacific Ocean, the box inverse results compare, quantitatively, most favorably with NCEP (Kalnay et al., 1996) and ECCO (Stammer et al., 2002), both of which also suggest a net gain of heat over the basin (0.9 PW and 0.6 PW respectively). Both products suggest rather more heat input to the ocean in the eastern tropics and somewhat less in the western warm pool region. They both disagree with the heat gain suggested by the box model in box 60 , but agree in character, if not magnitude, with the net gain of heat over the eastern Southern Ocean sector. These climatologies are less consistent in their pattern over the western sector.

Within the box model, the net gain of energy over the full Pacific from the atmosphere $(1.5 \pm 0.3 \mathrm{PW})$ is nearly balanced by the divergence of temperature transport 
supported by the flow out of the Pacific through the Indonesian Archipelago (1.1 $\pm 0.3 \mathrm{PW}$ relative to $0^{\circ} \mathrm{C}$, equivalent to $10.4 \times 10^{9} \mathrm{~kg} \mathrm{~s}^{-1}$ at an average temperature, $\bar{T} \simeq 26.4^{\circ} \mathrm{C}$ ). There is an additional small, though insignificant, divergence within the ACC which carries a temperature transport (relative to $\left.0^{\circ} \mathrm{C}\right)$ of $1.2 \pm 0.1 \mathrm{PW}\left(141 \times 10^{9} \mathrm{~kg} \mathrm{~s}^{-1}\right.$ at $\left.\bar{T} \simeq 2.2^{\circ} \mathrm{C}\right)$ across the S03 section between Tasmania and Antarctica and $1.3 \pm 0.1 \mathrm{PW}\left(133 \times 10^{9} \mathrm{~kg} \mathrm{~s}^{-1}\right.$ at $\bar{T} \simeq 2.4^{\circ} \mathrm{C}$ ) through Drake Passage. The mass transport into the Arctic through Bering Strait (here calculated as the net across the $47^{\circ} \mathrm{N}$ line) is associated with a southward temperature transport $(-0.07 \pm 0.1 \mathrm{PW})$. The resulting residual convergence of $0.3 \mathrm{PW}$ in the heat balance is not significantly different from zero.

\subsubsection{Meridional Heat Transport}

According to the mooring observations of Woodgate et al. (2006), the annual mean temperature transport through the Bering Strait is 0.003-0.006 PW. Although this outflow of heat into the Arctic can have a significant affect on the freshwater balance within the Arctic Ocean (Woodgate et al., 2006), compared to the calculated Model SR heat transport uncertainty across the long lines $(0.1-0.3 \mathrm{PW})$, it is not significant. Therefore, it shall be ignored, allowing us to calculate meridional heat transport estimates across the zonal lines in the North Pacific (Fig. 14). In the southern hemisphere, we have balanced mass to produce meridional heat transport estimates by combining our Pacific estimates with the Indian Ocean estimate of Ganachaud (2003b). The meridional heat transport estimated from the box model synthesis generally agrees with previous estimates (see references in Fig. 14), but tends toward lower values in both hemispheres.

At $47^{\circ} \mathrm{N}$, our small southward heat transport of $-0.07 \pm 0.1 \mathrm{PW}$ is consistent with all the climatologies and hydrographic estimates we examined except the earlier estimate by Hastenrath (1982). At this latitude, the western boundary current is carrying a northward temperature transport of $0.3 \pm 0.1 \mathrm{PW}\left(20.2 \times 10^{9} \mathrm{~kg} \mathrm{~s}^{-1}\right.$ at $\left.\bar{T}=3.7^{\circ} \mathrm{C}\right)$. The compensation 
or rather over-compensation for this transport occurs to the west of $160^{\circ} \mathrm{E}$, while across the rest of the basin there is net northward temperature transport. Since the estimated value of heat transport across $47^{\circ} \mathrm{N}$ is not significantly different from zero, and since compared to our uncertainty neither is the Woodgate et al. (2006) estimate of temperature transport out of the Pacific into the Arctic, the implied heat transport divergence between $47^{\circ} \mathrm{N}$ and Bering Strait is also not significant.

At $24^{\circ} \mathrm{N}$, there is a larger spread in the available transport estimates. Our value of 0.41 $\pm 0.26 \mathrm{PW}$ is about half that of Roemmich and McCallister (1989), Bryden et al. (1991) and Talley (2003), but similar to that of Ganachaud (2003b) and Stammer et al. (2002), especially when combined with the $47^{\circ} \mathrm{N}$ value to compute divergence between sections.

The inverse model suggests virtually zero heat transport across $10^{\circ} \mathrm{N}(0.03 \pm 0.26 \mathrm{PW})$. The balance is obtained through a near surface overturn consisting of a northward temperature transport in the uppermost layer of $1.0 \pm 0.1 \mathrm{PW}$, a southward transport of $-1.2 \pm 0.1 \mathrm{PW}$ in layers 2-5 ( 70-165 m) and a small northward transport of $0.2 \pm 0.1 \mathrm{PW}$ in layers $6-7$ (165-390 m). Laterally, the Mindanao Current effects a $-2.3 \pm 0.3 \mathrm{PW}$ temperature transport $\left(-33.6 \times 10^{9} \mathrm{~kg} \mathrm{~s}^{-1}\right.$ at $\left.\bar{T}=20.2^{\circ} \mathrm{C}\right)$ southward. Approximately two-thirds of the balancing interior northward transport occurs in the recirculation to the west of $140^{\circ} \mathrm{E}$. Nevertheless, in the eastern basin (east of $130^{\circ} \mathrm{W}$ ), there is a marked northward flow and southward return (see Figs. 5, 6a and $6 \mathrm{~b}$ ) which also contributes to the heat balance across $10^{\circ} \mathrm{N}$. It should also be noted that within the inverse model there is a large, $\mathrm{O}(1 \mathrm{PW})$, residual in the outcropping layers of the large box $10007\left(10^{\circ} \mathrm{N}\right.$ is the northern boundary) and smaller residuals of opposite sign in the lower layers (see the discussion in the next section).

The inverse model estimate of meridional heat transport across at $10^{\circ} \mathrm{N}$ is interesting as it represents departure from an already wide range of hydrographic estimates. These, previous estimates showed a northward heat transport at this latitude, of $0.7 \pm 0.5 \mathrm{PW}$ 
Wijffels et al. (1996), 0.44 $\pm 0.26 \mathrm{PW}$ (Macdonald, 1998), and 1.25 PW based on the Reid data set (Talley, 2003) All these estimates are based on the same hydrographic data set. However, as well as the extreme spatial variation seen in the mass transport (Section 3.1.3) at this latitude, the velocity field is known to be subject to both seasonal and inter-annual variability (JSKM) making the calculation of a mean value difficult. Furthermore, the trade winds produce a large and uncertain Ekman transport $\mathrm{O}\left(25-40 \times 10^{9} \mathrm{~kg} \mathrm{~s}^{-1}\right.$, depending on the wind product used), across $10^{\circ} \mathrm{N}$ to which box model heat transport estimates are sensitive. All these factors contribute to a strong variance and large uncertainty in heat flux across $10^{\circ} \mathrm{N}$.

In the South Pacific, comparing estimates of meridional heat transport (or rather, because there is a significant net mass transport, enthalpy, which is commonly referred to as temperature transport, $\mathrm{T}_{\theta}$ ) is complicated by the varying estimates of the Indonesian Throughflow and net mass transport through the sections. Combining our South Pacific estimates of $\mathrm{T}_{\theta}$ with the Indian Ocean estimates of Ganachaud and Wunsch (2000) after scaling by the respective estimates of $\mathrm{T}_{\theta}$ through the Indonesian Archipelago for the two models, we obtain Indo-Pacific estimates of heat transport south of the equator. At $17^{\circ} \mathrm{S}$, our net heat transport of $-0.9 \pm 0.7 \mathrm{PW}$ is lower than, but consistent with all previous estimates except that of Hastenrath (1982). At $32^{\circ} \mathrm{S}$, our estimate of $-0.6 \pm 0.4 \mathrm{PW}$ is consistent with, but slightly greater than that of Ganachaud and Wunsch (2000) and Talley (2003), and is also similar to the estimates of Sloyan and Rintoul (2001b) and Wijffels et al. (2001). All, but T03, were based on the same Pacific (P6) and Indian Ocean (I5) hydrographic lines.

The inverse model's meridional temperature transport estimates across South Pacific latitudes are small, and not significantly different from zero (0.3 and $0.1 \pm 0.3 \mathrm{PW}$ across $17^{\circ} \mathrm{S}$ and $32^{\circ} \mathrm{S}$, respectively). The East Australian Current carries between $-1.6 \mathrm{PW}$ $\left(-26.1 \times 10^{9} \mathrm{~kg} \mathrm{~s}^{-1}\right.$ at $\left.\bar{T}=15^{\circ} \mathrm{C}\right)$ at $17^{\circ} \mathrm{S}$ and $-1.9 \mathrm{PW}\left(-39.7 \times 10^{9} \mathrm{~kg} \mathrm{~s}^{-1}\right.$ at $\left.\bar{T}=12^{\circ} \mathrm{C}\right)$ at 
$32^{\circ} \mathrm{S}$ southward temperature transport, with most of the interior northward return transport occurring to the east of $140^{\circ} \mathrm{W}$.

Our Indo-Pacific estimates are extremely sensitive to the true value of Indian Ocean $\mathrm{T}_{\theta}$, first because it dominates the net Indo-Pacific values, and secondly, because we do not have a direct and completely consistent estimate of the Indian Ocean overturn or the net mass transport across the Indo-Pacific in this model. Ganachaud and Wunsch (2000), Wijffels et al. (2001) and Bryden and Beal (2001) discuss the various issues surrounding the calculation of $\mathrm{T}_{\theta}$ in the South Indian Ocean.

Integrating past climatologies from north to south results in a large spread in the indirect meridional heat transport estimates at $67^{\circ} \mathrm{S}$. Our estimate is essentially zero $(-0.01 \pm 0.02 \mathrm{PW})$, and results from very low temperatures and small temperature differences rather than weak north-south flows. The lack of significant meridional heat transport is consistent with the estimates of da Silva et al. (1994); Keith (1995); Trenberth and Solomon (1994). However, $67^{\circ} \mathrm{S}$ is the only latitude for which our value is obviously different from both the ECCO (Stammer et al., 2002) and NCEP (Kalnay et al., 1996) estimates which are both strongly southward. It is also significantly different from the SOC (Grist and Josey, 2003) value which is strongly northward.

\subsubsection{Heat Balance}

Within the box model, air-sea heat fluxes are not calculated solely from the ocean transport divergence, but rather are estimated as model unknowns (Equation 1) for each box. Along with the heat anomaly conservation equations which directly constrain our estimates of ocean heat transport, the constraints that form the basis for these estimates of air-sea exchange require a balance between transport divergence and air-sea heat flux. Without these constraints, the meridional heat transport results (Fig. 14, Section 3.4.2) do not change significantly, but extremely large gains in heat by the ocean dominate, 
particularly in the tropics, similar to the OAFlux+ISCCP estimates (Fig. 13). Requiring a balance between ocean heat divergence and air-sea heat flux reduces these air-sea heat flux estimates and produces the pattern shown in the figures. Throughout this section, a gain of heat by the ocean from the atmosphere is shown as a positive value. A loss is negative. Convergences are positive. Divergences are negative.

In the northernmost large box bounded by the hydrographic lines across $47^{\circ} \mathrm{N}$ and $24^{\circ} \mathrm{N}$, the net loss of heat to the atmosphere of $-0.4 \mathrm{PW}$ (Fig. 12a) arises from the input of energy through advection. Across $24^{\circ} \mathrm{N}$, there is a strong advective component in the upper three layers, two-thirds of which is returned in layers $4 \& 5$. The former carries the warmer surface waters of the Kuroshio Current, while the latter are the returning cooler surface waters in the interior. An additional weaker advective input occurs at the northern box boundary and 0.3 PW is mixed down into the non-outcropping layers. Vertical advection does not play a significant role in the balance which has a residual in the outcropping layers of $-0.15 \mathrm{PW}$. The compensation for this residual occurs in the convergence in layers 6 and 7, just below the outcrop.

The large subtropical box (Fig. 12b) defined by the lines across $24^{\circ} \mathrm{N}$ and $10^{\circ} \mathrm{N}$ gains 0.4 PW from the atmosphere, consistent with T03. This input is balanced by divergence in the outcropping layers and mixing through the thermocline. Although the top to bottom residual is tiny $(0.01 \mathrm{PW})$, the residual within the bulk outcropping layer is large $(-0.65 \mathrm{PW})$ and is perhaps indicative of missing or unresolved physics. In particular, vertical transport terms may not be well resolved.

Within the tropics (Fig. 12c), bounded by data across $17^{\circ} \mathrm{S}, 10^{\circ} \mathrm{N}$, and the Indonesian Passages, the 0.9 PW of heat gained from the atmosphere leaves the region in the surface waters to the south $(-1.0 \pm 0.1 \mathrm{PW})$ and north $(1.0 \pm 0.1 \mathrm{PW})$, as well as to the west $(-0.7 \pm 0.1 \mathrm{PW})$. The Indonesian Throughflow carries another $-0.3 \pm 0.1 \mathrm{PW}$ from the Pa- 
cific to the Indian Ocean in model layers 2 and 3. To supply this loss as well and the mixing down of another $1 \mathrm{PW}$, there is a convergence of heat in the lower outcropping layers and upwelling from beneath. The residual within the outcrop layers is also $\mathrm{O}(1 \mathrm{PW})$ and is balanced by the residuals in the lower layers. If it were assumed that the residuals could be taken up by the vertical advection term, which is not as well resolved as the diffusion coefficient (Equation 1), the upwelling of heat would be enhanced over what is shown.

The southern subtropical heat balance (Fig. 12d) is similar to its northern counterpart (Fig. 12b) in that there is uptake from the atmosphere, a strong advective input from the tropics in the upper most layers, divergence within the outcropping region beneath, and mixing to the lower layers. The vertical advective term is again small and not significantly different from zero, but suggests an overall pattern of upwelling.

There is a net uptake of heat from the atmosphere in the Southern Ocean box (Fig. 12e). This, together with warm subtropical surface waters entering from the north and divergence below, suggest a downwelling in the upper layers in this region. Below, but still within the outcrop layer, there is convergence and upwelling of intermediate waters and mode waters. There is a net loss of heat to the north $(0.18 \mathrm{PW})$ across $32^{\circ} \mathrm{S}$ within the outcrop layers due to advection and no net transport in these layers across southern boundary at $67^{\circ} \mathrm{S}$. The net top to bottom temperature flux estimate of $0.08 \pm 0.07 \mathrm{PW}$ is similar to the $0.13 \pm 0.04 \mathrm{PW}$ found by Sloyan and Rintoul (2001b). The pattern seems reasonable. However, the balance of heat in the model's Southern Ocean is dubious at best. Most of the numbers are so small south of $32^{\circ} \mathrm{S}$ as to be not significantly different from zero. Also, the southernmost values, labeled ACC in the figure, are a combination of the estimates across the large and variable inflow at S03, the nearly equally large and also variable outflow through Drake Passage (A21) and the northern boundary of boxes 7980 and 81. The latter are deemed questionable because the "mean" they are intended 
to represent is defined by summer transect data. In all likelihood, all model layers outcrop within these southern ocean boxes in the wintertime.

\section{Discussion and ECCO-GODAE Comparison}

Here we have presented a synthesis of Pacific hydrographic transects largely observed over a seven year period between 1989 and 1996. However, since two of the main zonal transects occurred in $1985\left(24^{\circ} \mathrm{N}\right.$ and $\left.47^{\circ} \mathrm{N}\right)$ and a short section in the South Pacific in 1998, the actual period of observation is nearly twice that: 13 years Furthermore, these data include observations from all four seasons. We have shown where the resulting 3dimensional circulation patterns and transport are similar to and different from the results of previous, often more regional studies, some of which include better temporal coverage. We have found, more often than not, that the box model estimate of the circulation is consistent with these previous findings. Nevertheless, it is necessary to ask whether it is reasonable to assume a steady state over a period of more than decade. Over what spatial and temporal scales, and in what regions can one reasonably assume that such a synthesis will provide useful qualitative and quantitative estimates of circulation?

With these questions in mind, we performed a comparison along Model SR's long transects with the results of the ECCO-GODAE global assimilation (Stammer et al., 2002, 2003). This comparison was intended to compare and contrast the solutions for the two different data synthesis techniques to better understand the "mean" state of the largescale, Pacific general circulation, and to begin to understand how the techniques used to arrive at these estimates affect our understanding of the circulation. We were not looking to dismiss one solution or the other because of mismatch.

The ECCO-GODAE global model (Stammer et al., 2002, 2003; Wunsch and He-

imbach, 2006) is a data synthesis bringing together a numerical model with a variety of 
observational data sets which include both in situ and satellite observations. It is a forward running general circulation numerical model (the MIT-GCM (Marshall et al., 1997)) defining the three components of velocity, temperature, salinity and sea surface height at each grid point, with an adjoint component which, through the method of Lagrange multipliers, seeks the minimum adjustment to a control vector (defined as temperature and salinity initial conditions, air-sea forcing fields and other parameters, e.g. mixing coefficients) consistent with model constraints defined by observations.

Iteration 177, version 2 of ECCO-GODAE is used for this analysis (ECCO henceforth). It covers the period $1993-2005$, has $1^{\circ} \times 1^{\circ}$ horizontal resolution, 23 vertical depth levels, and is considered global although it does not include the Arctic. It is constrained to the Hamburg hydrographic climatology (Gouretski and Koltermann, 2004) below $300 \mathrm{~m}$ and to the World Ocean Atlas monthly means (Levitus et al., 1994; Levitus and Boyer, 1994) and all available satellite information (e.g. SST, SSS, NCEP) above $300 \mathrm{~m}$. It includes constraints to the WOCE long line data used in Model SR that fall within its time frame. It also includes constraints intended to remove runaway trends, and therefore, should have skill in estimating the time-average circulation. Here we make comparisons to the timeaveraged ECCO Pacific circulation for the period 1994-2005.

Although the main focus of the ECCO investigations to date has been on temporal variations, the time-averaged fields have not been ignored. Using the 1993-2000 integration, Stammer et al. (2003) discuss various mean aspects of the circulation, including the nature of strong current regimes, and estimates of the oceanic heat and freshwater fluxes and flux divergences. ECCO continues to evolve as observations and constraints are updated. A variety of changes and improvements have occurred since the 2003 publication. For example, in the Stammer et al. (2003) integration, the time-averaged Drake Passage throughflow was $124 \times 10^{6} \mathrm{~m}^{3} \mathrm{~s}^{-1}$, less than both our inverse model estimate of $133 \pm 7 \times 10^{9} \mathrm{~kg} \mathrm{~s}^{-1}$ and the $140 \pm 7 \times 10^{6} \mathrm{~m}^{3} \mathrm{~s}^{-1}$ of Ganachaud and Wunsch (2000), both based on WOCE hydrography. 
The ECCO version used here produces a significantly larger estimate, $146.1 \pm 4.9 \times 10^{6} \mathrm{~m}^{3} \mathrm{~s}^{-1}$ (Olson, 2006).

The ECCO model grid is defined in depth space, whereas Model SR is defined in density space, complicating the comparison. In Table 12 and in the following discussion, the Model SR solution reference velocities have been applied to $10 \mathrm{dbar}$ initial-guess velocity fields. The transports have been recalculated in pressure space, ignoring the difference between pressure and depth. We do not compare the vertical circulation as our $\mathbf{w}$ and $\mathbf{k}_{\mathrm{z}}$ terms are defined to be orthogonal to $\gamma^{n}$ surfaces. Since mass is not completely conserved in individual box layers, vertical integrations over large pressure intervals are misleading. Calculation of Model SR uncertainties in pressure space are not attempted. The quoted ECCO uncertainties are the standard deviation of the monthly fields.

Major Pacific current transports are compared between these models (Table 12). The two sets of results are consistent in their estimates of both the mean transport and, somewhat surprisingly, the uncertainty, lending some credence to the ergodic assumption (at least at the scales represented). Unsurprisingly, the lateral position of some of these currents is different in the two models. The ECCO mean currents and recirculations tend to be broader because of the $1^{\circ}$ resolution and the temporal averaging. True time-mean current widths are likely narrower than the time-mean ECCO's (model resolution effect) and wider than Model SR's, or indeed any synoptic hydrographic section's. The vertical extent of the currents is generally less in ECCO than in Model SR, suggesting the need for further iteration to allow the less numerous subsurface observations to influence the deeper water column.

ECCO estimates of mean transport stream function across the Pacific long lines (Figs. 15a-15f, Table 13), exhibit differences compared to Model SR net transports due to the lack of a Bering Strait throughflow and net freshwater transports in ECCO. The surface 
outcropping layer circulations appear to be most different along the transects associated with the strongest wind fields. The shape and magnitude of the upper subsurface and intermediate layer circulations are more often similar. There is little similarity in flow patterns at depth. In the Southern Ocean across Drake Passage, the ACC dominates the transport stream function. The most obvious difference is that there are not ACC fronts in the non-eddy resolving, time-averaged ECCO results.

At the surface, the $24^{\circ} \mathrm{N}$ (Fig. 15b) and $32^{\circ} \mathrm{S}$ (Fig. 15e) results present a better match than most, perhaps because the subtropical gyre is strong near the surface. Closer to the equator at $10^{\circ} \mathrm{N}$ (Fig. 15c) and $17^{\circ} \mathrm{S}$ (Fig. 15d) the surface circulations bear less resemblance to one another. At $10^{\circ} \mathrm{N}$, the ECCO section begins further east within the South China Sea. The Mindanao Current can be seen in both the ECCO and the Model SR results, but whereas the net northward surface flow in Model SR carries about $8 \times 10^{6} \mathrm{~m}^{3} \mathrm{~s}^{-1}$, ECCO suggest a net of $18 \times 10^{6} \mathrm{~m}^{3} \mathrm{~s}^{-1}$. In the $100 \mathrm{~m}$ below this layer, the returning southward flow suggested by ECCO is also stronger so that the net transport in the upper $200 \mathrm{~m}$ is similar $\left(4-5 \times 10^{6} \mathrm{~m}^{3} \mathrm{~s}^{-1}\right)$. At $17^{\circ} \mathrm{S}$ in the western basin, the ECCO surface meridional circulation could be described as a smoothed version of the Model SR result, but in the eastern basin they bear no resemblance to one another. Both these sections are affected by strong, variable wind fields (Table 4) that may be at the root of the differences between the two results. At $47^{\circ} \mathrm{N}$ (Fig. 15a) where the winds are weaker, the net transport in the uppermost layers $(0-55 \mathrm{~m})$ is similar, but where Model SR suggests a western boundary current, a recirculation and northward surface transport across most of the basin, the mean suggested by ECCO consists of general southward transport across the entire basin which is the result of a more southerly mean track of the Kuroshio in ECCO. Below the surface (50-1000 $\mathrm{m})$ at $47^{\circ} \mathrm{N}$, the Model SR pattern of meridional transport is similar to that found near the surface, and within this depth range, the ECCO circulation shows much better agreement. 
In general, below the surface, away from the direct effect of the wind, the two estimates of circulation are in better agreement, particularly in the subtropics. At $10^{\circ} \mathrm{N}$, the mean northern shallow overturn described by ECCO (Fig. 15c) would appear to be stronger than that suggested by the hydrography alone (Fig. 4), while the depth of the overturn is similar. The Model SR southern shallow overturn with its core at $17^{\circ} \mathrm{S}$ at about $90 \mathrm{~m}$ (Fig. 4) is lost in depth coordinates (Fig. 15d). Nevertheless, the two models do suggest similar magnitudes and bottom depths for this feature. In both hemispheres, patterns are similar to about $1000 \mathrm{~m}$, but the magnitude of the ECCO gyre-scale flow is less in nearly every case. At $32^{\circ} \mathrm{S}$ (Fig. 15e) this pattern is particularly obvious.

At depth, net basin-wide transports are similar, but strong spatial variations on 100-1000 km scales in Model SR are absent in the time-averaged ECCO. At $10^{\circ} \mathrm{N}$, the strong barotropic signal (the vertical coherence of meridional flows noted in Section 3.1.3) seen in Model SR, is not evident in ECCO. The ECCO mean deep inflow at $32^{\circ} \mathrm{S}$ is confined further to the west than in Model SR, and is larger than in Model SR at $17^{\circ} \mathrm{S}$

In summary, Model SR (the one time hydrography) across some of the long lines presents a different picture of the surface circulation from that suggested by the spatially smooth, temporal-mean ECCO results, a more similar general pattern at intermediate depths, and a stronger, spatially more variable, and perhaps more realistic circulation at depth than currently in ECCO.

Lateral circulation and overturn are also compared to ECCO individual annual and monthly means (e.g. at $24^{\circ} \mathrm{N}$ Figs. $16 \mathrm{a}$ and $\left.16 \mathrm{~b}\right)$. The year to year variation in vertically integrated, meridional transport integrated from the west coast to any arbitrary point in the middle of the basin, ranges from about 5 to $10 \times 10^{6} \mathrm{~m}^{3} \mathrm{~s}^{-1}$ and decreases as the integration approaches the east coast (reflecting the total mass constraint). A variation of this magnitude would easily be taken up by a small reference surface adjustment in an 
inverse model, but only when constrained, reinforcing the idea that one must be careful when integrating hydrographically based solutions between arbitrary points. The range is larger at some locations and times. For instance, at $47^{\circ} \mathrm{N}$ (not shown) from the dateline east, the range is closer to $20 \times 10^{6} \mathrm{~m}^{3} \mathrm{~s}^{-1}$ with specific early years (1993-1995) responsible for the increase in spread. The ECCO 1993 and 1994 results are the only ones that might suggest an agreement with the cyclonic circulation in the eastern basin seen by the 1985 $47^{\circ} \mathrm{N}$ transect (lowest panel Fig. 15a).

The net ECCO transport estimates across the long lines indicate a seasonal cycle with an amplitude of $\sim 1 \times 10^{6} \mathrm{~m}^{3} \mathrm{~s}^{-1}$ or less across the North Pacific transects (Table 13). (Recall, Bering Strait is closed in this ECCO implementation.) Indonesian Throughflow variations increase the amplitude of the seasonal cycle to about $6 \times 10^{6} \mathrm{~m}^{3} \mathrm{~s}^{-1}$ across the southern sections. In all cases, net transport is highest in northern summer months. Comparing the spread to the standard deviation of the monthly means $\left(0.1-0.3 \times 10^{6} \mathrm{~m}^{3} \mathrm{~s}^{-1}\right.$ in the north and $1.3 \times 10^{6} \mathrm{~m}^{3} \mathrm{~s}^{-1}$ in the south) one can say that these cycles are significant. The actual range in the monthly values of net transport is approximately twice the amplitude of the seasonal cycle, suggesting that along the zonal lines the adopted Model SR uncertainties (Appendix A) were reasonable.

Time-averaged heat transports from the 1993-2000 ECCO integration suggest that although the character of the heat transport and heat flux divergences are consistent with other estimates from the literature, ECCO may be underestimating the net meridional heat transport in most basins and at most latitudes (Stammer et al., 2003) . Under-estimation may reflect the model's coarse grid which cannot resolve the sharp fronts in temperature and velocity of boundary currents. Although the present ECCO estimates of meridional heat transport are on the low side in the subtropical North Pacific, they are similar to other estimates in the tropics, perhaps slightly on the high side in the southern Indo- 
Pacific, and suggest strong southward transport of heat, similar to Kalnay et al. (1996), in the Indian and Pacific sectors of Southern Ocean (Fig. 14).

In conclusion, the positions of some major ocean currents as depicted by the ECCO mean are not necessarily the same as those found using the one-time hydrographic transects. The surface (outcropping) circulations tend to be different in regions of strong winds. The ECCO estimates are spatially smoothed by the grid size, and temporally smoothed through averaging, while the Model SR estimates are contaminated by the meso-scale eddy field and represent a mix of quasi-synoptic observations from various seasons. The deep circulation patterns also tend to be different. This difference might decrease as the ECCO model is further iterated. The vast majority of assimilated observations are from the surface and upper ocean. Consequently, the initial ECCO iterations have worked hardest to achieve agreement in the upper ocean. On the other hand, the upper layer, subsurface and intermediate circulations are quite often similar in character and magnitude, indicating not only that the observations are constraining both models to similar solutions, but also that the "mean" circulation at these depths suggested by the hydrography alone is reasonable, as long as the eddy field is taken into account.

Historically, much of our current understanding of large-scale ocean circulation has been based upon the explicit and/or implicit assumption that a "mean" circulation exists. While temporal variability must be recognized and investigated, the idea (or ideal) of a time-averaged general circulation should not be dismissed. Ocean data assimilation models and methods suffer from similar issues to those disussed here, concerning a priori and $a$ posteriori error estimates (see Appendix A). Also, they are complex and computationally expensive, and therefore, not always appropriate or feasible. Furthermore, as they continue to develop, they will benefit from comparison to results from different analysis techniques. In this light, the box model synthesis should continue to provide a valuable comparison point for time-dependent analyses. 


\section{Acknowledgments}

We are thankful for the efforts of all the scientists, ship's officers, and crew who helped to collect, calibrate and process the WOCE sections used here, as well the WHPO (now CCHDO) that has maintained the publically available database that includes these observations. We would also like to express our gratitude to the three reviewers of this manuscript who took great care in providing detailed, thoughtful comments and suggestions. This work was funded by National Science Foundation grants OCE-9710102, OCE9712209 and OCE-0079383, and also benefited from work on closely related projects funded by NSF grants OCE-0223421 and OCE-0623261, and NOAA grant NA17RJ1223 funded through CICOR. For G.C.J. NASA funding came under Order W-19,314. Any opinions, findings, and conclusions or recommendations expressed in this material are those of the authors and do not necessarily reflect the views of the National Science Foundation. The ECCO comparison was made possible through collaboration with the MIT ECCO group and internal WHOI funding. PMEL contribution number 3232.

\section{A Appendix: Model Uncertainty}

In a Gauss-Markov based box inversion (Wunsch, 1996) such as Models LR and SR, a priori estimates of uncertainty must be given for all constraints and unknowns. The latter can also be interpreted as estimates of solution magnitude when the initial estimate of an unknown is zero. For a detailed analysis of various aspects of uncertainty on this type of problem see Ganachaud (2003a). Here we provide a discussion of the logic used to choose the a priori estimates for Model SR. 


\section{A.1 Calculation of initial estimates of data covariance}

Data covariance estimates $\left(\mathbf{R}_{n n}\right)$ describe the uncertainty in each constraint, as well as the covariance among all the constraints. Lacking objective information on the latter we began with initial estimates of variance only (Tables 5 and 6 ). Within individual boxes and/or across lines the following should be considered: (1) the uncertainty in throughflow estimates, here the Bering Strait $\left( \pm 0.3-0.7 \times 10^{9} \mathrm{~kg} \mathrm{~s}^{-1}\right)$ and the Indonesian Passages $\left( \pm 5 \times 10^{9} \mathrm{~kg} \mathrm{~s}^{-1}\right)$; (2) the uncertainty in the baroclinic variability, $\mathrm{O}\left(5 \times 10^{6} \mathrm{~m}^{3} \mathrm{~s}^{-1}\right)$ according to Ganachaud (2003a); (3) the uncertainty due to measurement noise, $\mathrm{O}\left(3 \times 10^{6} \mathrm{~m}^{3} \mathrm{~s}^{-1}\right)$ suggested by Ganachaud (2003a) for mid-latitudes where it is dominated by ageostrophic vertical heave of density surfaces by internal waves; (4) the uncertainty due to unobserved bottom triangle transport, $\mathrm{O}\left(1 \times 10^{6} \mathrm{~m}^{3} \mathrm{~s}^{-1}\right)$ (Ganachaud, 2003a); (5) the uncertainty in the freshwater (evaporation minus precipitation plus river runoff) transport or divergence - here taken conservatively to be 30\% (Table 5); (6) The error due to unobserved high frequency Ekman fluctuations (again see Ganachaud (2003a) for details) is here assumed to be negligible. The net uncertainty arising from these sources, (1) through (6), assuming that they are independent of one another, is $6-8 \times 10^{9} \mathrm{~kg} \mathrm{~s}^{-1}$. However, such a large a priori, assumed uncertainty in each of the small or even each of the large boxes immediately wipes out any possibility of connecting a $10 \times 10^{9} \mathrm{~kg} \mathrm{~s}^{-1}$ throughflow between its entrance into the Pacific in the Southern Ocean and its exit through the Indonesian Archipelago.

Instead, we decided to apply what should be considered an optimistic base uncertainty estimate in the top to bottom mass flux divergence in each of the small boxes of $1 \times 10^{9} \mathrm{~kg} \mathrm{~s}^{-1}$. This estimate would suggest that on the most direct path between the entrance of net transport south of Tasmania to an exit through the Indonesian Passages the accumulated uncertainty would be $2.2 \times 10^{9} \mathrm{~kg} \mathrm{~s}^{-1}$, while the accumulated error on water passing through two-thirds of the small boxes would be $6 \times 10^{9} \mathrm{~kg} \mathrm{~s}^{-1}$. For the sake of con- 
sistency, we placed the same $1 \times 10^{9} \mathrm{~kg} \mathrm{~s}^{-1}$ base uncertainty on the mass flux divergence of the large boxes and vertically integrated mass transport across the zonal and meridional lines. To this base value we added: the uncertainty in Ekman transport determined from the variance in 5 different wind products (Table 4), and for transport constraints, the variance due to uncertainties in the initial estimates of freshwater and throughflows. We took uncertainty in the individual layer constraints to be $2 \times 10^{9} \mathrm{~kg} \mathrm{~s}^{-1}$, with the Ekman uncertainty included in the bulk outcropping layers. This value choice implies strong correlations in the uncertainties among the different layers which act to reduce the uncertainty in the vertically integrated total. These uncertainties are quite, if not overly, optimistic. If the majority of the model constraints could not have been met within these uncertainties, these values could not have been used.

We chose uncertainty in the top to bottom silicic acid divergence constraints to be $50 \mathrm{kmol} \mathrm{s}^{-1}$. The mean value of silicic acid over all layers and all small boxes is $52 \mu \mathrm{mol} \mathrm{kg}^{-1}$. This value multiplied by $1 \times 10^{9} \mathrm{~kg} \mathrm{~s}^{-1}$ suggests the uncertainty used. Uncertainty in layer anomaly constraints is based upon the $2 \times 10^{9} \mathrm{~kg} \mathrm{~s}^{-1}$ advective scale, uses a diffusive scale of $0.3 \times 10^{-4} \mathrm{~m}^{-2} \mathrm{~s}^{-1}$ and the variance in concentration and concentration gradient at the interfaces (Wijffels et al., 1996; Ganachaud, 1999). We gave the constraints which require the sum of vertical mass transport through a particular interface of a large box to match the sum of the transport through the associated small boxes an uncertainty of $0.3 \times 10^{9} \mathrm{~kg} \mathrm{~s}^{-1}$. This value is somewhat arbitrary, but assumes that most of the uncertainty in the layer divergence constraints derives from the lateral transport through the box.

As mentioned in Section 2.3, a stepwise approach is used to find the Model SR solution, first solving for the unknowns in the large box model (LR) as defined by the zonal lines (Fig. 1a), the constraints (Tables 5 and 6), and the initial variance estimates (Table 7 ). The Model LR solution, and solution and data covariance matrices $\left(\mathbf{R}_{n n}^{-1}\right)$ are then used as input to the small box model (SR). The method for using the solution and 
covariances provided by the large box model as input to the small box model is the same as that used in Macdonald (1998) and is mathematically the same as running both models simultaneously, but allows a convenient mechanism for running test cases, and for looking at the effect of the small box constraints on the solution.

\section{A.2 How well are the constraints applied to the inverse model met?}

As has been found previously (Macdonald, 1998; Ganachaud, 1999) for Gauss-Markov type solutions, the constraint equations are, for the most part, better met than would be expected if the input uncertainties were truly represented by a Gaussian distribution. In other words, as much as we may dislike constraints not being met, the solution is meeting more of them than perhaps it should. For a Gaussian distribution $99.7 \%$ of the equations would be met within a $3 \sigma$ range, $97.9 \%$ within $2 \sigma$ and $68.3 \%$ or $\sim$ two-thirds within $1 \sigma$. The model results show all but 9 out of the 3108 (i.e. 99.7\%) of the constraints are met within $3 \sigma$ (where $\sigma$ is the initial estimate of the uncertainty in the constraints). All but $60(98.1 \%)$ are met within $2 \sigma$, and all but $378(87.8 \%)$ are met within $1 \sigma$. These statistics tell us nothing about particular estimates of uncertainty, they do suggest that, in general, we have not severely under-estimated the input constraint uncertainties. If we had, many more constraints would not have been met. By the same token, neither have we severely over-estimated them, in which case far more would have been met.

Of the 60 constraints not met to within $2 \sigma$

- 3 are transport constraints associated the deep flow into the Pacific (discussed in Section 3.1.2);

- 3 are boxes in which top to bottom mass conservation is not met. They all lie between $10^{\circ} \mathrm{N}$ and $24^{\circ} \mathrm{N}$. It is possible that the strong tropical variability which led Ganachaud (1999) to avoid the P4 transect was not restricted to baroclinic variability in the re- 
gion of the Mindanao Current (mitigated in the present model through the use of repeat transects), but rather has a component within the interior that creates data incompatibilities. The constraints in question require a zero mass convergence within $\pm 1 \times 10^{9} \mathrm{~kg} \mathrm{~s}^{-1}$. The residuals are between 2.1 and $2.2 \times 10^{9} \mathrm{~kg} \mathrm{~s}^{-1}$. We do not consider these results to be necessarily unrealistic, as top to bottom mass conservation to within $1 \times 10^{9} \mathrm{~kg} \mathrm{~s}^{-1}$ is quite strict given the discussion above, compared to the requirements of previous inversions (Ganachaud, 2003a; Macdonald, 1998; Álvarez et al., 2003) and given the temporal variability illustrated in Section 4.

- 3 are outcropping constraints in boxes 3233 and 4445, and the larger box containing them, 10003. Here, the residuals are $\mathrm{O}\left(4 \times 10^{6} \mathrm{~m}^{3} \mathrm{~s}^{-1}\right)$ and are likely due to temporal and spatial aliasing.

- 5 are constraints requiring the sum of the vertical transport in the small boxes to match that in the associated large boxes.

- 46 are volume and anomaly property conservation constraints in 20 different boxes, including all the tropical boxes, the four subtropical boxes, 39, 40, $4142 \& 10006$, and the northwestern boxes 1325 and 1426. More than half of these unmet property constraints occur in layers $6 \& 7$, and require conservation of heat anomaly. In general, heat anomaly conservation in layer $6\left(26.2<\gamma^{n}<26.6\right)$ is problematic for the boxes surrounding the equator. Layer 5 is the uppermost non-outcropping layer in this region. Its heat anomaly constraint is met to within 1.1 and $1.4 \sigma$ for box 10006 and 10007, respectively. However, the input uncertainty for layer 5 heat anomaly conservation is more than twice as large as the input uncertainty for layer 6 . The difference in these initial estimates is due to the greater variance in interface values and gradients higher in the water column. Nevertheless, the residuals associated with these constraints are quite small, with a mean magnitude of heat divergence in the layers associated with unmet anomaly constraints being $0.04 \pm 0.07 \mathrm{PW}$. The largest heat residual $(0.36 \mathrm{PW})$ occurs in the lowest layer of 
the large tropical box, 10003. A few of the salinity and phosphate anomaly constraints are also not well met, but there does not appear to be any particular pattern to these.

Taking a closer look at the 20 least well met constraint equations (Table A.1), a few features stand out. First, many of the layers in which constraints are not met are the deepest in the boxes, the ones with the smallest volumes and upper interface areas, and those that intersect with topography. In a number of these cases (the heat constraints in layer 15 for boxes 10003 and 10007 for example), the numbers (including the input estimates of uncertainty) are just too small to be useful or believable. The residuals are negligible in terms of the net heat budget results and should not be considered on their own. Second, there were some difficulties in getting the sum of the vertical transport across the lower interfaces in the smaller boxes to match that of the larger boxes. This problem is likely due to the method of computing the interface areas, which included a manual component. Although an effort was made to force consistency in the lateral definition of the layer interfaces in Models LR and SR, the issue still existed, particularly in the lower layers affected by bathymetry. Nevertheless, of the 56 vertical transport matching constraints, only the five listed here were not met to within $2 \sigma$.

Requiring a balance between ocean heat divergence and air-sea heat flux (Section 3.4.3) reduces the number of equations not met within $2 \sigma$ to 52 . Most (43) are still anomaly constraints, and 7 are bulk outcropping layer constraints. Of the latter, most involve heat in eastern tropical region. Including these constraints brings independent information to the system and improves the model by tightening the relationship between the small and large boxes. Overall, statistically speaking, the models behave sensibly. 


\section{B Appendix: Velocity Field Initial Assumptions}

To calculate geostrophic velocities, an initial reference surface for each station pair must be specified. The velocity at this reference surface does not necessarily have to be zero. As mentioned previously, tests in specific regions (e.g. near the Samoan Passages and within the ACC) using some non-zero initial reference velocities were run. However, for models LR and SR initial estimates of reference surface velocity were $0 \pm 2 \mathrm{~cm} \mathrm{~s}^{-1}$. Across the ACC they were set to $0 \pm 10 \mathrm{~cm} \mathrm{~s}^{-1}$.

These initial zero velocity reference surfaces (ZVS) (Fig. B.1) were specified mainly as pressures, although a few were set as density or temperature surfaces. The ZVS were chosen either from the literature or individually by sector or station pair in manner a consistent with expected circulation of certain water masses. For example:

- Most of the ZVS for the $32^{\circ} \mathrm{S}$ section P06 came from the detailed analysis of that section Wijffels et al. (2001), however, for the sector north of New Zealand (the northern boundary of box 68), the ZVS for ten pairs were set to 2500 dbar to allow some southward recirculation of Lower Circumpolar Water on the eastern side of the Tonga-Kermadec Trench as seen in current meter records.

- On P14, south of New Zealand, the ZVS were raised off the bottom to allow eastward flow of bottom water south of the Campbell Plateau.

- On the western side of the southern boundary of box 73 , the ZVS were raised to reduce initial estimates of southward flow, while they were placed at the bottom on the eastern side to obtain southward flow consistent with property extrema.

Of the 2976 station pairs with reference surfaces (i.e. not including the 96 within $2^{\circ}$ of the equator), approximately one fourth had ZVS either at the bottom or within $20 \mathrm{~m}$ of the bottom. ZVS along tropical meridional lines were set to 1000 dbar. In the subtropical 
North Pacific the reference surface for most of the meridional lines was set to $2500 \mathrm{dbar}$, the canonical depth of interface between UCDP and NPDW (Fig. 2).

For our models, the deepest common level (DCL) was defined to be the pressure of the deepest 2 dbar level measured by both stations in a pair, unless the pair was manually flagged as having intervening topography, in which case the DCL was set the depth of the topographic feature. When the specified reference surface was found to be deeper than intervening topography, it too was set equal to the depth of the topography. The velocity at the DCL was assumed to be constant to the bottom, and bottom triangle areas were calculated assuming linear topography between each cast. The resulting bottom triangles had an average transport of $-0.004 \pm 0.137 \times 10^{9} \mathrm{~kg} \mathrm{~s}^{-1}$, while the minimum and maximum were $-1.8 \times 10^{9} \mathrm{~kg} \mathrm{~s}^{-1}$ and $1.9 \times 10^{9} \mathrm{~kg} \mathrm{~s}^{-1}$, respectively. In the initial model these summed to produced a significant net divergence over the full Pacific in the bottom triangles of $-12.0 \times 10^{9} \mathrm{~kg} \mathrm{~s}^{-1}$. This value was reduced only slightly in the final model to $-11.5 \times 10^{9} \mathrm{~kg} \mathrm{~s}^{-1}$ suggesting that it would not have been a good idea to ignore bottom triangles within this Pacific Ocean setup.

The vertically and horizontally integrated convergence over the full basin (all the small boxes, including both the geostrophic and Ekman flow) prior to the inversion based on these ZVS was $0.9 \times 10^{9} \mathrm{~kg} \mathrm{~s}^{-1}$. Accordingly, the average initial convergence and divergence within the small boxes (Fig. B.1) was small, however the variance was large $\left(0.02 \pm 14 \times 10^{9} \mathrm{~kg} \mathrm{~s}^{-1}\right)$. In five boxes $(38,47,50,73$ and 5859) this initial imbalance was order $1 \times 10^{9} \mathrm{~kg} \mathrm{~s}^{-1}$ or less, equal to that required by the model constraints (Table 5 ). In 22 $(40 \%)$ of the small boxes and in two large boxes $(10006,10007)$ the initial imbalances were $5 \times 10^{9} \mathrm{~kg} \mathrm{~s}^{-1}$ or less. However, there were also three small boxes (57,61 and 69) and one large box (10005) where the initial convergence or divergence was greater than $30 \times 10^{9} \mathrm{~kg} \mathrm{~s}^{-1}$. It was sometimes the case that neighboring boxes had nearly equal imbalances of opposite sign (e.g. boxes 57 and 61 with -35 and $34 \times 10^{9} \mathrm{~kg} \mathrm{~s}^{-1}$, respectively; boxes 56 and 60 with 
17 and $-16 \times 10^{9} \mathrm{~kg} \mathrm{~s}^{-1}$; and boxes 1426 and 35 with -15 and $\left.15 \times 10^{9} \mathrm{~kg} \mathrm{~s}^{-1}\right)$. However, there were also groups of boxes with imbalances of the same sign (e.g. the southwestern boxes 5859, 60, 6667, 68, 69, 74 and 7980 all negative and many contributing to the large initial imbalance in box 10005). Even large initial box imbalances were expected because the transects are not synoptic, and all the large boxes and nearly half the small boxes intersect topography. It was the work of the inversion to reduce these imbalances in a three dimensional sense, subject to all the specified constraints (not just mass balance) to the levels shown in Fig. 5.

\section{References}

Álvarez, M., Rios, A. F., Pérez, F. F., Bryden, H. L., Roson, G., 2003. Transport and budgets of total inorganic carbon in the subpolar and temperate North Atlantic. Global Biogeochemical Cycles 17, 10.1029/2002GB001881.

Anderson, L. A., Sarmiento, J. L., 1994. Redfield ratios of remineralization determined by nutrient data analysis. Global Biogeochemical Cycles 8, 65-80.

Baumgartner, A., Reichel, E., 1975. The World Water Balance. Elsevier Science, NY, 179pp.

Bingham, F. M., Talley, L. D., 1991. Estimates of Kuroshio transport using an inverse technique. Deep-Sea Research 38 (Suppl. 1A), 21-43.

Book, J. A., Wimbush, M., Imawaki, S., Ichikawa, H., Uchida, H., Kinoshita, H., 2002. Kuroshio temporal and spatial variations south of Japan determined from inverted echo sournde measurements. Journal of Geophysical Research 107(C9), 3121, doi:10.1029/2001JC000795.

Bowen, M. M., Wilkin, J. L., Emery, W. J., 2005. Variability and forcing of the East Australian Current. Journal of Geophysical Research 110 No. C03019, doi:10.1029/2004JC002533 1-10.

Broecker, W. S., 1987. The biggest chill. Natural History Magazine 47, 75-82. 
Broecker, W. S., 1991. The great conveyor. Oceanography 4, 79-89.

Bryden, H. L., Beal, L. M., 2001. Role of the Agulhas Current and Indian Ocean circulation and associated heat and frehswater fluxes. Deep-Sea Research I 48, 1821-1845.

Bryden, H. L., Roemmich, D. H., Church, J. A., 1991. Ocean heat transport across $24^{\circ} \mathrm{N}$ in the Pacific. Deep-Sea Research 38, 297-324.

CCHDO, 2009. CLIVAR and Carbon Hydrographic Data Office. http://whpo.ucsd.edu (accessed August 2009).

Chen, C., Beardsley, R. C., Limeburner, R., 1992. The structure of the Kuroshio southwest of Kyushu: velocity, transport and potential vorticity fields. Deep-Sea Research 39, 245268.

Cunningham, S. A., Alderson, S. G., King, B. A., Brandon., M. A., 2002. Transport and variability of the Antarctic Circumpolar Current in Drake Passage repeat hydrography on WOCE section SR1b from 1993 to 2000. URL http://www.soc.soton.ac.uk/JRD/HYDRO/drake/index.php, 6pp,(accessed August, 2009) .

Cunningham, S. A., Alderson, S. G., King, B. A., Brandon, M. A., 2003. Transport and variability of the Antarctic Circumpolar Current in Drake Passage. Journal of Geophysical Research 108,doi:10.1029/2001JC001147, 17pp.

da Silva, A. M., Young, C. C., Levitus, S., 1994. Algorithms and procedures, Vol. 1, Atlas of surface marine data. NOAA Atlas NESDIS 6, 74pp.

Freeland, H., 2001. Observations of the flow of abyssal water through the Samoa Passage. Journal of Physical Oceanography 31, 2273-2279.

Ganachaud, A. S., 1999. Large scale oceanic circulation and fluxes of freshwater,heat, nutrient and oxygen. Ph.D. thesis, Massachusetts Institute of Technology/Woods Hole Oceanographic Institution Joint Program in Oceanography, Cambridge, Mass., 266 pp.

Ganachaud, A. S., 2003a. Error budget of inverse box models: The North Atlantic. Journal of Atmosphere and Ocean Technology 20, 1641-1655. 
Ganachaud, A. S., 2003b. Large-scale mass transports, water mass formation, and diffusivities estimated from World Ocean Circulation Experiment WOCE hydrographic data. Journal of Geophysical Research 108, 1-24.

Ganachaud, A. S., Gourdeau, L., Kessler, W. S., 2008. Bifurcation of the Subtropical South Equatorial Current against New Caledonia in December 2004 from a hydrogrpahic inverse box model. Journal of Physical Oceanography accepted.

Ganachaud, A. S., Wunsch, C., 2000. Improved estimates of global ocean circulation, heat transport and mixing from hydrographic data. Nature 408, 454-456.

Gordon, A. L., 1986. Interocean exchange of thermocline water. Journal of Geophysical Research 91, 5037-5046.

Gourdeau, L., Kessler, W. S., Davis, R. S., Sherman, J., Maues, C., Kesternare, E., 2008. Zonal jets entering the Coral Sea. Journal of Physical Oceanography 38, 715-725.

Gouretski, V. V., Koltermann, K. P., 2004. WOCE global hydrographic climatology, a technical report. Tech. Rep. Nr. 35, Berichte des BSH.

Grist, J. P., Josey, S. A., 2003. Inverse analysis adjustment of the SOC air-sea flux climatology using ocean heat transport constraints. Journal of Climate 20, 3274-3295.

Hastenrath, S., 1982. On meridional heat transports in the world ocean. Journal of Physical Oceanography 12, 922-927.

Hellerman, S., Rosenstein, M., 1983. Normal monthly wind stress over the World Ocean with error estimates. Journal of Physical Oceanography 13, 1093-1104.

Heywood, K. J., Garabato, A. J. N., Stevens, D. P., 2002. High mixing rates in the abyssal Southern Ocean. Nature 415, 1011-1014.

Hill, A. E., Hickey, B. M., Shillington, F. A., Strub, P. T., Brink, K. H., Barton, E. D., Thomas, A. C., 1998. Eastern ocean boundaries coastal segment. In: A. R. Robinson, K. H. B. (Ed.), The Sea, The Global Coastal Ocean, Regional Studies and Syntheses. John Wiley \& Sons, inc., pp. 30-67. 
Holfort, J., Johnson, K. M., Schneider, B., Siedler, G., Wallace, D. W. R., 1998. The meridional transport of dissolved inorganic carbon in the South Atlantic Ocean. Global Biogeochemical Cycles 12 (3), 479-499.

Ichikawa, H., Beardsley, R. C., 1993. Temporal and spatial variability of volume transport of the Kuroshio in the East China Sea. Deep-Sea Research 40, 583-605.

Imawaki, S., Uchida, H., Ichikawa, H., Fukasaw, M., Umatani, S., ASUKA Group, 2001. Satellite altimeter monitoring the Kuroshio transport south of Japan. Geophysical Research Letters 24 (1), 17-20.

Johnson, C. G., 1998. Deep water properties, velocities and dynamics over ocean trenches. Journal of Marine Research 56, 329-347.

Johnson, C. G., Sloyan, B. M., Kessler, W. S., McTaggart, K. E., 2002. Direct measurements of upper ocean currents and water properties across the tropical Pacific during the 1990's. Progress in Oceanography 52, 31-61.

Johnson, G. C., McPhaden, M. J., 1999. Interior pycnocline flow from the subtropical to the equatorial Pacific Ocean. Journal of Physical Oceanography 29, 3073-3089.

Johnson, G. C., McPhaden, M. J., Rowe, G. D., McTaggart, K. E., 2000. Upper equatorial Pacific Ocean current and salinity variability during the 1996-1998 El Nino - La Nina cycle. Journal of Geophysical Research 105, 1037-1053.

Johnson, G. C., Robbins, P. E., Hufford, G. E., 2001. Systematic adjustments of hydrographic sections for internal consistency. Journal of Atmosphere and Ocean Technology 18 (7), 1234-1244.

Johnson, G. C., Rudnick, D. L., Taft, B. A., 1994. Bottom water variability in the Samoa Passage. Journal of Marine Research 52, 177-196.

Johnson, G. C., Toole, J. M., 1993. Flow of deep and bottom waters in the Pacific at $10^{\circ} \mathrm{N}$. Deep-Sea Research 40, 371-394.

Josey, S., Kent, E., Oakley, D., Taylor, P., 1996. A new global air-sea heat and momentum flux climatology. International WOCE Newsletter 24, 3-5. 
Josey, S. A., Kent, E. C., Taylor, P. K., 2002. On the wind stress forcing of the ocean in the SOC climatology: Comparisons with the NCEP/NCAR, ECMWF, UWM/COADS and Hellerman and Rosenstein datasets. Journal of Physical Oceanography 32, 1993-2019. Kalnay, E., Kanamitsu, M., Kistler, R., Collins, W., Deaven, D., Gandin, L., Iredell, M., Saha, S., White, G., Woollen, J., Zhu, Y., Leetmaa, A., Reynolds, B., 1996. P/NCAR 40-year reanalysis project. Bulletin of the American Meteorologic Society. Soc. 77, 437471.

Kashino, Y., Ishida, A., Kuroda, Y., 2005. Variability of the Mindanao Current: mooring observation results. Geophysical Research Letters 32, doi:10.1029/2005GL023880,1-4.

Kawabe, M., Taira, K., 1995. Flow distribution at $165^{\circ}$ e in the Pacific Ocean. In: Sakai, H., Nozaki, Y. (Eds.), Biogeochemical Processes and Ocean Flux in the Western Pacific. Terra Scientific Publishing Company (TERRAPUB), Tokyo, pp. 629-649.

Kawabe, M., Fujio, S., Yanagimoto, D., 2003. Deep-water circulation at low latitudes in the western North Pacific. Deep-Sea Research I 50, 631-656.

Kawabe, M., Yanagimoto, D., Kitagawa, S., Kuroda, Y., 2005. Variations of the deep western boundary current in Wake Island Passage. Deep-Sea Research I 52, 1121-1137.

Keith, D. W., 1995. Meridional energy transport: uncertainty in zonal means. Tellus Series A 47 , no $1,30-44$.

Kessler, W. S., Gourdeau, L., 2006. Wind-driven zonal jets in the South Pacific Ocean. Geophysical Research Letters 33, doi:10.1029/2005GL025084.

Kessler, W. S., Johnson, G. C., Moore, D. W., 2002. Sverdrup and nonlinear dynamics of the Pacific equatorial currents. Journal of Physical Oceanography 33, 994-1008.

Klink, J., Nowlin Jr., W. D., 2001. Antarctic Circumpolar Current. In: Steele, J. H., Thorpe, S. A., Turekian, K. K. (Eds.), Encyclopedia of Ocean Sciences. Academic Press, London, UK, pp. 151-159.

Levitus, S., Boyer, T. P., 1994. World ocean database 1998, Vol.4, Temperature. Tech. Rep. NOAA Atlas NESDIS 4, U.S. Govt. Print. Off, Washington, D. C. 
Levitus, S., Burgett, R., Boyer, T. P., 1994. World ocean database 1998, Vol.3, Salinity. Tech. Rep. NOAA Atlas NESDIS 3, U.S. Govt. Print. Off, Washington, D. C.

Levitus, S., Conkright, M. E., Boyer, T. P., O’Brien, T., Antonov, J., Stephens, C., Stathoplos, L., Johnson, D., Gelfeld, R., 1998. World ocean database 1998, Vol.1, Introduction. Tech. Rep. NOAA Atlas NESDIS 18, U.S. Govt. Print. Off, Washington, D. C., 346 pp.

Lux, M., Mercier, H., Arhan, M., 2001. Interhemsipheric exchanges of mass and heat in the Atlantic Ocean in January-March 1993. Deep-Sea Research I 48, 605-638.

Macdonald, A. M., 1993. Property fluxes at $30^{\circ} \mathrm{S}$ and their implications for the PacificIndian Throughflow and the global heat budget. Journal of Geophysical Research , 68516868.

Macdonald, A. M., 1998. The global ocean circulation: a hydrographic estimate and regional analysis. Progress in Oceanography 41, 281-382.

Macdonald, A. M., Baringer, M. O., Wanninkhof, R., Lee, K., Wallace, D. W. R., 2003. A 1998-1992 comparison of inorganic carbon and its transport across $24.5^{\circ} \mathrm{n}$ in the Atlantic. Deep-Sea Research II 50, 3041-3064.

Macdonald, A. M., Wunsch, C., 1996. A global estimate of the ocean circulation and heat fluxes. Nature 383, 436-439.

Marshall, J., Adcroft, A., Hill, C., Perelman, L., Helsey, C., 1997. A finite-volume, incompressible Navier-Stokes model for studies of the ocean on parallel computers. Journal of Geophysical Research 102, 5753-5766.

Mata, M. M., Tomczak, M., Wijffels, S., Church, J. A., 2000. East Australian Current volume transports at $30^{\circ} \mathrm{S}$ : estimates from the World Ocean Circulation Experiment hydrographic sections PR11/P6 and the PCM3 current meter array. Journal of Geophysical Research 105, 28,509-28,526.

McPhaden, M. J., Busalacchi, A. J., Cheney, R., Donguy, J.-R., Gage, K. S., Halpern, D., Ji, M., Julian, P., Meyers, G., Mitchum, G. T., Niiler, P. P., Picaut, J., Reynolds, R. W., Smith, N., Takeuchi, K., 1998. The Tropical Ocean-Global Atmosphere observing 
system: A decade of progress. Journal of Geophysical Research 103(C7), 14,169-14,240. Mecking, S., Robbins, P., Macdonald, A. M., Toole, J. M., 2004. Oxygen utilization and nutrient remineralization rates in the Pacific Ocean. Geophysical Research Abstracts 6, 004400, SRef-ID: 1607-7962/gra/WEGU04-A04400.

Mercier, H., Arhan, M., Lutjeharms, J. R. E., 2003. Upper-layer circulation in the eastern Equatorial and South Atlantic Ocean in January-March 1995. Deep-Sea Research I 50, $863-887$.

Muench, R. D., 2004. Introduction to the issue. Deep-Sea Research II 53 (1-2), 2-4.

Morris, M., Stanton, B., Neil, H., 2001. Subantarctic oceanography around New Zealand: preliminary results from an ongoing survey. New Zealand Journal of Marine and Freshwater Research 35, 499-519.

Munk, W., 1966. Abyssal recipes. Deep-Sea Research 13, 707-730.

Munk, W., Wunsch, C., 1998. Abyssal recipes ii: energetics of tidal and wind mixing. DeepSea Research I 45, 1977-2010.

Naveira Garabato, A. C., Polzin, K. L., King, B. A., Heywood, K. J., Visbeck, M., 2004. Widespread intense turbulent mixing in the Southern Ocean. Science 303, 210-213.

Olson, E., 2006. Oceanic transports of heat and salt from a global model and data. Masters Thesis, Mass. Inst. of Technol./Dept. of Earth, Atmospheric, and Planetary Sciences Cambridge, Mass., 50 pp.

Onishi, H., Ohtani, K., 1999. On seasonal and year to year variation in the flow of the Alaskan Stream in the central North Pacific. J. Oceanogr. 55, 597-608.

Orsi, A. H., Whitworth III, T., Nowlin, Jr., W. D., 1995. On the meridional extent and fronts of the Antarctic Circumpolar Current. Deep-Sea Research 42 (5), 641-673.

Owens, W. B., Warren, B. E., 2001. Deep circulation in the northwest corner of the Pacific Ocean. Deep-Sea Research I 48, 959-993.

Polzin, K. L., Toole, J. M., Ledwell, J. R., Schmitt, R. W., 1997. Spatial variability of turbulent mixing in the abyssal ocean. Science 276, 93-96. 
Redfield, A. C., Ketchum, B. H., Richards, F. A., 1963. The influence of organisms on the comparison of sea-water. In: Hill, M. N. (Ed.), The Sea. Vol. 2. Wiley-Interscience, New York, pp. 26-77.

Reid, J. L., 1973. Transpacific hydrographic sections at lats $43^{\circ} \mathrm{S}$ and $28^{\circ} \mathrm{S}$ : The Scorpio Expedition -III. - upper water and a note on southward flow at mid-depth. Deep-Sea Research 20, 39-49.

Reid, J. L., 1986. On the total geostrophic circulation of the South Pacific Ocean, flow patterns, tracers and transports. Progress in Oceanography 16, 1-61.

Reid, J. L., 1994. On the total geostrophic circulation of the North Atlantic Ocean: Flow patterns, tracers, and transports. Progress in Oceanography 33, 1-92.

Reid, J. L., 1997. On the total geostrophic circulation of the Pacific Ocean: Flow patterns, tracers and transports. Progress in Oceanography 39, 263-352.

Reid, J. L., 2003. On the total geostrophic circulation of the Indian Ocean: Flow patterns, tracers and transports. Progress in Oceanography 56, 137-186.

Rintoul, S. R., 1991. South Atlantic interbasin exchange. Journal of Geophysical Research 96 (C2), 2675-2692.

Rintoul, S. R., Hughes, C. W., Olbers, D., 2001. The Antarctic Circumpolar Current system. In: G. Siedler, J. C., Gould, J. (Eds.), Ocean Circulation and Climate. Academic Press, pp. 271-302.

Rintoul, S. R., Sokolov, S., 2001. Baroclinic transport variability of the Antarctic Circumpolar Current south of Australia (WOCE repeat section SR3). Journal of Geophysical Research 106, 2815-2832.

Roach, A. T., Aagaard, K., Pease, C. H., Salo, S. A., Weingartner, T., Pavlov, V., Kulakov, M., 1995. Direct measurements of transport and waters properties through the Bering Strait. Journal of Geophysical Research 100, 18443-18457.

Roemmich, D., Gilson, J., Cornuelle, B., Weller, R., 2001. Mean and time-varying meridional transport of heat at the tropical/subtropical boundary of the North Pacific Ocean. 
Journal of Geophysical Research 106, (1999JC000150) 8957-8970.

Roemmich, D., Hautala, S., Rudnick, D., 1996. Northward abyssal transport through the Samoan passage and adjacent regions. Journal of Geophysical Research 101 (C6), 1403914055 .

Roemmich, D., McCallister, T., 1989. Large scale circulation of the North Pacific Ocean. Progress in Oceanography 22, 171-204.

Rossow, W. B., Schiffer, R. A., 1999. Advances in understanding clouds from ISCCP. Bulletin of the American Meteorology Society 80, 2261-2288.

Rudnick, D. L., 1997. Direct velocity measurments in the Samoan Passage. Journal of Geophysical Research 102, 3293-3302.

Sainz-Trapaga, S. M., Goni, G. J., Sugimoto, T., 2001. Identification of the Kuroshio Extension, its Bifurcation and Northern Branch from altimetry and hydrographic data during October 1992 - August 1999: Spatial and Temporal Variability. Geophysical Research Letters 28, 1759-1762.

Schmitz, W., 1996. On the world ocean circulation: Volume II, the Pacific and Indian oceans/A global update. Tech. Rep. WHOI 96-08, Woods Hole Oceanographic Institution, Woods Hole, Massachusetts, 237 pp.

Schmitz, Jr., W. J., 1995. On the interbasin-scale thermohaline circulation. Reviews in Geophysics 33 (2), 151-173.

Sloyan, B. M., Rintoul, S. R., 2001a. Circulation, renewal, and modification of Antarctic Mode and Intermediate Water. Journal of Physical Oceanography 32, 1005-1030.

Sloyan, B. M., Rintoul, S. R., 2001b. The Southern Ocean limb of the global deep overturning circulation. Journal of Physical Oceanography 31, 143-173.

Smith, W. H. F., Sandwell, D. T., 1997. Global seafloor topography from satellite altimetry and ship depth soundings. Science 277, 1957-1962.

Stammer, D., Wunsch, C., Giering, R., Eckert, C., Heimbach, P., Marotzke, J., Adcroft, A., Hill, C. N., Marshall, 2003. Volume, heat, and freshwater transports of the global ocean 
circulation 1993-2000, estimated from a general circulation model constrained by World Ocean Circulation Experiment (WOCE) data. Journal of Geophysical Research 105, No. C1, 10.1029/2001JC001115, p.1-23.

Stammer, D., Wunsch, C., Giering, R., Eckert, C., Heimbach, P., Marotzke, J., Adcroft, A., Hill, C. N., Marshall, J., 2002. Global ocean circulation during 1992-1997, estimated from ocean observations and a general circulation model. Journal of Geophysical Research 107 No. 9, 10.1029/2001JC000888 p. 1-27.

Stommel, H., Arons, A. B., 1960a. On the abyssal circulation of the World Ocean-I. Stationary planetary flow on a sphere. Deep-Sea Research 6, 140-154.

Stommel, H., Arons, A. B., 1960b. On the abyssal circulation of the World Ocean II. An idealized model of the circulation patter and amplitude in oceanic basins. Deep-Sea Research 6, 217-233.

Stommel, H., Stroup, E. D., Reid, J. L., Warren, B. A., 1973. Transpacific hydrographic sections at lats $43^{\circ} \mathrm{S}$ and $28^{\circ} \mathrm{S}$ : The Scorpio Expedition-I, Preface. Deep-Sea Research $20,1-7$.

Strub, P. T., Mesías, J. M., Montecino, V., Rutllant, J., Salinas, S., 1998. Coast ocean circulation off western South America. In: A. R. Robinson, K. H. Brink. (Eds.), The Sea, The Global Coastal Ocean, Regional Studies and Syntheses. John Wiley \& Sons, Inc., pp. 271-302.

Sverdrup, H. V., 1947. Wind driven currents in a baroclinic ocean with application to the equatorial currents of the eastern Pacific. Proceedings of the National Academy of Science 33, 318-326.

Taft, B. S., Hayes, S. P., Friederich, G. E., Codispoti, L. A., 1991. Flow of abyssal water into the Samoa Passage. Deep-Sea Research 38(Suppl.), S103-S128.

Talley, L., 1993. Distribution and formation of North Pacific intermediate water. Journal of Physical Oceanography 23 (3), 517-537. 
Talley, L. D., 2003. Shallow, intermediate and deep overturning components of the global heat budget. Journal of Physical Oceanography 33, 530-560.

Talley, L. D., 2007. Hydrographic Atlas of the World Ocean Circulation Experiment (WOCE). Volume 2: Pacific Ocean. (eds. M. Sparrow, P. Chapman and J. Gould), International WOCE Project Office, Southampton, U.K., ISBN 0-904175-54-5, http://wwwpord.ucsd.edu/whp_atlas/pacific_index.html (accessed August 2009).

Talley, L. D., 2008. Freshwater transport estimates and the global overturning circulation: shallow, deep and throughflow components. Progress in Oceanography 78, 257-303.

Talley, L. D., Joyce, T. M., de Szoeke, R. A., 1991. Transpacific sections at $47^{\circ} \mathrm{N}$ and $152^{\circ} \mathrm{W}$ : distribution of properties. Deep-Sea Research 38 (Suppl. 1A), 63-82.

Talley, L. D., Nagata, Y., Fujimura, M., Iwao, T., Kono, T., Inagake, D., Hirai, M., Okuda, K., 1995. North Pacific intermediate water in the Kuroshio/Oyashio mixed water region. Journal of Physical Oceanography 25 (4), 475-501.

Talley, L. D., Reid, J. L., Robbins, P. E., 2003. Data-based meridional overturning streamfunctions for the global ocean. Journal of Climate 16, 3213-3226.

Talley, L. D., Pickard, G. L., Emery, W. J., Swift, J., 2009. Descriptive Physical Oceanography: An Introduction (Sixth Edition). Elsevier, Boston, in preparation.

Thurnherr, A. M., 2006. Diapycnal mixing associated with an overflow in a deep submarine canyon. Deep-Sea Research II 53, 194-206.

Tomczak, M., Godfrey, J. S., 1994. Regional Oceanography: An Introduction. Pergamon, Oxford U.K., 422 pp.

Trenberth, K. E., Large, W. G., Olson, J. G., 1990. The mean annual cycle in global ocean wind stress,. Journal of Physical Oceanography 20, 1742-1760.

Trenberth, K. E., Olson, J. G., Large, W. G., 1989. A global ocean wind stress climatology based on ECMWF analyses. Tech. Rep. NCAR Technical Note 338+STR, National Center for Atmospheric Research, Boulder, Colorado, 93 pp. 
Trenberth, K. E., Solomon, A., 1994. The global heat balance: Heat transport in the atmosphere and ocean. Climate Dynamics 10, 107-134.

Tsimplis, M. N., Bacon, S., Bryden, H. L., 1998. The circulation of the subtropical South Pacific derived from hydrographic data. Journal of Geophysical Research 103, 21,44321,468 .

Uchida, H., Yamamoto, H., Ichikawa, K., Kaneko, I., Fukasawa, M., Kawano, T., Kumamoto, Y., 2007. Flow of abyssal water into Wake Island Passage: Properties and transports from hydrographic surrveys. Journal of Geophysical Research 112, doi:10.1029/2006JC004000.

Warren, B. A., Owens, W. B., 1985. Some preliminary results concerning deep northernboundary currents in the North Pacific. Progress in Oceanography 14, 537-551.

Warren, B. A., Owens, W., 1988. Deep currents in the central subarctic Pacific Ocean. Journal of Physical Oceanography 18 (4), 529-551.

Whitworth, T. III, Peterson, R. G., 1985. The volume transport of the Antarctic Circumpolar Current from bottom pressure measurements. Journal of Physical Oceanography $15,810-816$.

Whitworth, T. III., Warren, B. A., Nowlin, W. D. Jr., Rutz, S. B., Pillsbury, R. D., Moore, M. I., 1999. On the deep western-boundary current in the Southwest Pacific Basin. Progress in Oceanography 43, 1-54.

Wijffels, S., Firing, E., Toole, J., 1995. The mean structure and variability of the Mindanao Current at $8^{\circ}$ N. Journal of Geophysical Research 101, 14111-14121.

Wijffels, S. E., 1993. Exchanges between hemispheres and gyres: a direct approach to the mean circulation of the equatorial Pacific. Ph.D. thesis, Massachusetts Institute of Technology/Woods Hole Oceanographic Institution Joint Program in Oceanography, WHOI93-42, 267 pp.

Wijffels, S. E., Hall, M. M., Joyce, T., Torres, D. J., Hacker, P., Firing, E., 1998. Multiple deep gyres of the western North Pacific: A WOCE section along $149^{\circ} \mathrm{E}$. Journal of 
Geophysical Research 103 (C6), 12985-13009.

Wijffels, S. E., Toole, J. M., Bryden, H. L., Fine, R. A., Jenkins, W. J., Bullister, J. L., 1996. The water masses and circulation at $10^{\circ} \mathrm{N}$ in the Pacific. Deep-Sea Research 43 , $501-544$.

Wijffels, S. E., Toole, J. M., Davis, R., 2001. Revisiting the South Pacific subtropical circulation: A synthesis of World Ocean Circulation Experiment observations along $32^{\circ} \mathrm{S}$. Journal of Geophysical Research 106, 19,481-19,513.

Woodgate, R. A., Aagaard, K., Weingartner, T. J., 2006. Interannual changes in the Bering Strait fluxes of volume, heat and freshwater between 1991 and 2004. Geophysical Research Letters 33, doi:10.1029/2006GL026931.

Worthington, L. V., Kawai, H., 1972. Comparison between deep sections across the Kuroshio and the Florida Current and Gulf Stream. In: Stommel, H., Yoshida, K. (Eds.), Kuroshio-Its Physical Apsects. University of Tokyo Press, pp. 371-385.

Wunsch, C., 1978. The general circulation of the North Atlantic west of $50^{\circ} \mathrm{W}$ determined from inverse methods. Reviews in Geophysics 16, 583-620.

Wunsch, C., 1996. The Ocean Circulation Inverse Problem. Cambridge University Press, 442 pp.

Wunsch, C., Heimbach, P., 2006. Decadal changes in the North Atlantic and Pacific meridional overturning and heat flux. Journal of Physical Oceanography 36(11), doi:10.1175/JPO2957.1, 2012-2024.

Wunsch, C., Hu, D., Grant, B., 1983. Mass, heat and nutrient fluxes in the South Pacific Ocean. Journal of Physical Oceanography 13, 725-753.

Yu, L., Weller, R. A., 2007. Objectively analyzed air-sea heat fluxes for the global ice-free oceans (1981-2005). Bulletin of the American Meteorology Society 88, 527-539.

Zhu, X., Han, I., Park, J., Ichikawa, H., Murakami, K., Kaneko, A., Ostrovskii, A., 2003. The northeastward current southeast of Okinawa Island observed during November 2000 to August 2001. Geophysical Research Letters 30, doi:10.1029/2002GL015867. 
Zhu, X., Ichikawa, H., K.Ichikawa, Takeuchi, K., 2004. Volume transport variability southeast of Okinawa Island estimated from satellite altimeter data. Journal of Oceanography $60,953-962$. 


\section{List of Figures}

1a WOCE hydrographic sections used to define inverse model boxes overlaid on Smith and Sandwell (1997) bathymetry.

1b Inverse model box numbers overlaid on Smith and Sandwell (1997) bathymetry. Small boxes are labeled in black. The red lines outline the large boxes defined by basin-spanning transects. Box 10003, mentioned in the text, is the combination of 10006 and 10007 without the P04 line at $10^{\circ} \mathrm{N}$.

1c Pacific place names and topographic features mentioned in the text.

2 The model's 16 neutral density $\left(\mathrm{kg} \mathrm{m}^{-3}\right)$ surfaces are shown here as dark solid lines overlaid on the salinity (PSS-78) contours (light gray lines and color shading) along P15 $\left(170^{\circ} \mathrm{W}\right)$. Labels indicate approximate positions of several water masses (Talley, 1993; Talley et al., 1995; Sloyan and Rintoul, 2001a,b; Wijffels et al., 2001) found within the Pacific Ocean, and listed in Table 3. SPTW and NPTW are South and North Pacific Tropical Water, respectively. Similar property sections for all of the WOCE sections are available in (Talley, 2007).

3 Upper panel: station locations for hydrographic sections crossing the ACC. Lower panel: mass transport across the ACC, integrated from southernmost station pair northward $\left(10^{9} \mathrm{~kg} \mathrm{~s}^{-1}\right)$. ACC fronts: SACCF-diamond, $\mathrm{PF}$-circle, SAF-asterisk. 
4 Upper panels: zonally integrated profiles of mass transport across zonal lines in neutral density layers $\left(10^{9} \mathrm{~kg} \mathrm{~s}^{-1}\right)$. Lower panel: Using the profiles above and integrating from the bottom up, the overturning stream function estimated by the model. Between $32^{\circ} \mathrm{S}$ and $67^{\circ} \mathrm{S}$, and between $17^{\circ} \mathrm{S}$ and $10^{\circ} \mathrm{N}$ there is divergence equal to the Indonesian Passage + the Bering Strait throughflow. Arrows indicate flow direction.

5 Absolute mass transport integrated across box boundaries. Arrows are placed at mean geographical positions of stations pairs used in the integration. All arrows representing transports greater than $50 \times 10^{9} \mathrm{~kg} \mathrm{~s}^{-1}$ are the same length. Magenta values in the center of each box represent the divergence in the vertically integrated mass transport. Units are $10^{9} \mathrm{~kg} \mathrm{~s}^{-1}$.

6a Absolute full water column mass transport integrated from South to North meridional lines, and from East to West along zonal lines. Arrows are placed at the mid-point of the transport they represent (here $10 \times 10^{9} \mathrm{~kg} \mathrm{~s}^{-1}$ ). Numbers in black are the residual (mass convergence or divergence) within the model boxes, rounded to the nearest integer value in units $1 \times 10^{9} \mathrm{~kg} \mathrm{~s}^{-1}$, i.e. values less than $0.5 \times 10^{9} \mathrm{~kg} \mathrm{~s}^{-1}$ are not shown. Circles represent the mid-points between station pairs with color indicating the pair average potential temperature within the layer set. Unlike Fig 5, boxes 56 and 57 do not appear in this depiction. 
6b Same as Fig. 6a for model layers 1-3, $\left(19.0-24.8 \gamma^{n}\right)$ representing subtropical and tropical surface waters. Here, each black arrow represents $5 \times 10^{9} \mathrm{~kg} \mathrm{~s}^{-1}$. Red arrow heads and blue tails represent dia-neutral transport, upwelling and downwelling, through the layer set upper and lower interfaces, respectively. Associated transport values are rounded to the nearest $0.1 \times 10^{9} \mathrm{~kg} \mathrm{~s}^{-1}$. Values less than $0.05 \times 10^{9} \mathrm{~kg} \mathrm{~s}^{-1}$ are not printed. Black dots represent station positions. Grey lines indicate the mean winter outcrop of the layer set density extrema computed from climatology (Levitus et al., 1998). Colors indicate vertically averaged potential temperature in the layer set.

6c Same as Fig. 6b for model layers $4-5,\left(24.8-26.2 \gamma^{n}\right)$ representing Central Waters in the mid-Pacific and surface water south of approximately $25^{\circ} \mathrm{S}$ and north of $47^{\circ} \mathrm{N}$. Here, each black arrow represents $5 \times 10^{9} \mathrm{~kg} \mathrm{~s}^{-1}$.

6d Same as Fig. 6b for model layers 6-8, $\left(26.2-27.1 \gamma^{n}\right)$ representing Subantarctic Mode and North Pacific Intermediate waters. Here, each black arrow represents $5 \times 10^{9} \mathrm{~kg} \mathrm{~s}^{-1}$.

6e Same as Fig. 6b for model layers 9-10, $\left(27.1-27.6 \gamma^{n}\right)$ representing mainly Antarctic Intermediate Water. Here, each black arrow represents $5 \times 10^{9} \mathrm{~kg} \mathrm{~s}^{-1}$.

6f Same as Fig. 6b for model layers $11-12,\left(27.6-28.0 \gamma^{n}\right)$ representing mainly North Pacific Deep Water. Here, each black arrow represents $5 \times 10^{9} \mathrm{~kg} \mathrm{~s}^{-1}$.

6g Same as Fig. 6b for model layer 13, $\left(28.0-28.1 \gamma^{n}\right)$ representing Upper Circumpolar Deep Water. Here, each black arrow represents $5 \times 10^{9} \mathrm{~kg} \mathrm{~s}^{-1}$.

6h Same as Fig. 6b for model layers $14-15,\left(28.1 \gamma^{n}\right.$-Bottom) representing Lower Circumpolar Deep Water and Antarctic Bottom Water. Note, arrows represent $2 \times 10^{9} \mathrm{~kg} \mathrm{~s}^{-1}$. Here, each black arrow represents $2 \times 10^{9} \mathrm{~kg} \mathrm{~s}^{-1}$. 
7a Model-derived mass-transport stream function $\left(10^{9} \mathrm{~kg} \mathrm{~s}^{-1}\right)$ integrated from west to east along the $\mathrm{P} 01,47^{\circ} \mathrm{N}$ zonal line in sets of model layers defined to maximize the net north/south transport. On right: layers, neutral density limits $\left(\mathrm{kg} \mathrm{m}^{-3}\right)$ and net meridional transport $\left(10^{9} \mathrm{~kg} \mathrm{~s}^{-1}\right)$.

7b Same as Fig. $7 \mathrm{a}$ for $\mathrm{P} 03,24^{\circ} \mathrm{N}$.

7c Same as Fig. 7a for P04, $10^{\circ} \mathrm{N}$.

7d Same as Fig. 7a for P21, $17^{\circ} \mathrm{S}$

7e Same as Fig. 7a for P06, $32^{\circ} \mathrm{S}$.

8 Model SR mass transport across box edges in the deep northwest Pacific. Magnitude is indicated by arrow length and boldface values. Values in parenthesis represent horizontal mass convergence (positive) or divergence (negative). The left-hand panel describes the upper deep layers ( 800-2500 m). The right-hand panel describes the lower deep layers $(\sim 2500$ m-bottom $)$

9 Inverse estimates of diapycnal velocity in each of the small boxes (as labeled) and in each the large boxes (right hand column). Axes are the same for all graphs, but labeled only on box 10004 (second up from the bottom on the right). Inverse solutions for $\mathbf{w}$ only exist for non-outcropping interfaces. Interface 0 is the surface. Interface 16 is the bottom. Values are in units of $10^{-6} \mathrm{~cm} \mathrm{~s}^{-1}$.

10 Inverse estimates of diapycnal mass transport across the non-outcropping interfaces of the large boxes (black bars) with uncertainty (gray bars). Where gray bars exceed the length of the black bars, the transport values are not significantly different from zero. Positive/negative values indicate upwelling/downwelling. 
11 Inverse estimates of diapycnal diffusivities in each of the small boxes (as labeled) and in each the large boxes (right hand column). Axes are the same for all graphs, but labeled only on box 10004 (second up from the bottom on the right). Inverse solutions for $\mathbf{k}_{\mathrm{z}}$ only exist for non-outcropping interfaces. Interface 0 is the surface. Interface 16 is the bottom. Values are in units of $\mathrm{cm}^{2} \mathrm{~s}^{-1}$.

12a The mass (upper panel) and heat (lower panel) balance in the large box defined by the zonal transects across $24^{\circ} \mathrm{N}$ and $47^{\circ} \mathrm{N}$. $\mathrm{T}_{\mathrm{v}}$ and $\mathrm{T}_{\mathrm{w}}$ are the horizontal and dianeutral advective transport estimates, respectively. $\mathrm{T}_{\mathrm{O}}$ is air-sea heat flux estimate. Lines separate neutral density surfaces (indicated by $\Gamma$ on far right with mean northern and southern boundary depths on the right and left, respectively). Dashed lines outcrop. The layer residuals are shown on the left in parentheses.

12b Same as Fig. 12a for the box defined by the $10^{\circ} \mathrm{N}$ and $24^{\circ} \mathrm{N}$ transects.

12c Same as Fig. 12a for the box defined by the $17^{\circ} \mathrm{S}$ and $10^{\circ} \mathrm{N}$ transects.

12d Same as Fig. 12a for the box defined by the $32^{\circ} \mathrm{S}$ and $17^{\circ} \mathrm{S}$ transects.

12e Same as Fig. 12a for the box defined by the $67^{\circ} \mathrm{S}$ and $32^{\circ} \mathrm{S}$ transects.

13 Upper panel: inverse model air-sea exchange of heat (energy) flux. Inverse model results (shown in red) are compared to estimates from surface flux climatologies, in particular: (COADS) da Silva et al. (1994); (NCEP) Kalnay et al. (1996); (SOC) Grist and Josey (2003); Keith (1995); (OAFlux+ISCCP) latent and sensible heat Yu and Weller (2007) combined with radiation Rossow and Schiffer (1999); and (ECCO) Stammer et al. (2002). Asterisks indicate a lack of data within the climatology for comparison. Lower panel: small boxes have been grouped together to increase the signal to noise ratio. 
14 Estimates of Indo-Pacific meridional transport of heat. In the legend " $\mathrm{T}_{\mathrm{ip}}$ " indicates where an estimate of mass transport through the Indonesian Archipelago has been calculated or assumed in the process of estimating heat transport. South of the equator, our estimates for the Pacific have been added to the Indian Ocean temperature transport estimates of Ganachaud and Wunsch (2000) which have been scaled for the difference in $T_{\text {ip }}$ temperature transport. Individual estimates north of the equator are for the Pacific only. Units are PW.

15 a)Integrated absolute mass transport across $\mathrm{P} 01,47^{\circ} \mathrm{N}$ for Model SR (thin line) and ECCO-GODAE (thick line). Values to the right indicate: ECCO-GODAE model layers included in the integration, chosen to best illustrate changes in net vertical transport and similarities between the two models; depth of the interfaces bounding the layer sets; and net layer set transport. Integration is performed from west to east. The three values in parentheses in upper left are the net difference in transport, mean absolute value of the ratio of Model SR to ECCO-GODAE transport, and mean absolute value of transport difference per kilometer. Positive values indicate northward flow. b)Same as Fig. 15a for P03, $24^{\circ}$ N. c)Same as Fig. 15 a for P04, $10^{\circ}$ N. d)Same as Fig. 15 a for P21, $17^{\circ} \mathrm{S}$.

15e Same as Fig. 15a for P06, $32^{\circ} \mathrm{S}$.

$15 \mathrm{f}$ Same as Fig. 15a for Drake Passage, $88^{\circ} \mathrm{W}$.

16a Mass transport stream function integrated from west to east along P03, $24^{\circ} \mathrm{N}$ in both ECCO-GODAE and Model SR illustrating the year to year variation according to ECCO. The thick solid blue line is the same as the thin line in the lowest panel of Fig $15 \mathrm{~b}$. 
16b Same as right panel, here illustrating the monthly variation with the minimum, maximum, mean and standard deviation taken over all ECCO Aprils and Mays compared to P03, which was carried out during April and May of 1985.

B.1 Pressure of initial geostrophic velocity reference surfaces (dbars) for Pacific station pairs. Velocities at station pairs within $2^{\circ}$ of the equator are based on absolute velocity estimates, and therefore, do not require reference surfaces. The values in blue and red are the initial top to bottom convergences and divergences in the boxes, respectively. Units $10^{9} \times 10^{9} \mathrm{~kg} \mathrm{~s}^{-1}$. 


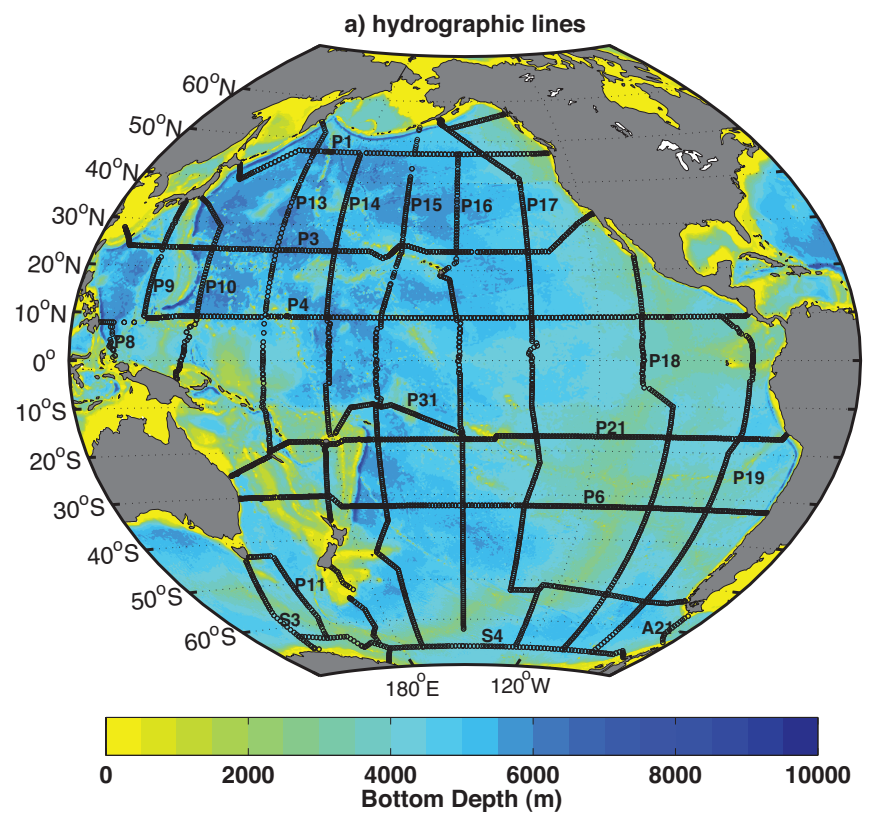

Fig. 1a. WOCE hydrographic sections used to define the inverse model boxes overlaid on Smith and Sandwell (1997) bathymetry.

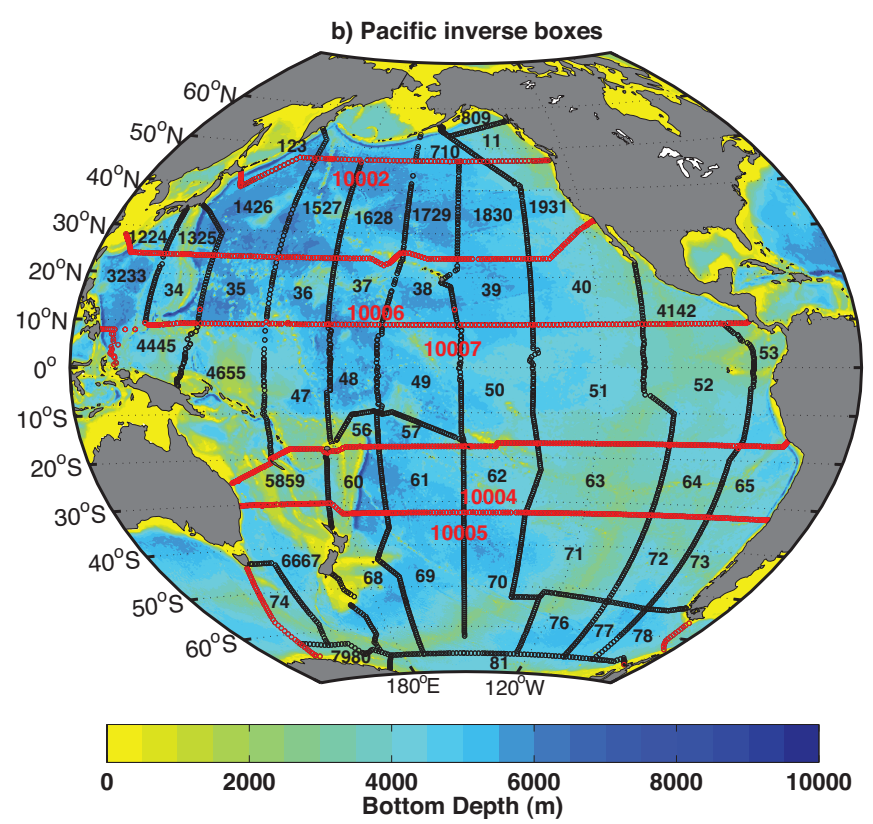

Fig. 1b. Inverse model box numbers overlaid on Smith and Sandwell (1997) bathymetry. Small boxes are labeled in black. The red lines outline the large boxes defined by basin-spanning transects. Box 10003, mentioned in the text, is the combination of 10006 and 10007 without the P04 line at $10^{\circ} \mathrm{N}$. 


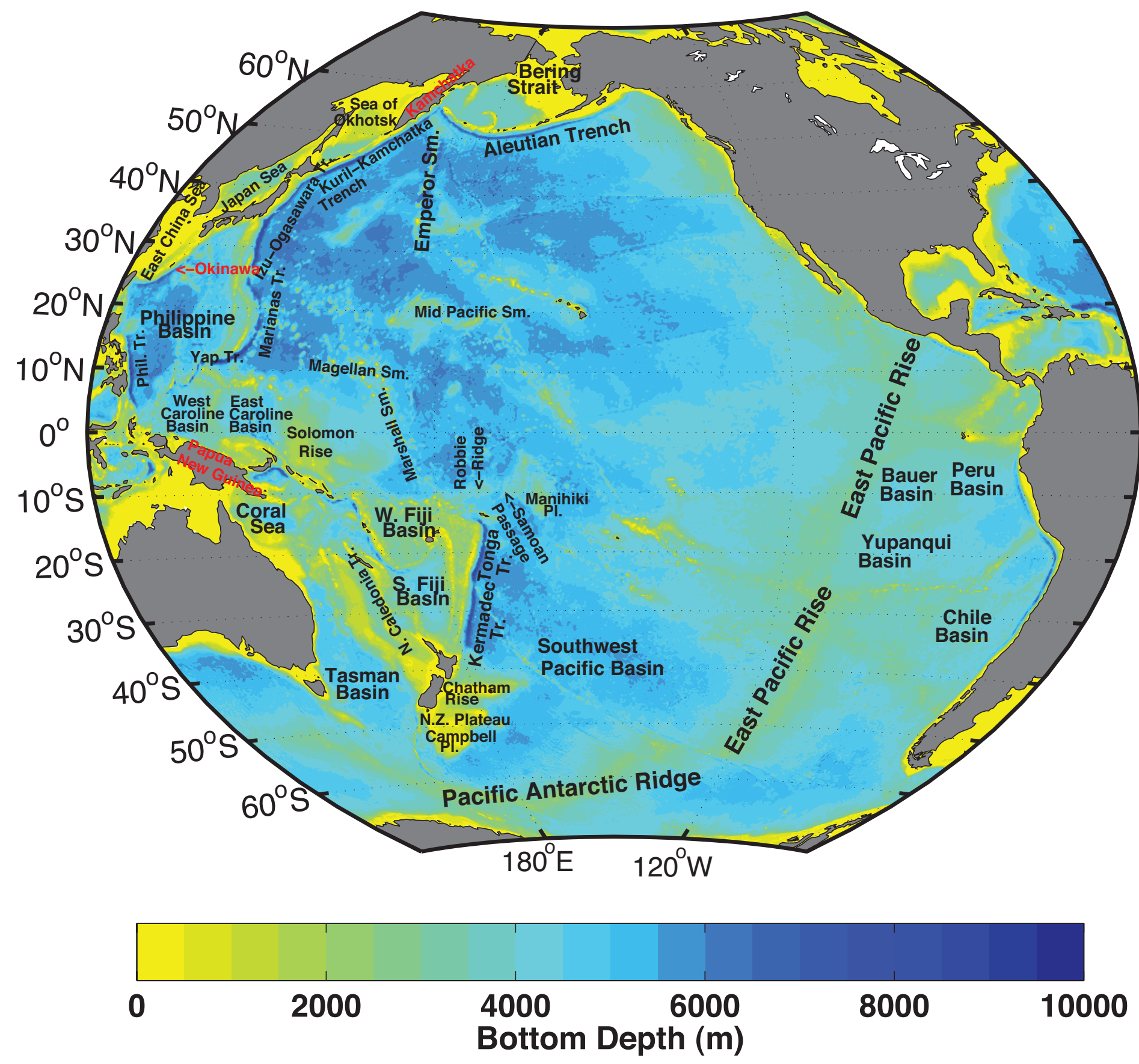

Fig. 1c. Pacific place names and topographic features mentioned in the text. 


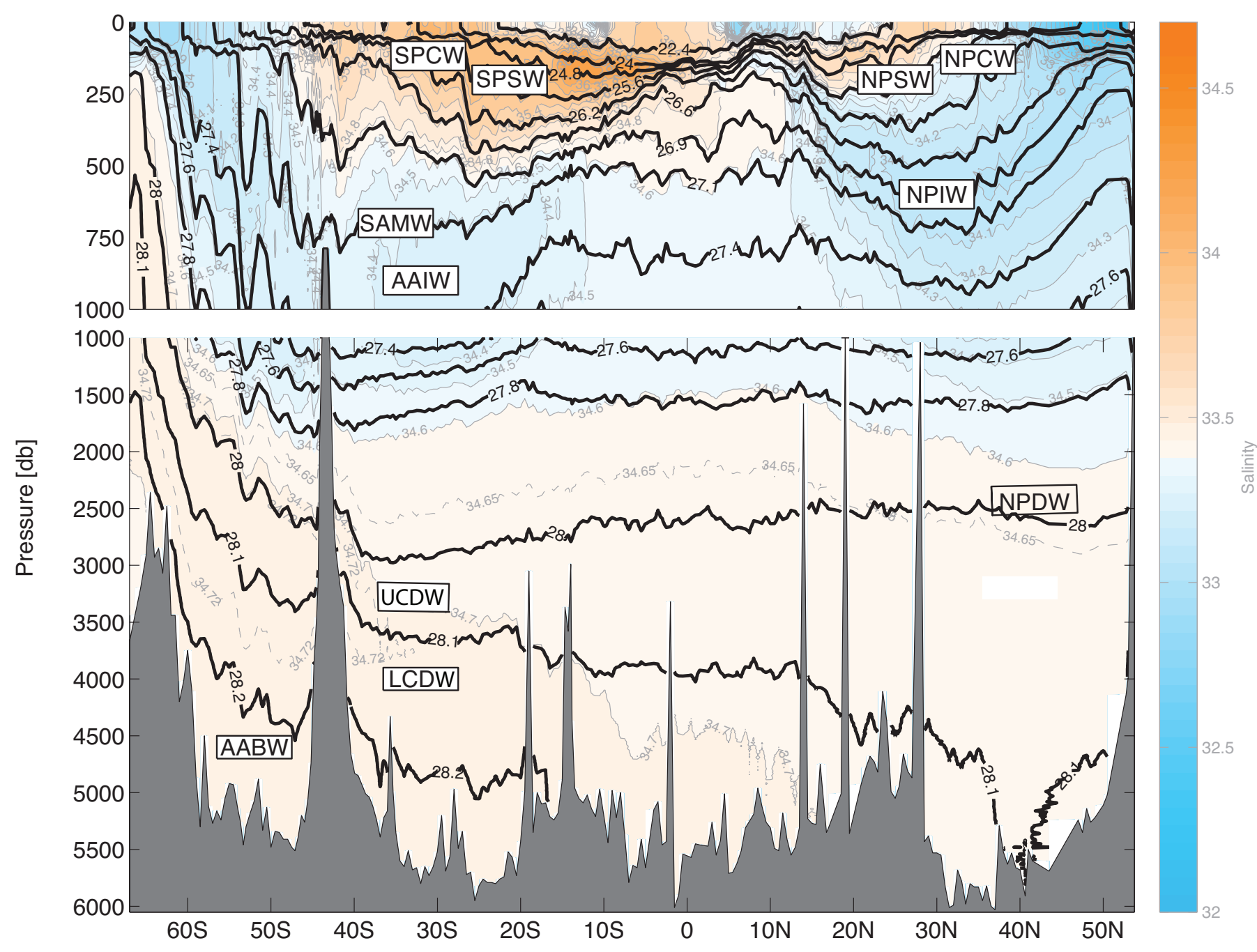

Fig. 2. The model's 16 neutral density $\left(\mathrm{kg} \mathrm{m}^{-3}\right)$ surfaces are shown here as dark solid lines overlaid on the salinity (PSS-78) contours (light gray lines and color shading) along P15 $\left(170^{\circ} \mathrm{W}\right)$. Labels indicate approximate positions of several water masses (Talley, 1993; Talley et al., 1995; Sloyan and Rintoul, 2001a,b; Wijffels et al., 2001) found within the Pacific Ocean, and listed in Table 3. SPTW and NPTW are South and North Pacific Tropical Water, respectively. Similar property sections for all of the WOCE sections are available in (Talley, 2007). 

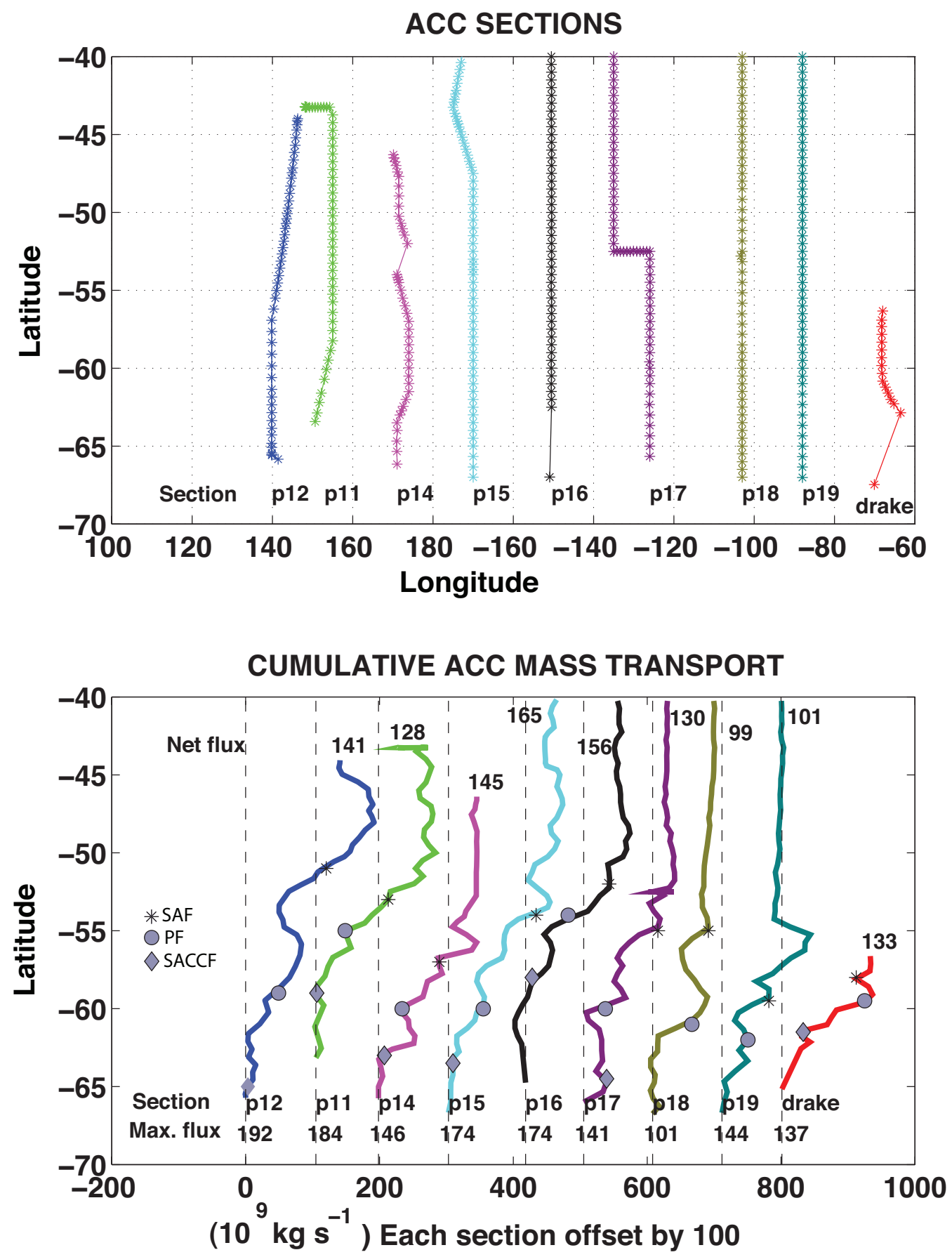

Fig. 3. Upper panel: station locations for hydrographic sections crossing the ACC. Lower panel: mass transport across ACC, integrated from southernmost station pair northward $\left(10^{9} \mathrm{~kg} \mathrm{~s}^{-1}\right)$. ACC fronts: SACCF-diamond, PF-circle, SAF-asterisk. 

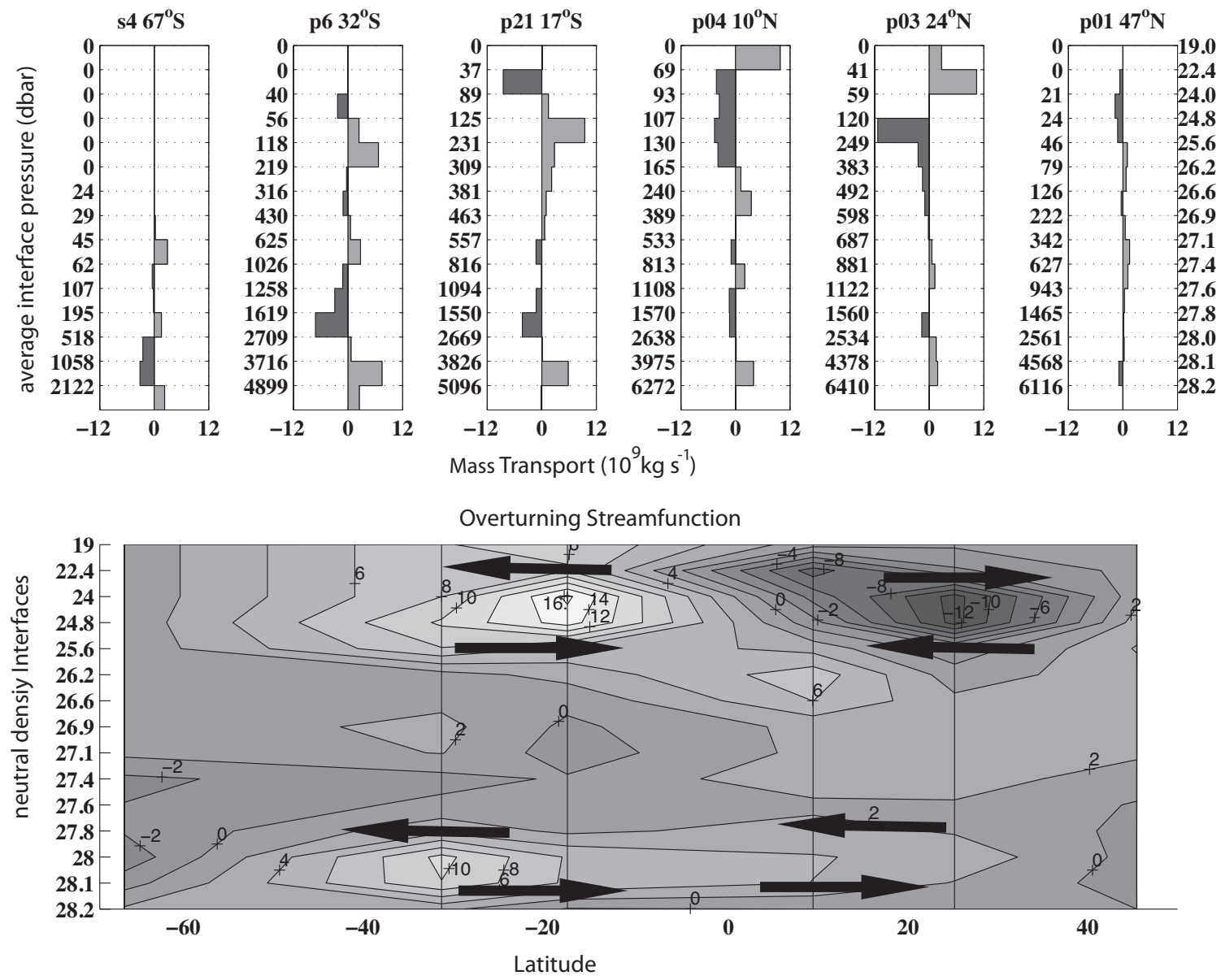

Fig. 4. Upper panels: zonally integrated profiles of mass transport across zonal lines in neutral density layers $\left(10^{9} \mathrm{~kg} \mathrm{~s}^{-1}\right)$. Lower panel: Using the profiles above and integrating from the bottom up, the overturning stream function estimated by the model. Between $32^{\circ} \mathrm{S}$ and $67^{\circ} \mathrm{S}$, and between $17^{\circ} \mathrm{S}$ and $10^{\circ} \mathrm{N}$ there is divergence equal to the Indonesian Passage + the Bering Strait throughflow. Arrows indicate flow direction. 


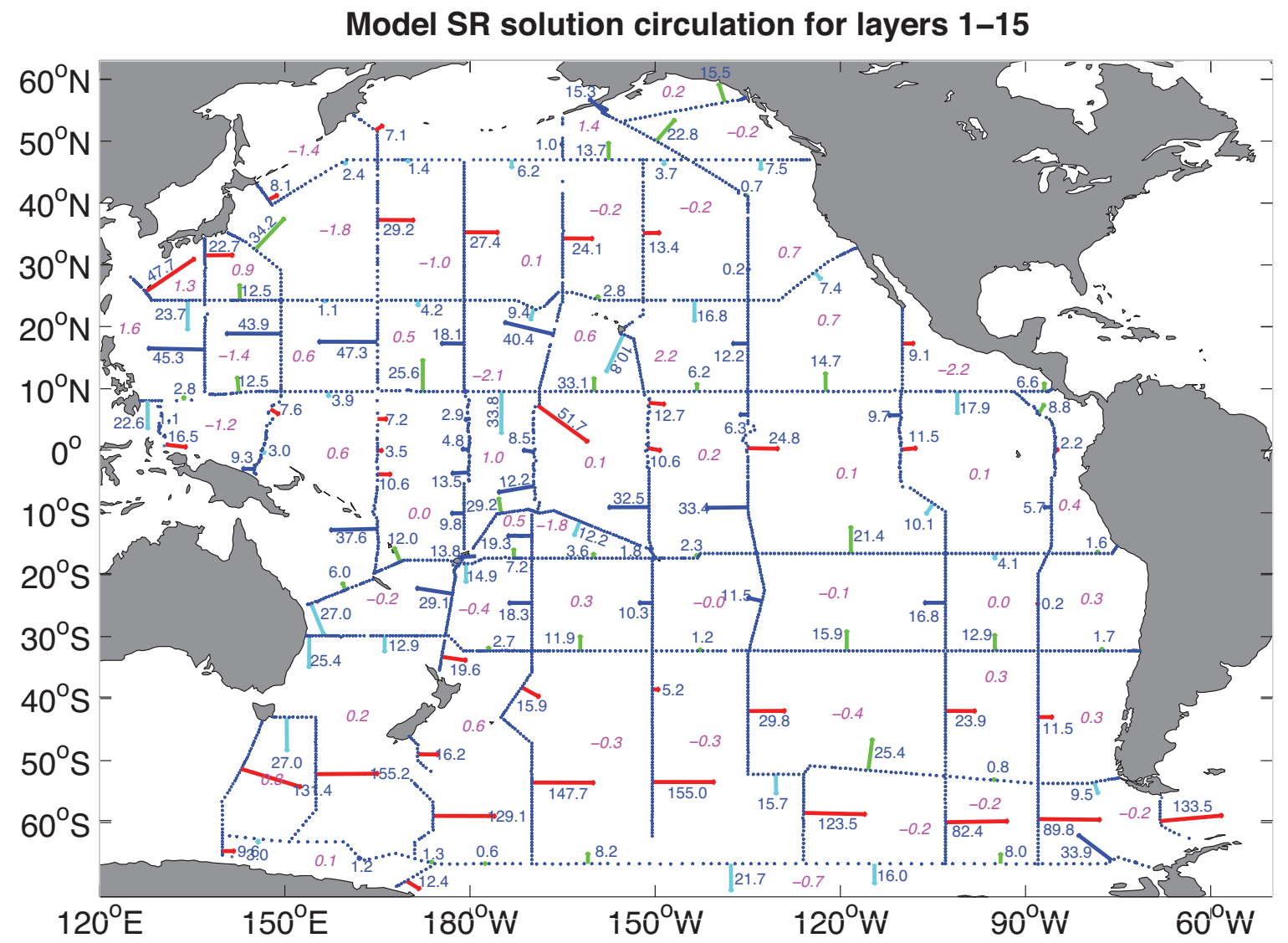

Fig. 5. Absolute mass transport integrated across box boundaries. Arrows are placed at mean geographical positions of stations pairs used in the integration. All arrows representing transports greater than $50 \times 10^{9} \mathrm{~kg} \mathrm{~s}^{-1}$ are the same length. Magenta values in the center of each box represent the divergence in the vertically integrated mass transport. Units are $10^{9} \mathrm{~kg} \mathrm{~s}^{-1}$. 
Transport Stream Function for Full Water Column

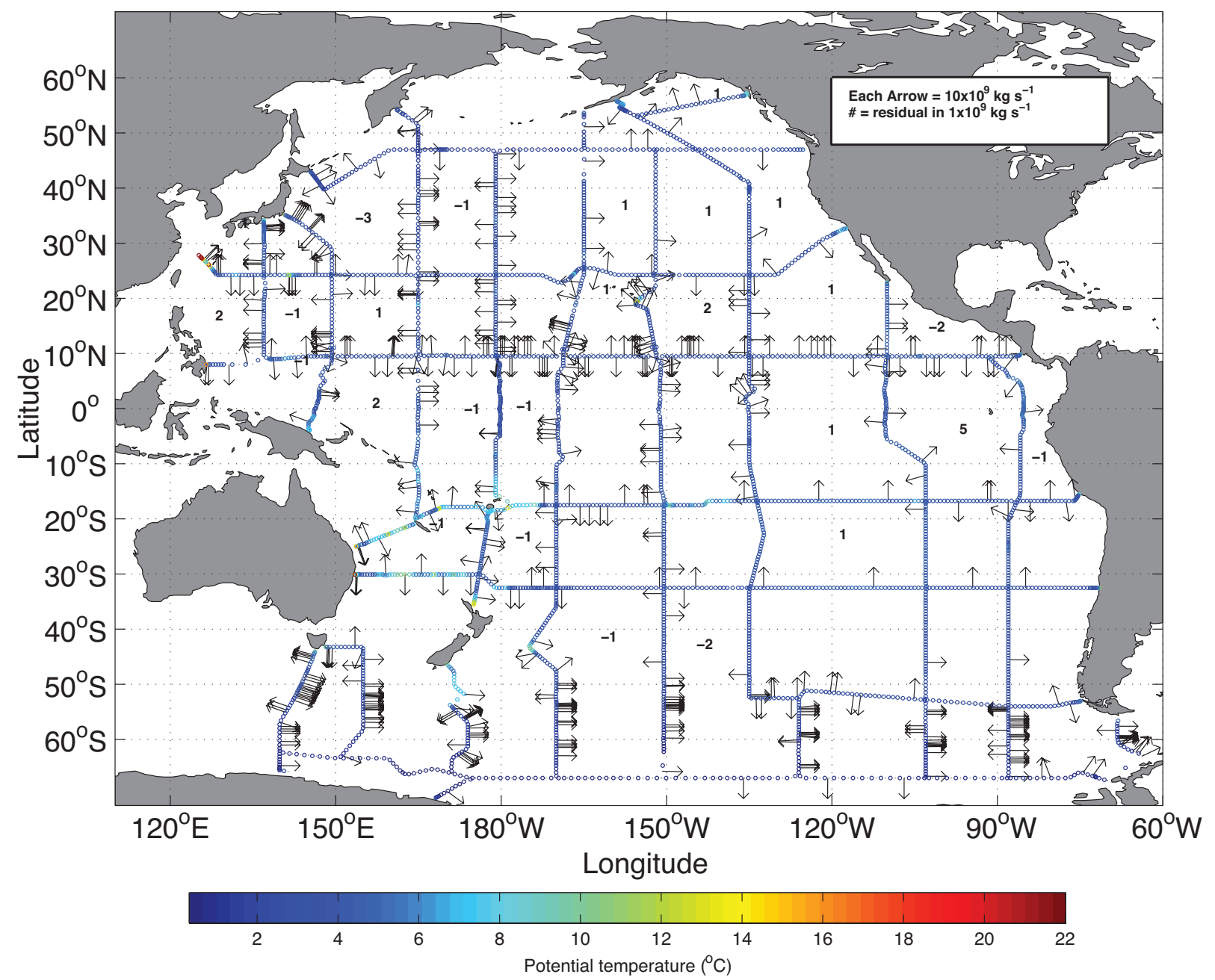

Fig. 6a. Absolute full water column mass transport integrated from South to North meridional lines, and from East to West along zonal lines. Arrows are placed at the mid-point of the transport they represent (here $10 \times 10^{9} \mathrm{~kg} \mathrm{~s}^{-1}$ ). Numbers in black are the residual (mass convergence or divergence) within the model boxes, rounded to the nearest integer value in units $1 \times 10^{9} \mathrm{~kg} \mathrm{~s}^{-1}$, i.e. values less than $0.5 \times 10^{9} \mathrm{~kg} \mathrm{~s}^{-1}$ are not shown. Circles represent the mid-points between station pairs with color indicating the pair average potential temperature within the layer set. Unlike Fig 5, boxes 56 and 57 do not appear in this depiction. 
Transport Stream Function for Surface Water

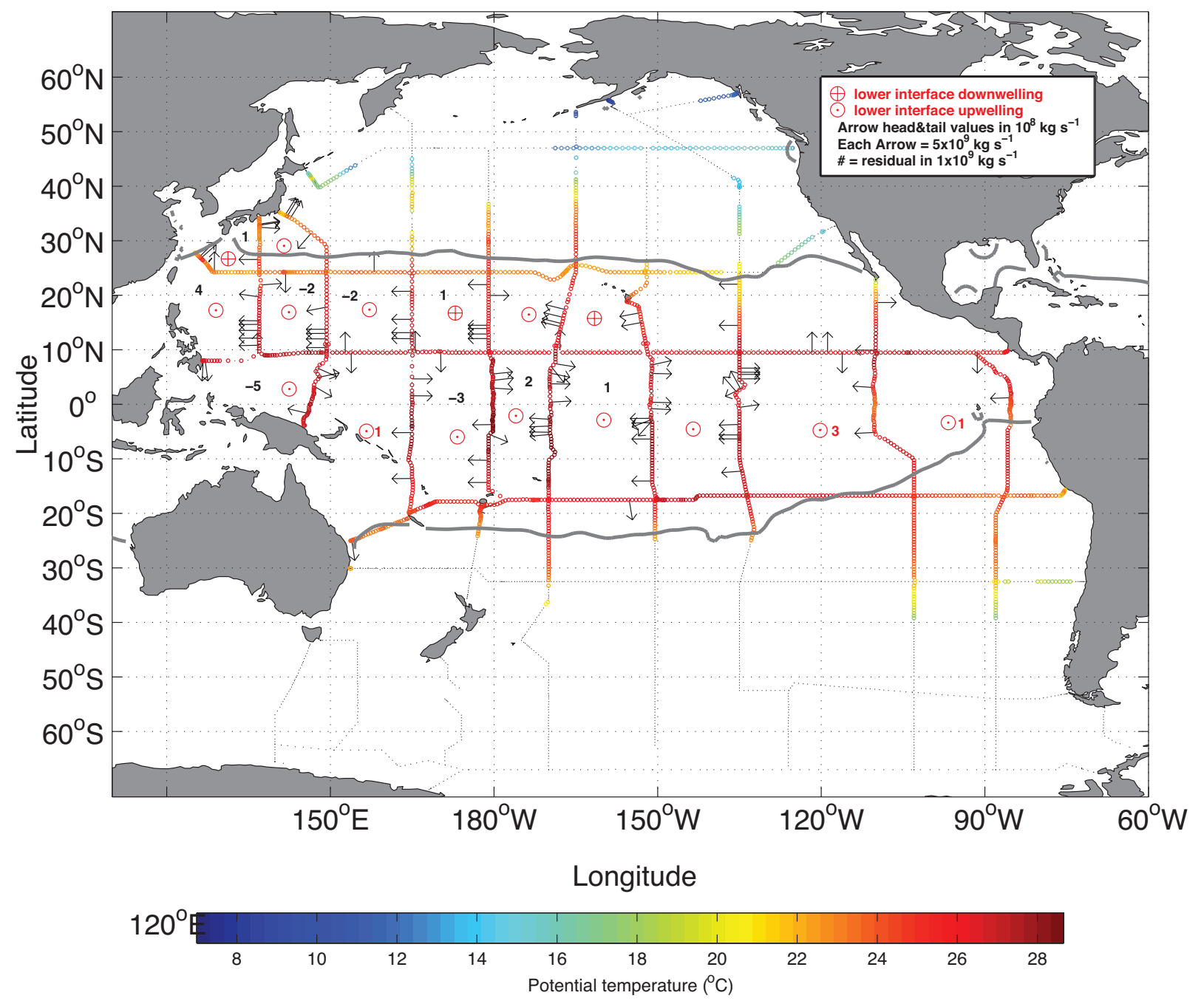

Fig. 6b.

Same as Fig. 6a for model layers 1-3, $\left(19.0-24.8 \gamma^{n}\right)$ representing subtropical and tropical surface waters. Here, each black arrow represents $5 \times 10^{9} \mathrm{~kg} \mathrm{~s}^{-1}$. Red arrow heads and blue tails represent dia-neutral transport, upwelling and downwelling, through the layer set upper and lower interfaces, respectively. Associated transport values are rounded to the nearest $0.1 \times 10^{9} \mathrm{~kg} \mathrm{~s}^{-1}$. Values less than $0.05 \times 10^{9} \mathrm{~kg} \mathrm{~s}^{-1}$ are not printed. Black dots represent station positions. Grey lines indicate the mean winter outcrop of the layer set density extrema computed from climatology (Levitus et al., 1998). Colors indicate vertically averaged potential temperature in the layer set. 
Transport Stream Function for Surface \& Central Water
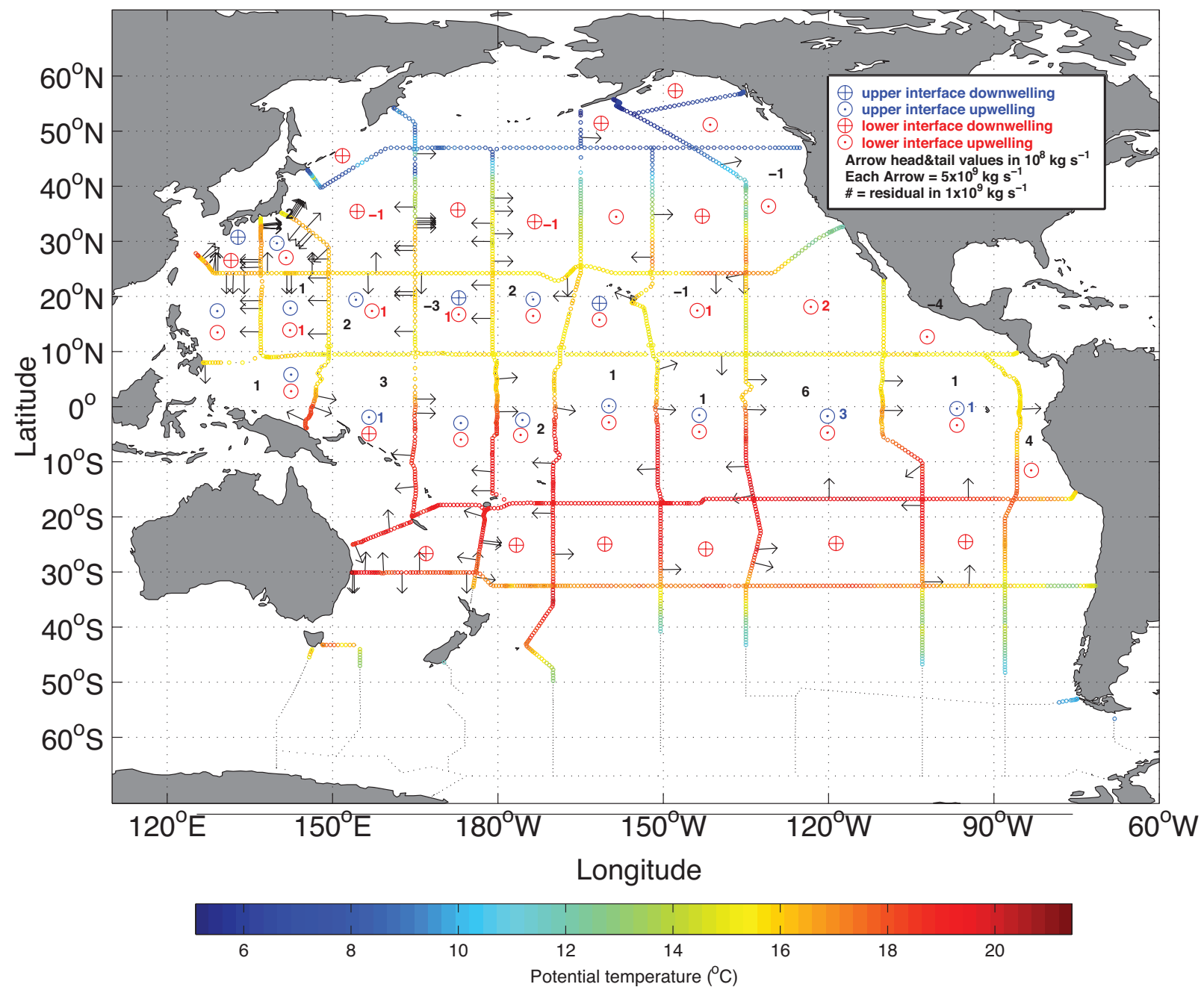

Fig. 6c.

Same as Fig. 6b for model layers 4-5, $\left(24.8-26.2 \gamma^{n}\right)$ representing Central Waters in the midPacific and surface water south of approximately $25^{\circ} \mathrm{S}$ and north of $47^{\circ} \mathrm{N}$. Here, each black arrow represents $5 \times 10^{9} \mathrm{~kg} \mathrm{~s}^{-1}$. 
Transport Stream Function for Mode \& Intermediate Waters

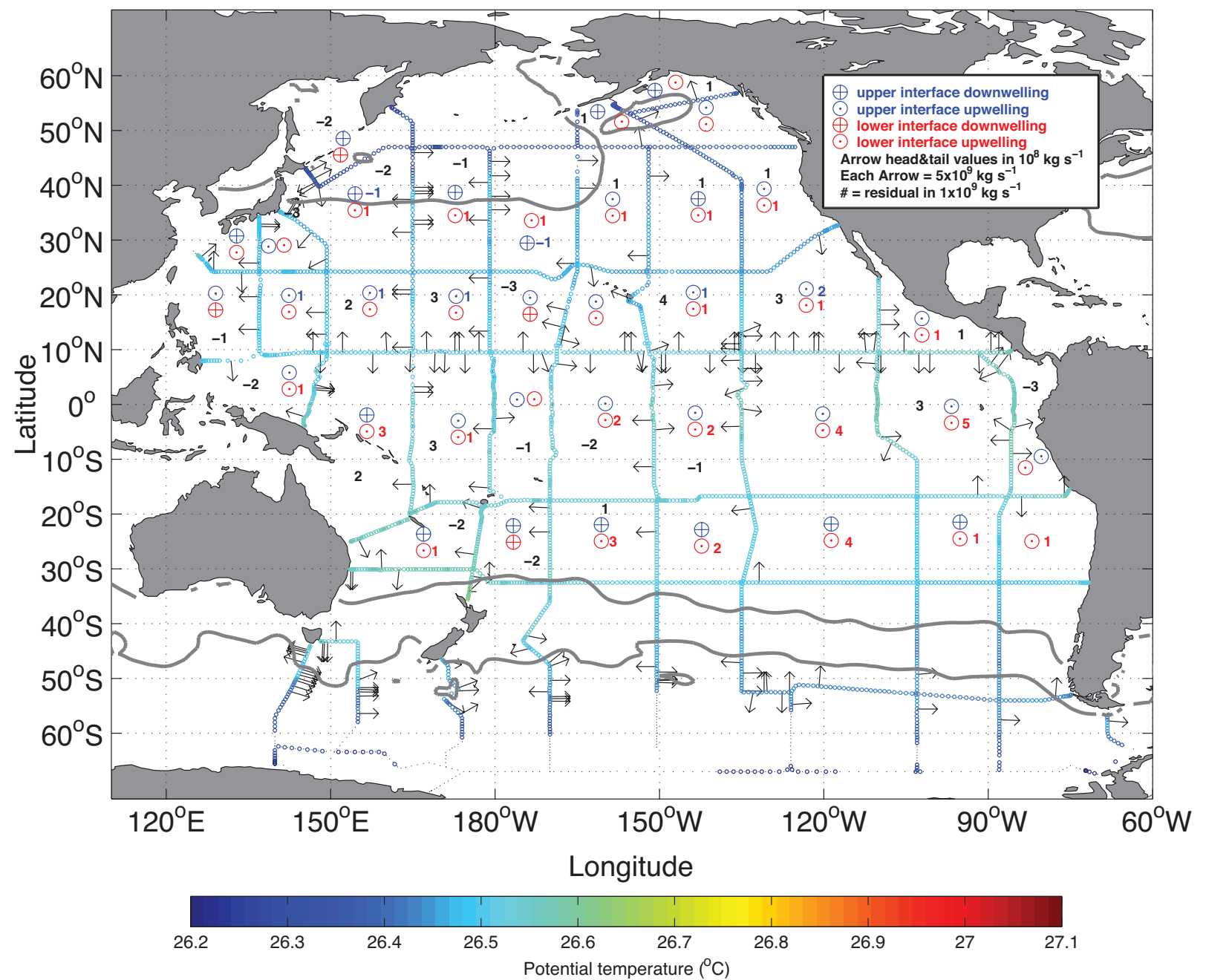

Fig. 6d.

Same as Fig. 6b for model layers 6-8, $\left(26.2-27.1 \gamma^{n}\right)$ representing Subantarctic Mode and North Pacific Intermediate waters. Here, each black arrow represents $5 \times 10^{9} \mathrm{~kg} \mathrm{~s}^{-1}$. 
Transport Stream Function for AAIW
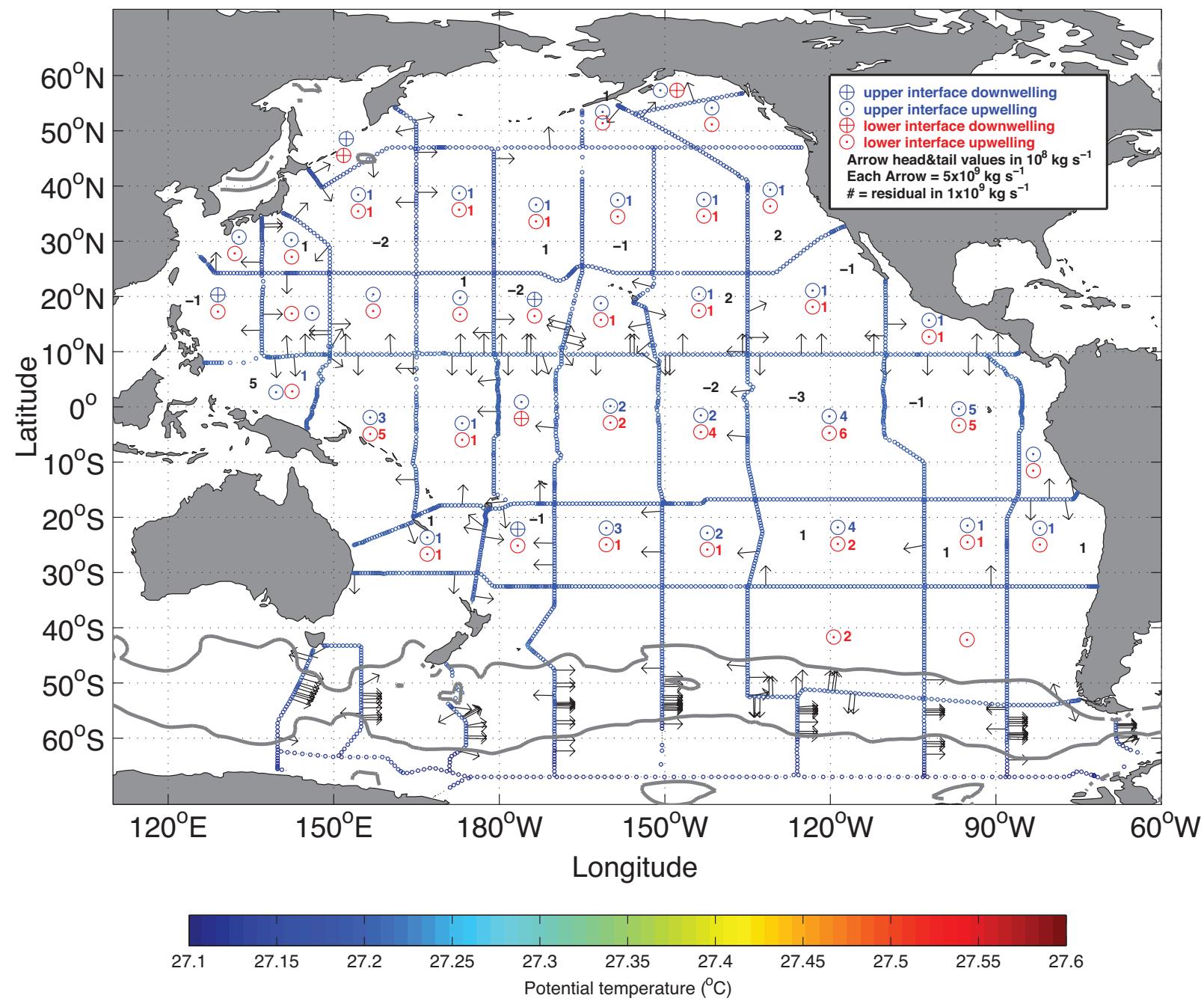

Fig. 6e.

Same as Fig. 6b for model layers 9-10, $\left(27.1-27.6 \gamma^{n}\right)$ representing mainly Antarctic Intermediate Water. Here, each black arrow represents $5 \times 10^{9} \mathrm{~kg} \mathrm{~s}^{-1}$. 
Transport Stream Function for NPDW
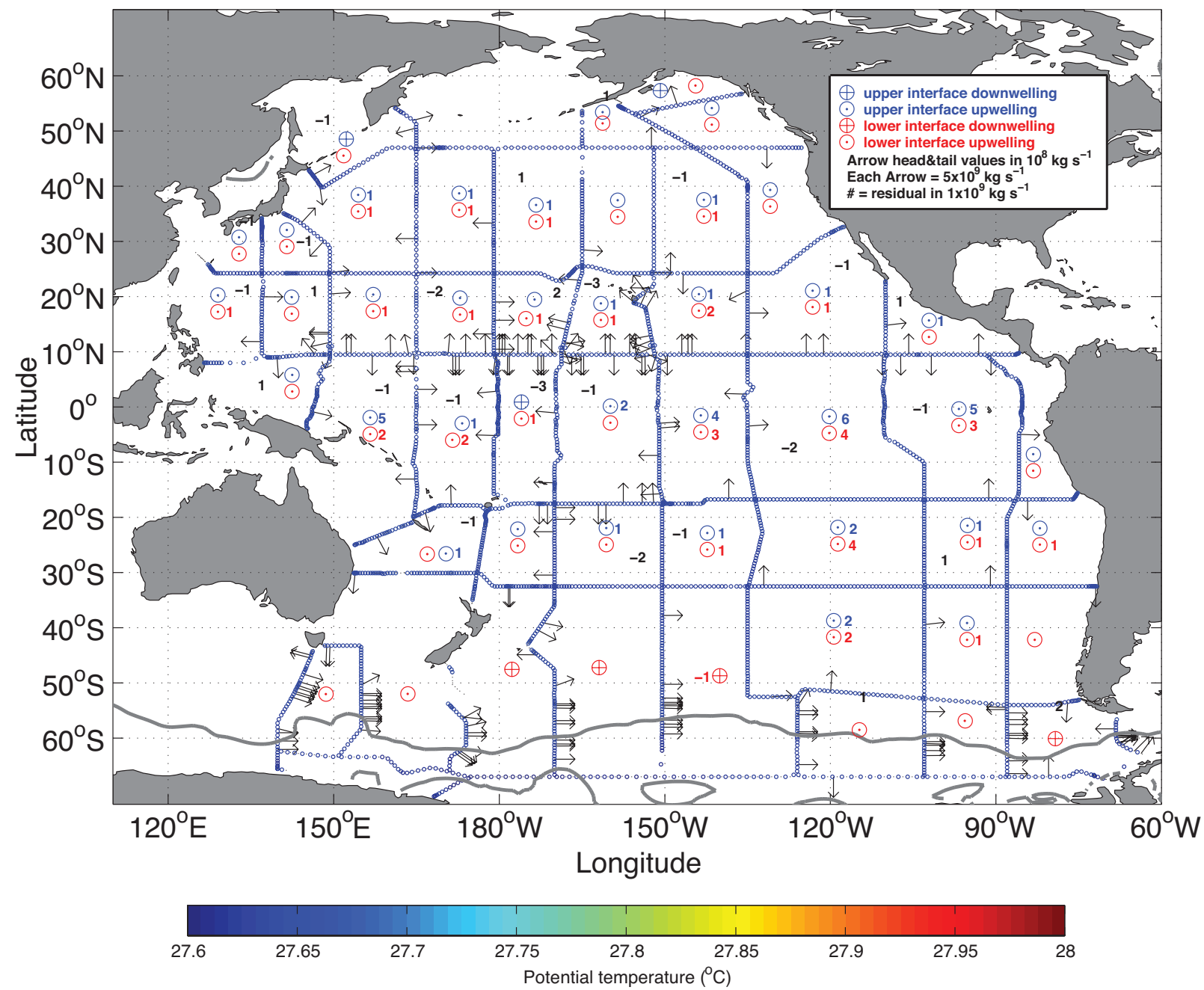

Fig. 6f.

Same as Fig. 6b for model layers 11-12, $\left(27.6-28.0 \gamma^{n}\right)$ representing mainly North Pacific Deep Water. Here, each black arrow represents $5 \times 10^{9} \mathrm{~kg} \mathrm{~s}^{-1}$. 
Transport Stream Function for UCDW
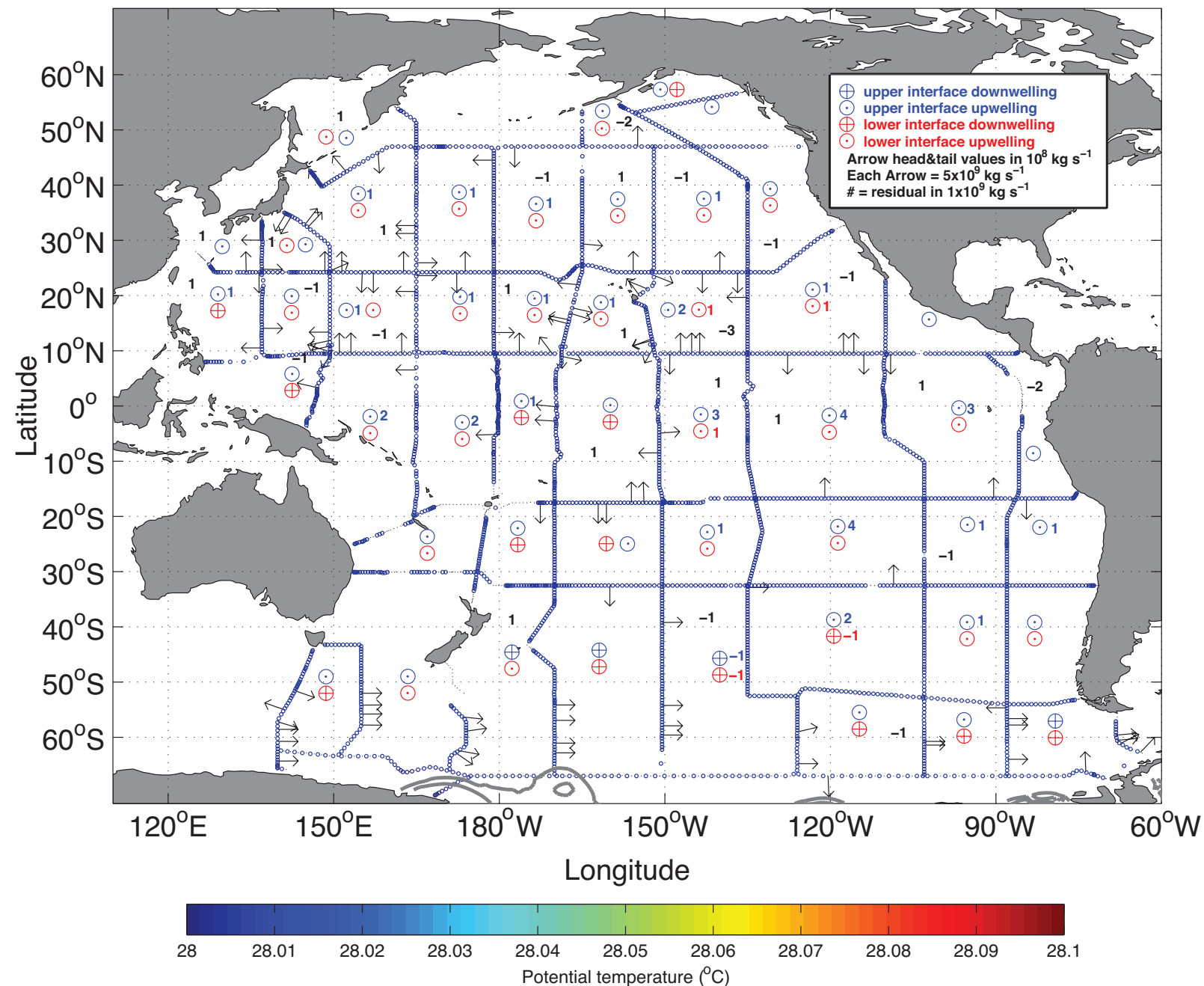

Fig. 6g.

Same as Fig. 6b for model layers 13, $\left(28.0-28.1 \gamma^{n}\right)$ representing Upper Circumpolar Deep Water. Here, each black arrow represents $5 \times 10^{9} \mathrm{~kg} \mathrm{~s}^{-1}$. 
Transport Stream Function for LCDW \&AABW

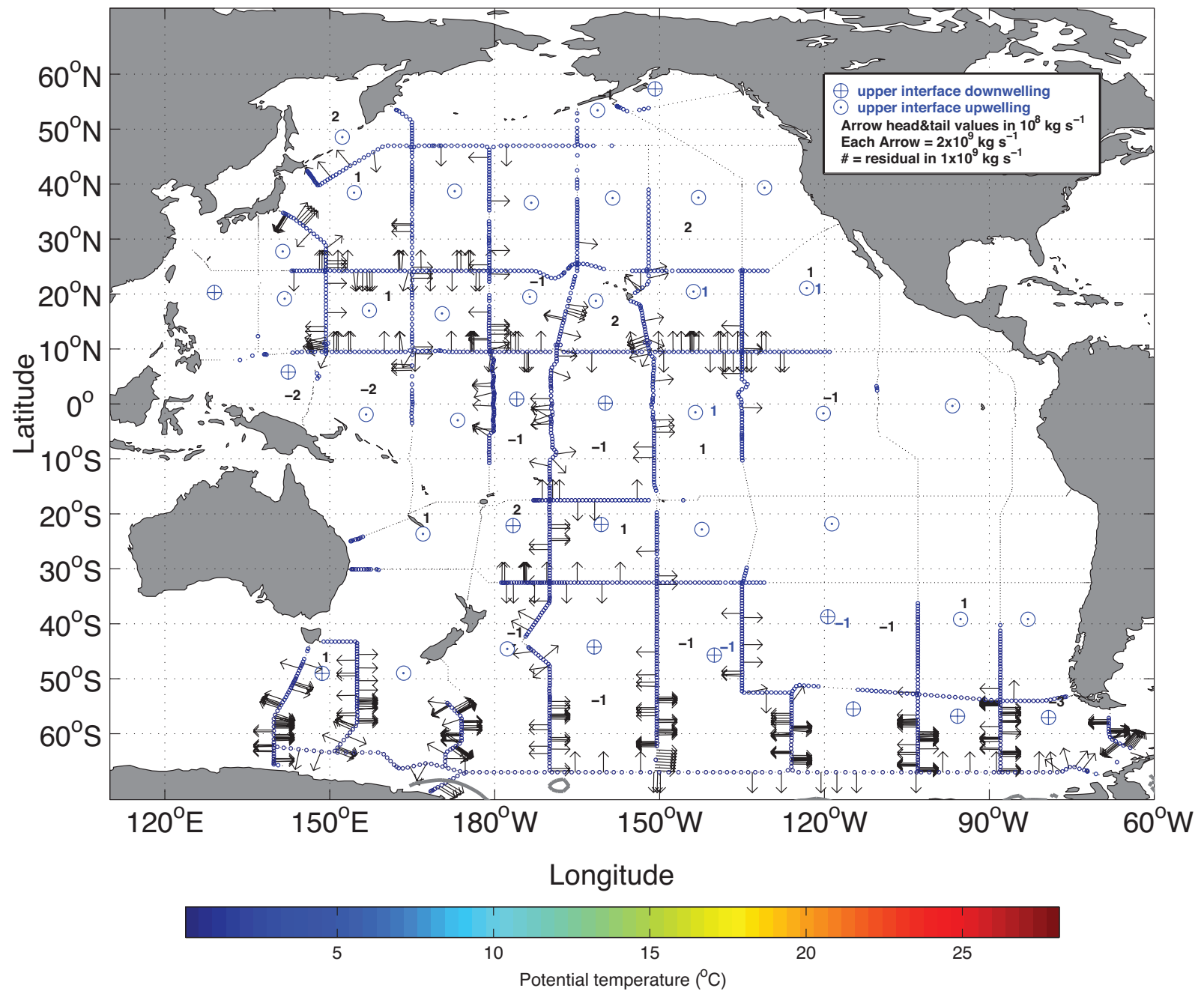

Fig. 6 h.

Same as Fig. 6b for model layers 14-15, (28.1 $\gamma^{n}$-Bottom) representing Lower Circumpolar Deep Water and Antarctic Bottom Water. Note, arrows represent $2 \times 10^{9} \mathrm{~kg} \mathrm{~s}^{-1}$. Here, each black arrow represents $2 \times 10^{9} \mathrm{~kg} \mathrm{~s}^{-1}$. 


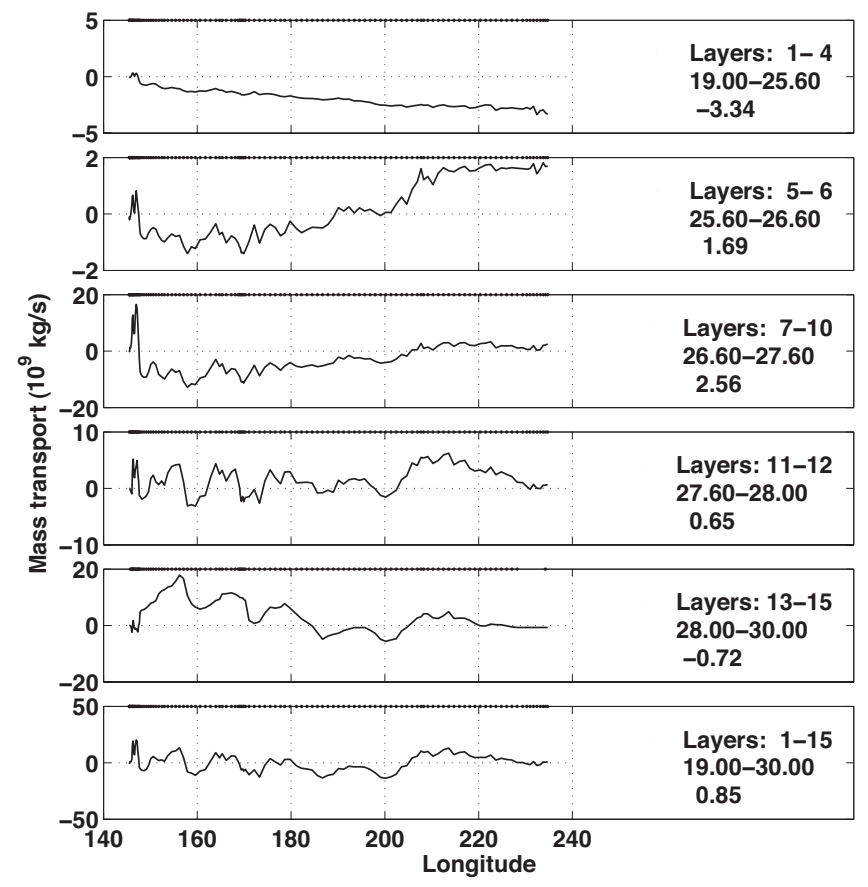

Fig. 7a. Model-derived mass-transport stream function $\left(10^{9} \mathrm{~kg} \mathrm{~s}^{-1}\right)$ integrated from west to east along the $\mathrm{P} 01,47^{\circ} \mathrm{N}$ zonal line in sets of model layers defined to maximize the net north/south transport On right: layers, neutral density limits $\left(\mathrm{kg} \mathrm{m}^{-3}\right)$ and net meridional transport $\left(10^{9} \mathrm{~kg} \mathrm{~s}^{-1}\right)$.

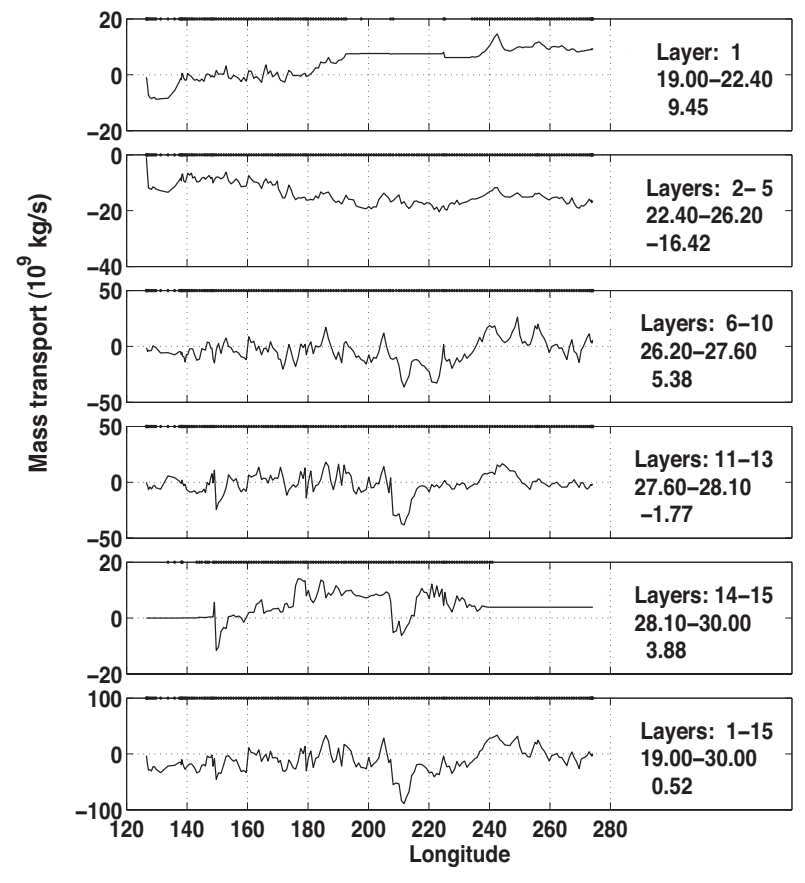

Fig. 7c. Same as Fig. 7a for P04, $10^{\circ} \mathrm{N}$.

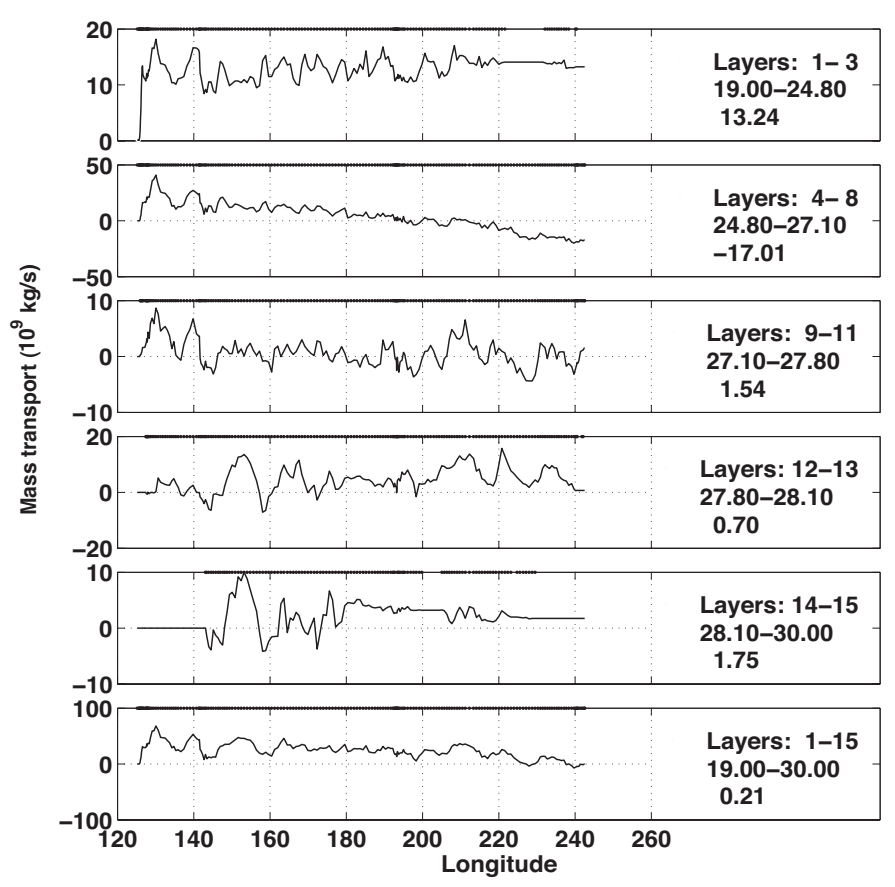

Fig. 7b. Same as Fig. 7a for P03, $24^{\circ} \mathrm{N}$.

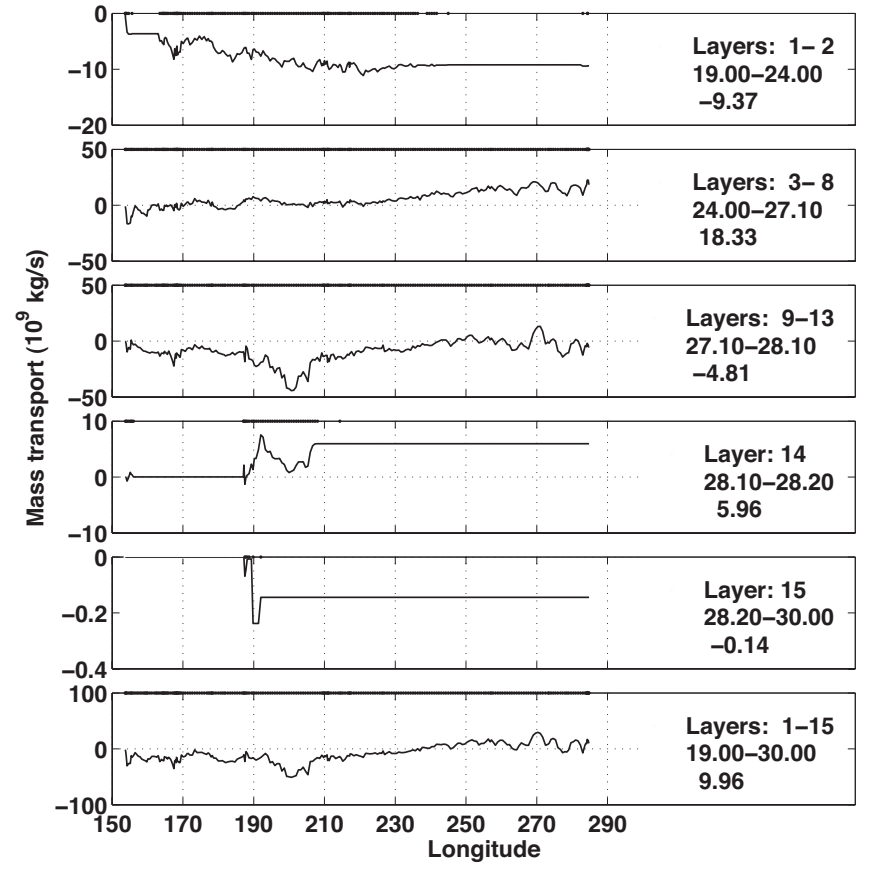

Fig. 7d. Same as Fig. 7a for $\mathrm{P} 21,17^{\circ} \mathrm{S}$. 


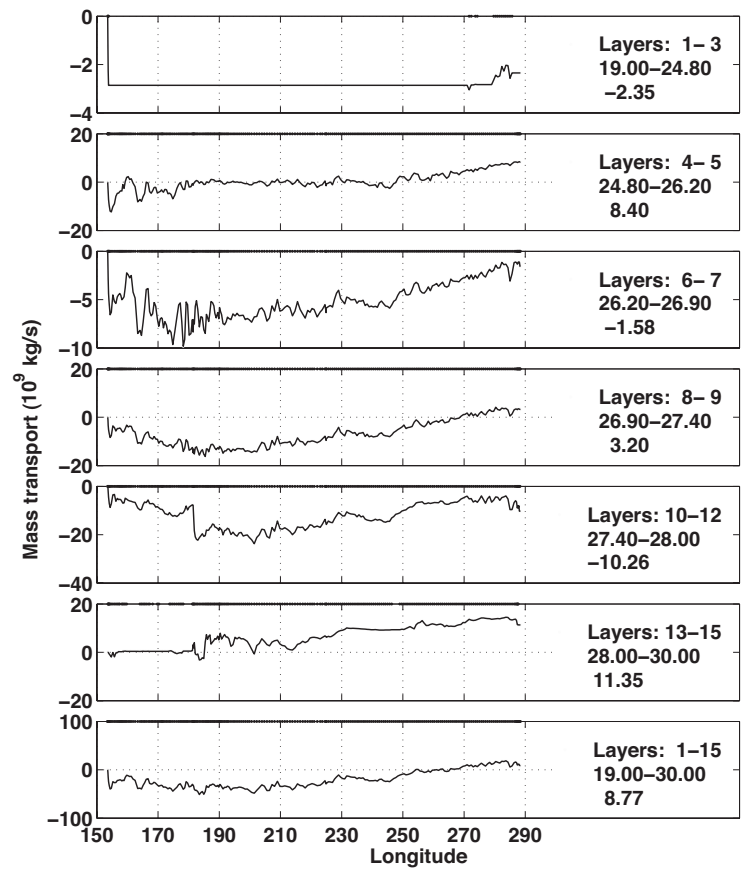

Fig. 7e. Same as Fig. 7a for $\mathrm{P} 06,32^{\circ} \mathrm{S}$. 
a) Layers 10-12, $\gamma^{\mathrm{n}} 27.4-28$

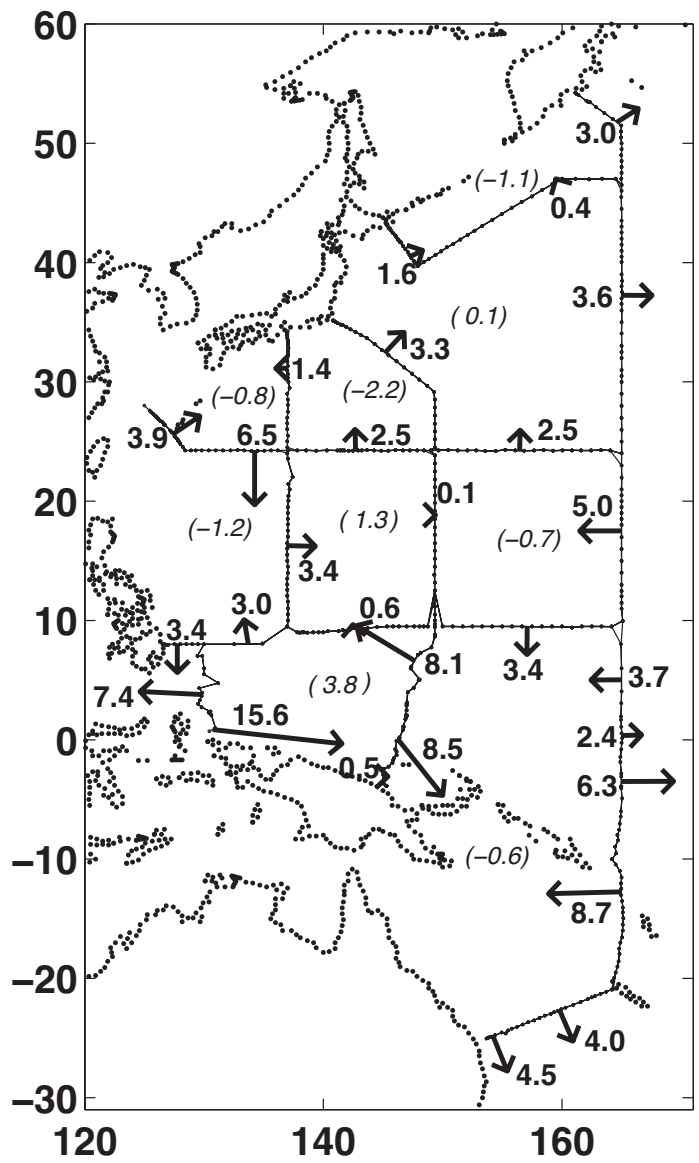

b) Layers 13-14, $\gamma^{\mathrm{n}}$ 28-28.2

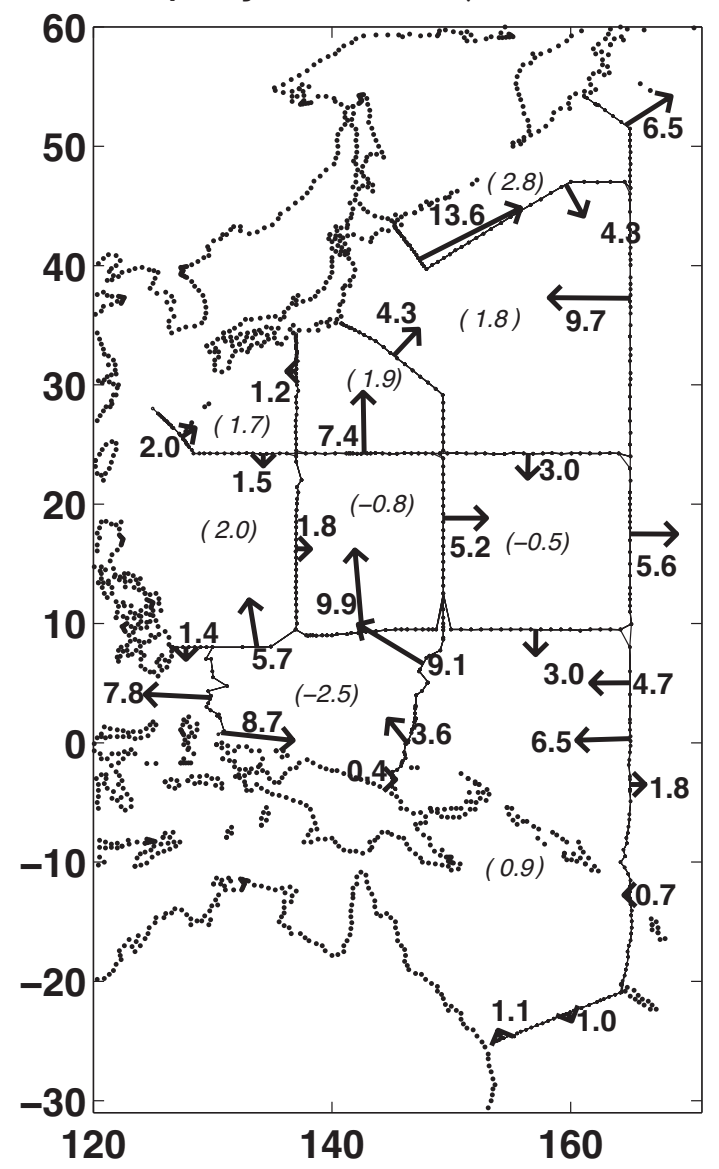

Fig. 8. Model SR mass transport across box edges in the deep northwest Pacific. Magnitude is indicated by arrow length and boldface values. Values in parenthesis represent horizonal mass convergence (positive) or divergence (negative). The left-hand panel describes the upper deep layers $(\sim 800-2500 \mathrm{~m})$. The right-hand panel describes the lower deep layers $(\sim 2500$-bottom $)$. 


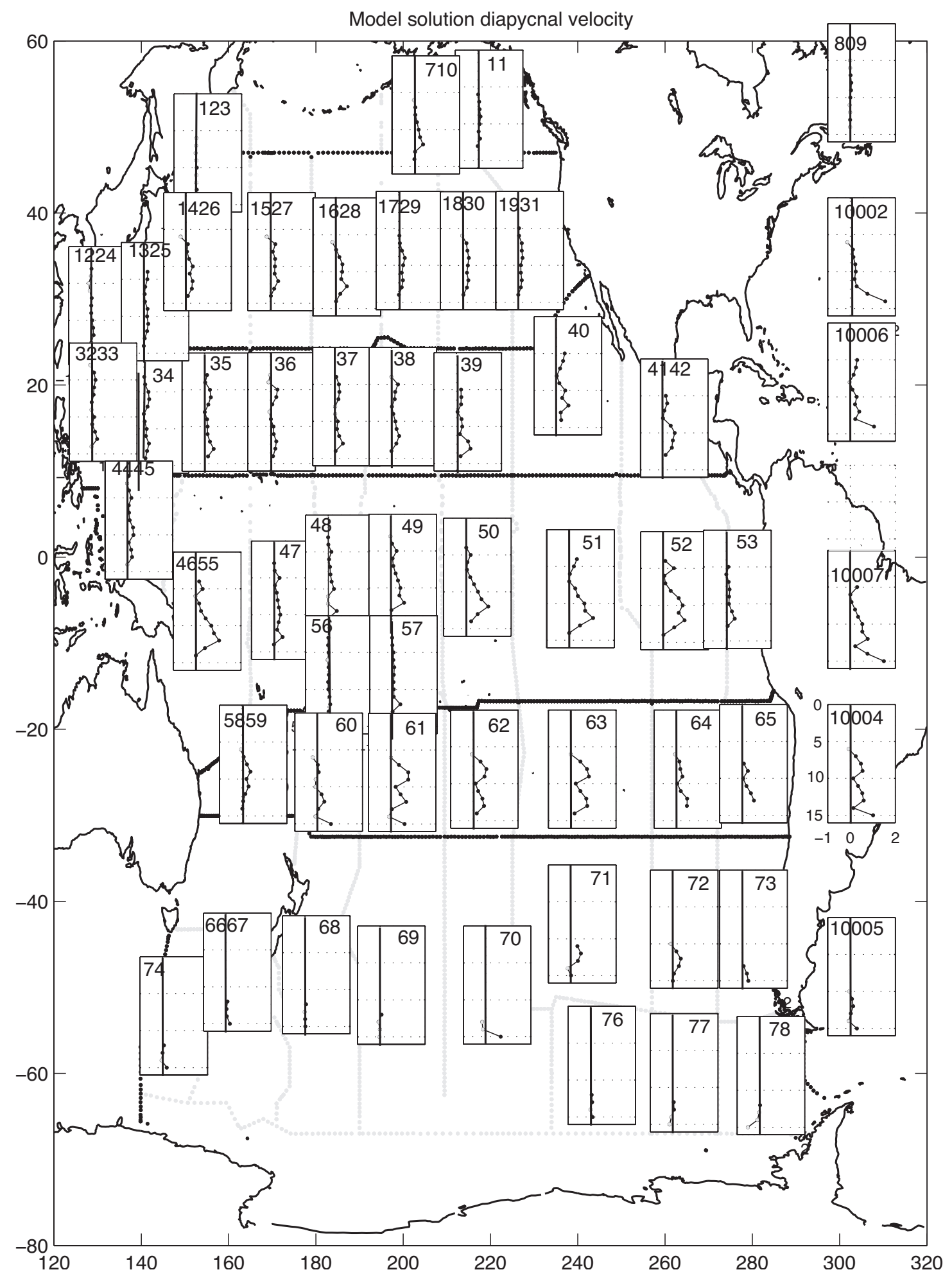

Fig. 9. Inverse estimates of diapycnal velocity in each of the small boxes (as labeled) and in each the large boxes (right hand column). Axes are the same for all graphs, but labeled only on box 10004 (second up from the bottom on the right). Inverse solutions for $\mathbf{w}$ only exist for non-outcropping interfaces. Interface 0 is the surface. Interface 16 is the bottom. Values are in units of $10^{-6} \mathrm{~cm} \mathrm{~s}^{-1}$. 


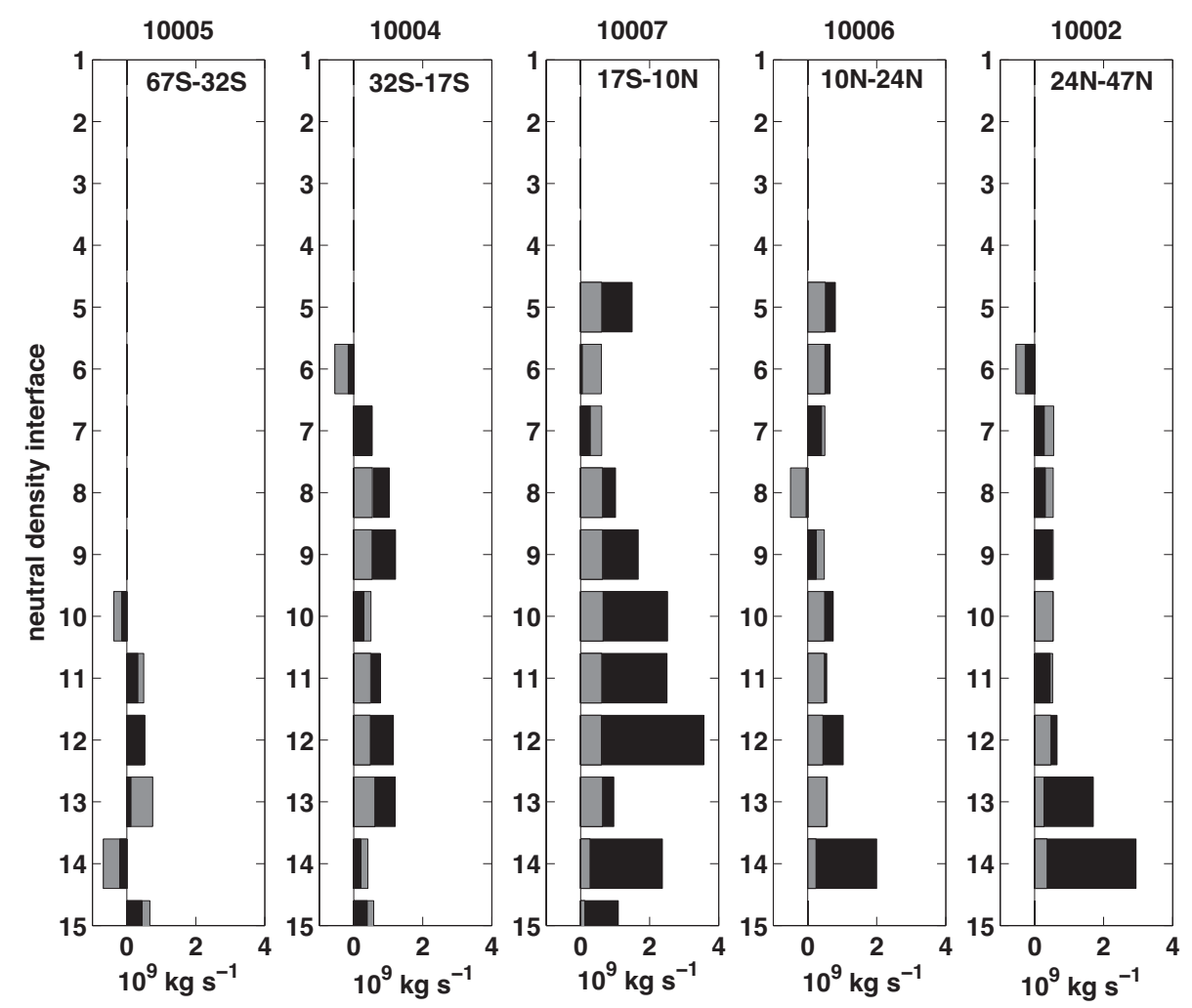

Fig. 10. Inverse estimates of diapycnal mass transport across the non-outcropping interfaces of the large boxes (black bars) with uncertainty (gray bars). Where gray bars exceed the length of the black bars, the transport values are not significantly different from zero. Positive/negative values indicate upwelling/downwelling. 


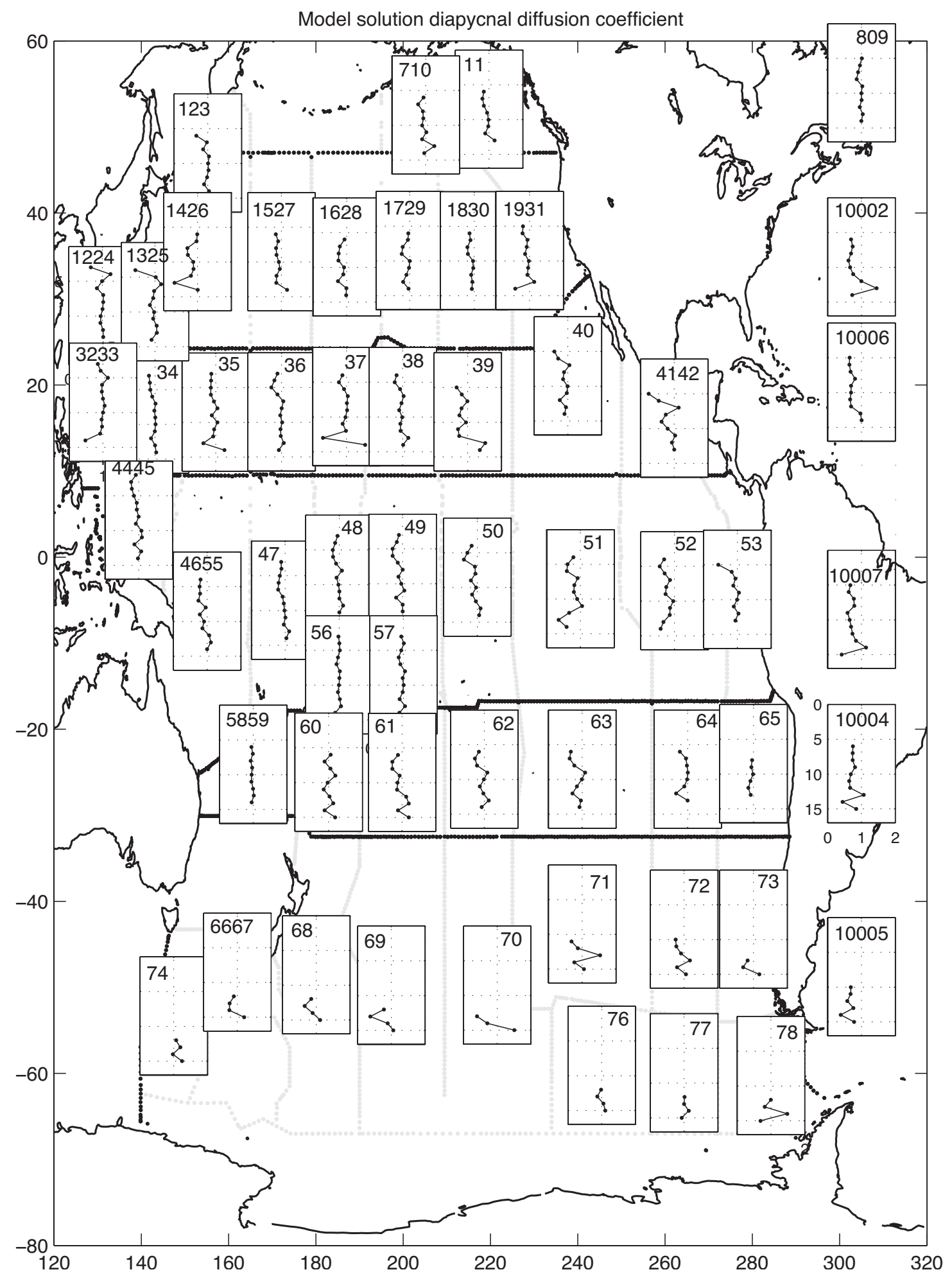

Fig. 11. Inverse estimates of diapycnal diffusivities in each of the small boxes (as labeled) and in each the large boxes (right hand column). Axes are the same for all graphs, but labeled only on box 10004 (second up from the bottom on the right). Inverse solutions for $\mathbf{k}_{\mathrm{z}}$ only exist for non-outcropping interfaces. Interface 0 is the surface. Interface 16 is the bottom. Values are in units of $\mathrm{cm}^{2} \mathrm{~s}^{-1}$. 


\section{Box 10002 mass balance $\left(10^{9} \mathrm{~kg} \mathrm{~s}^{-1}\right)$}

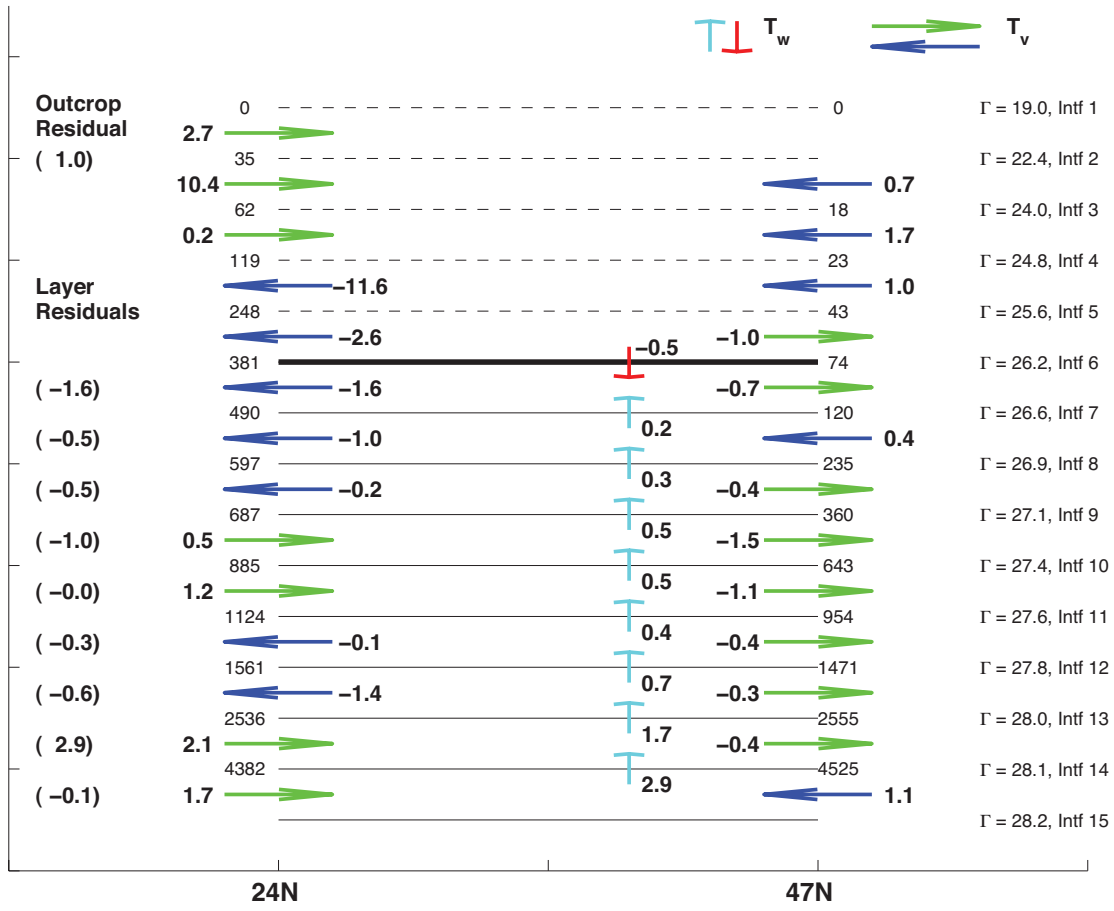

Box 10002 heat balance (PW)

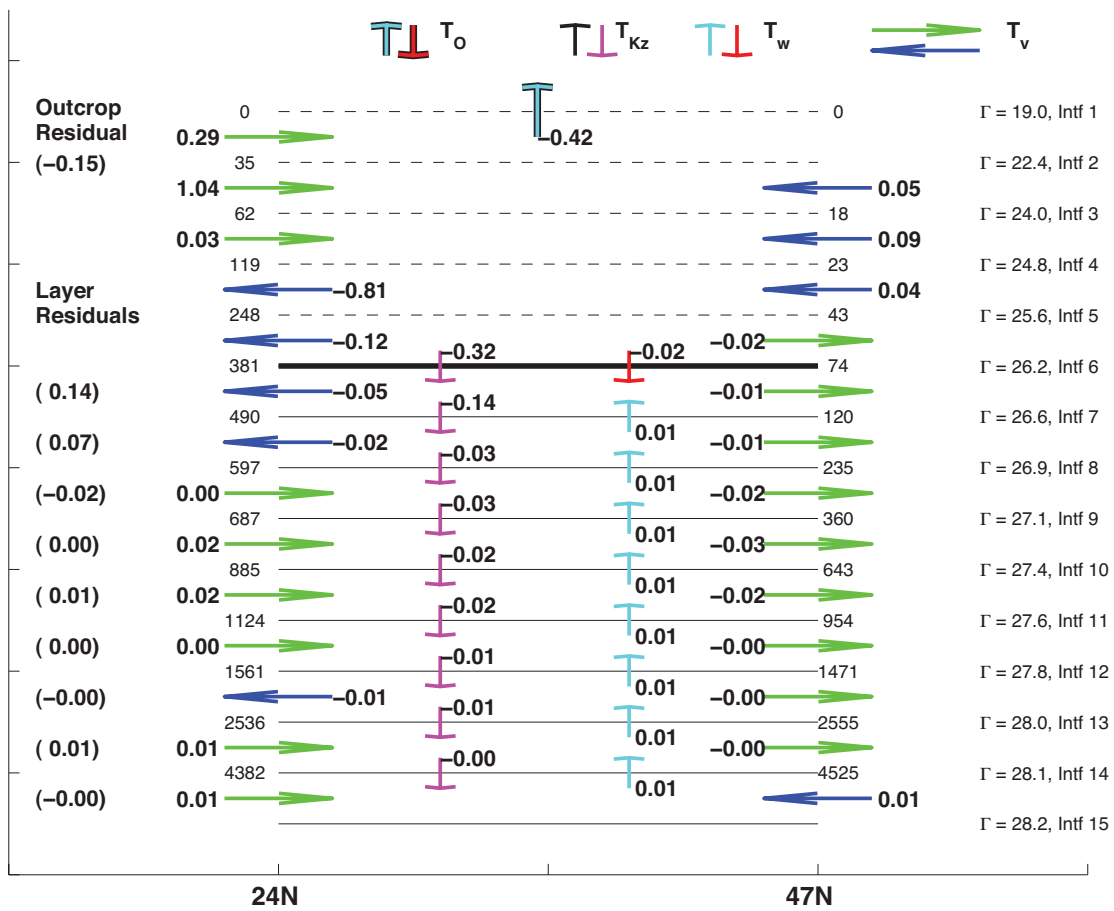

Fig. 12a. The mass (upper panel) and heat (lower panel) balance in the large box defined by the zonal transects across $24^{\circ} \mathrm{N}$ and $47^{\circ} \mathrm{N} . \mathrm{T}_{\mathrm{v}}$ and $\mathrm{T}_{\mathrm{w}}$ are the horizontal and dianeutral advective transport estimates, respectively. $\mathrm{T}_{\mathrm{o}}$ is air-sea heat flux estimate. Lines separate neutral density surfaces (indicated by $\Gamma$ on far right with mean northern and southern boundary depths on the right and left, respectively). Dashed lines outcrop. The layer residuals are shown on the left in parentheses. 


\section{Box 10006 mass balance $\left(10^{9} \mathrm{~kg} \mathrm{~s}^{-1}\right)$}

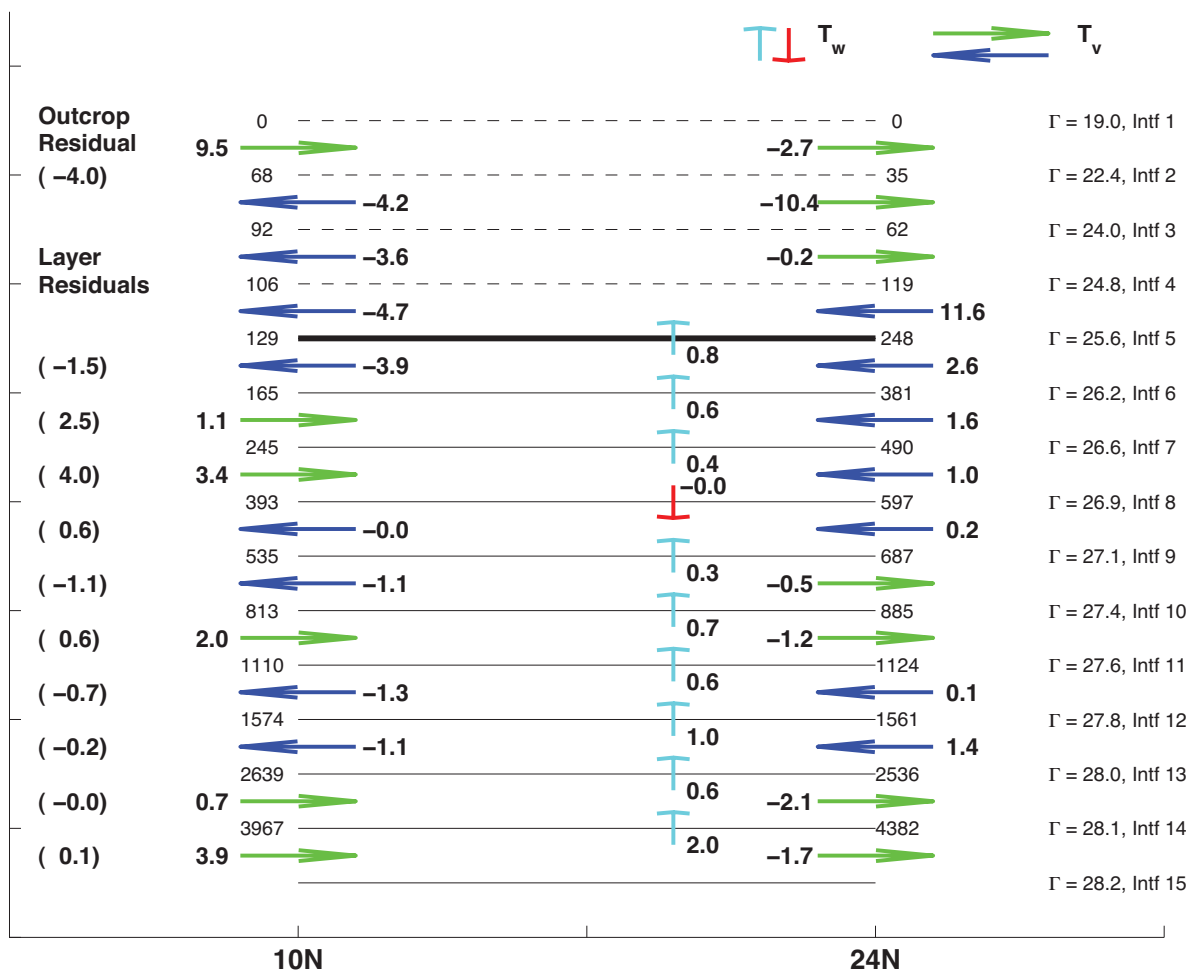

Box 10006 heat balance (PW)

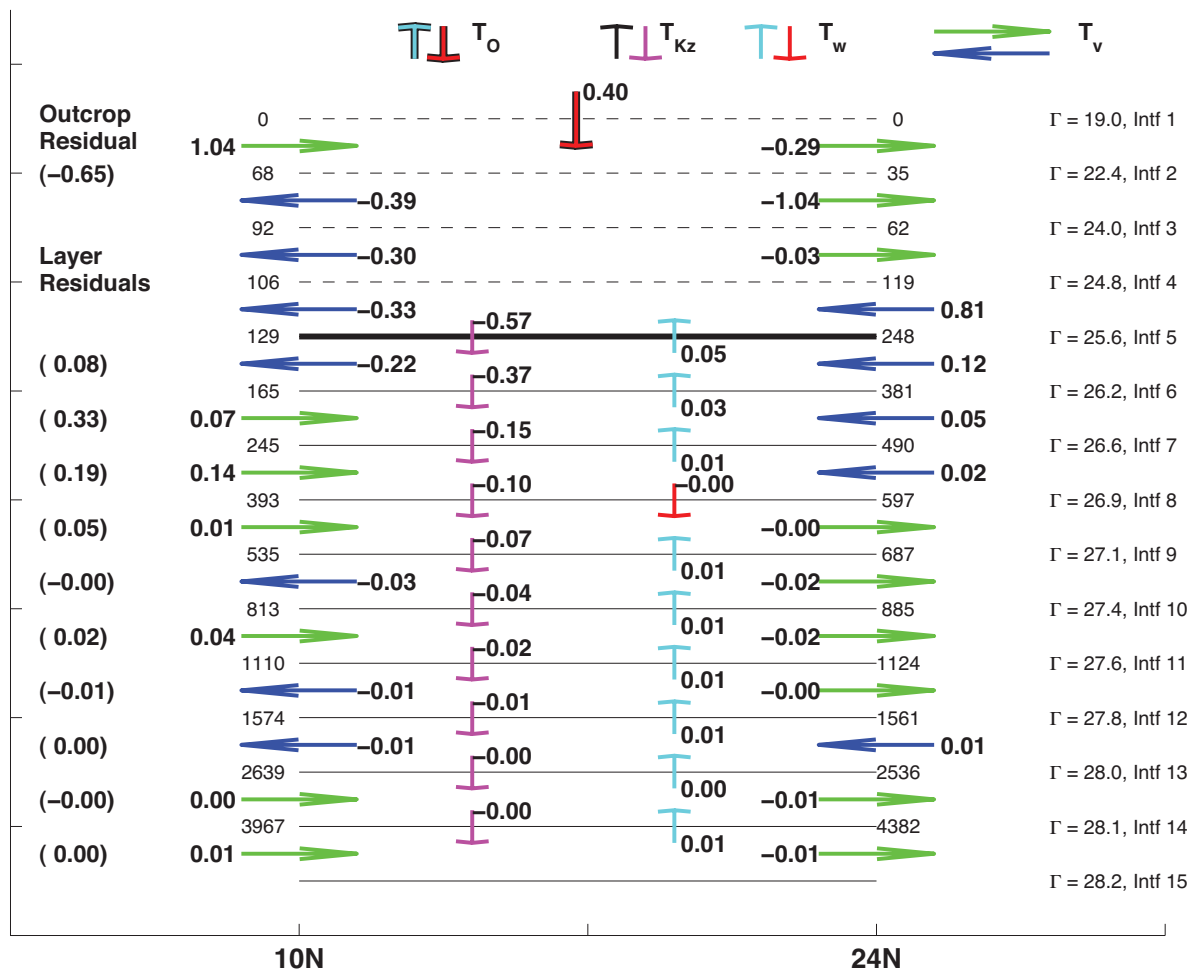

Fig. 12b.

Same as Fig. 12a for the box defined by the $10^{\circ} \mathrm{N}$ and $24^{\circ} \mathrm{N}$ transects. 


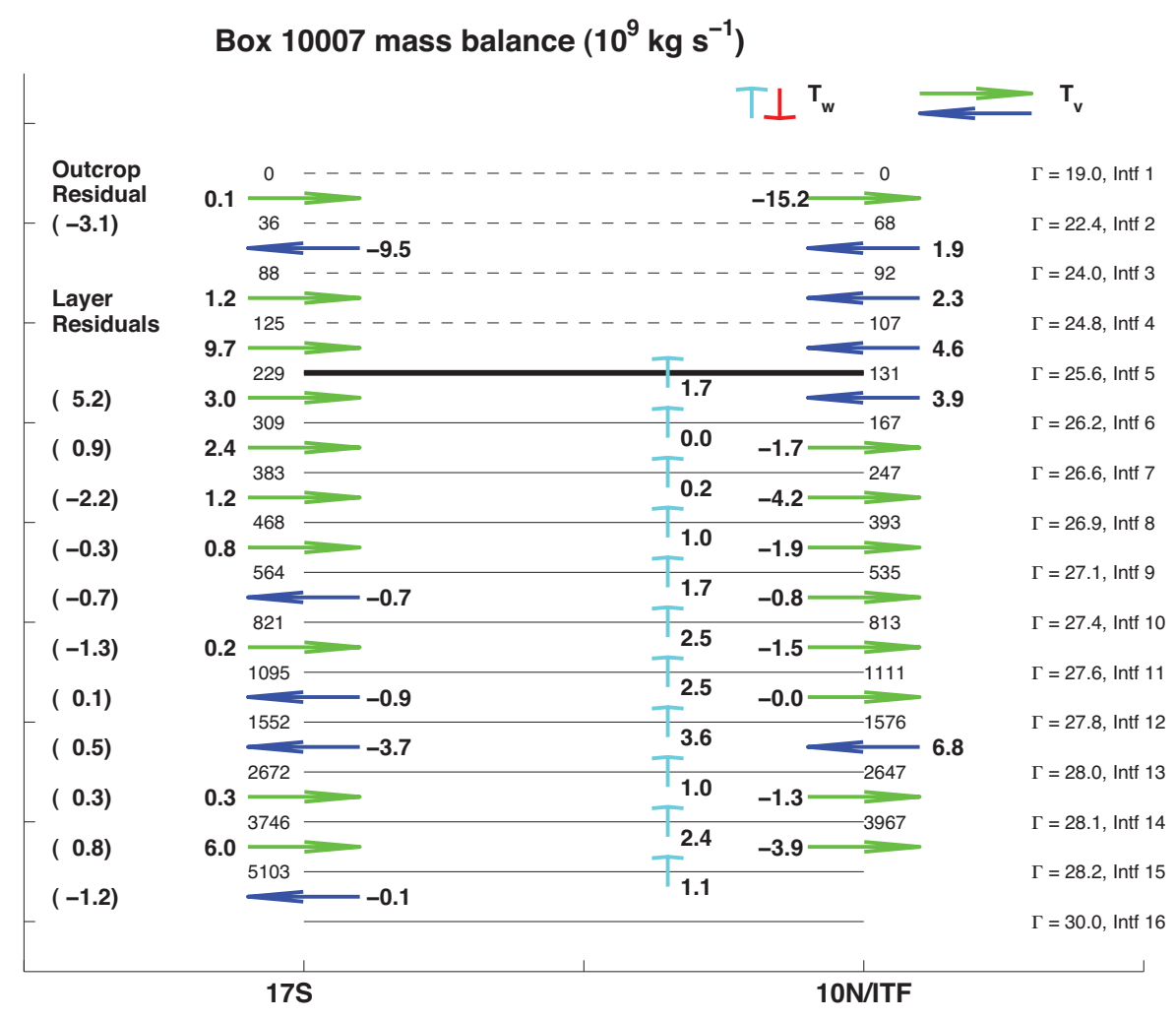

\section{Box 10007 heat balance (PW)}

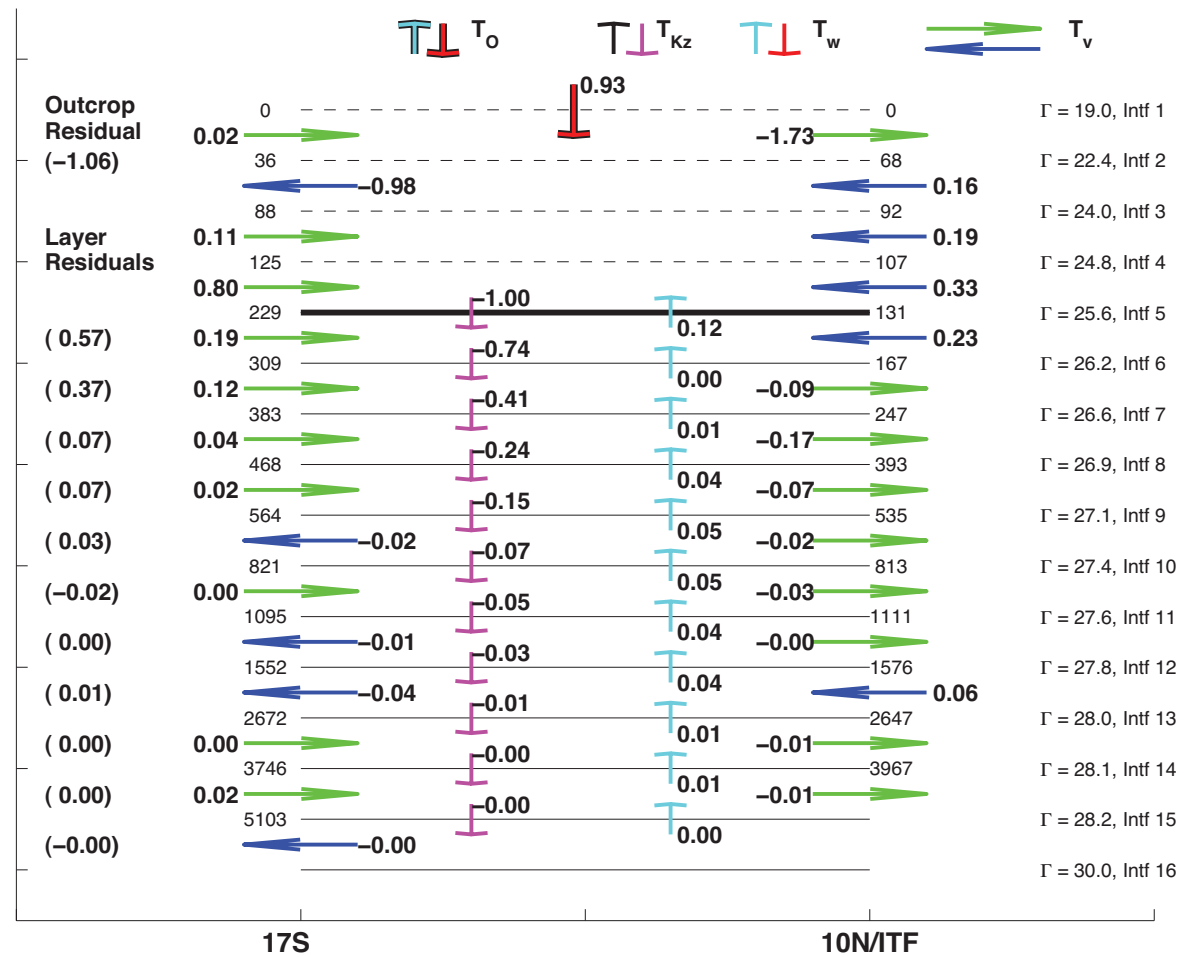

Fig. 12c.

Same as Fig. 12a for the box defined by the $17^{\circ} \mathrm{S}$ and $10^{\circ} \mathrm{N}$ transects. 

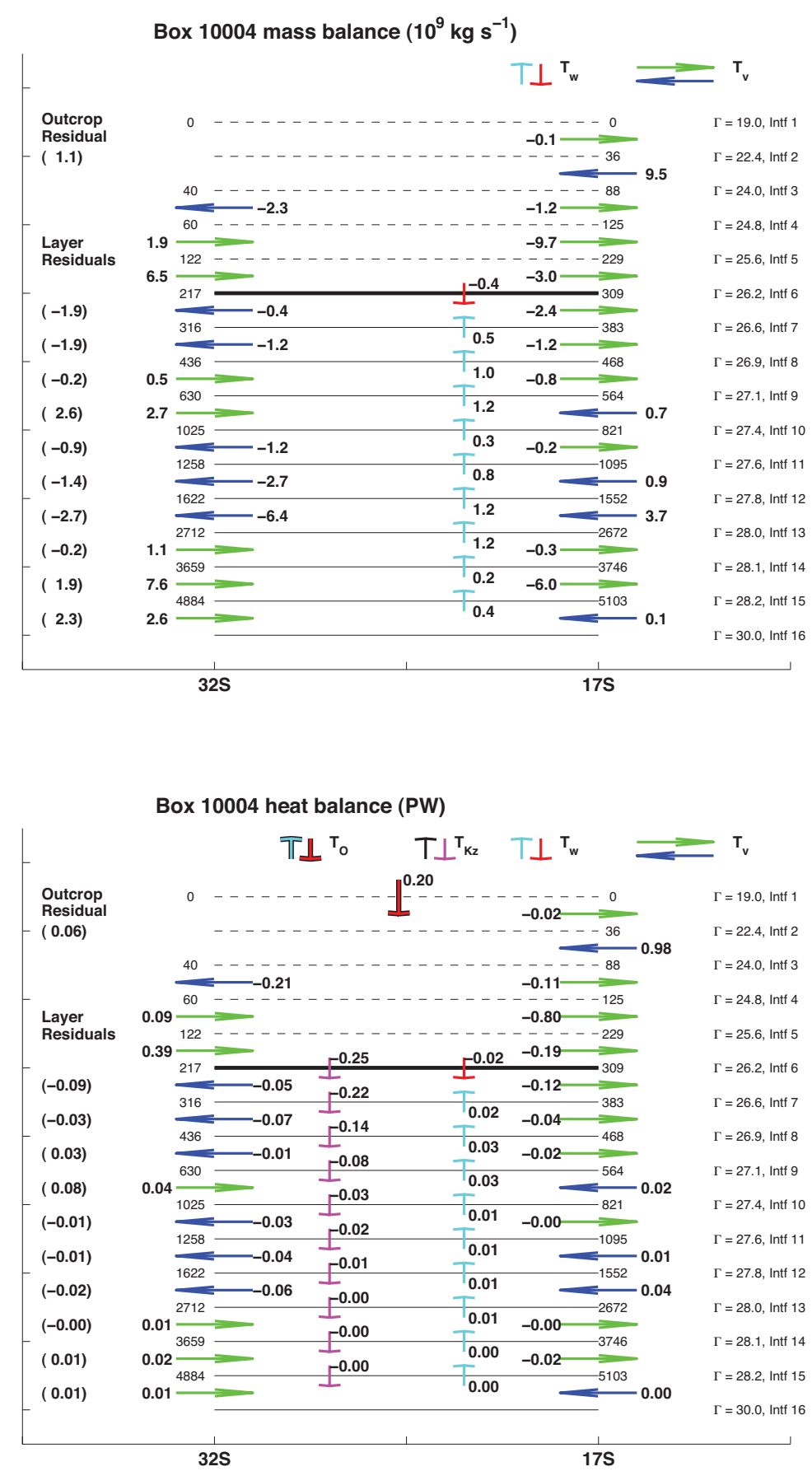

Fig. 12d.

Same as Fig. 12a for the box defined by the $32^{\circ} \mathrm{S}$ and $17^{\circ} \mathrm{S}$ transects. 

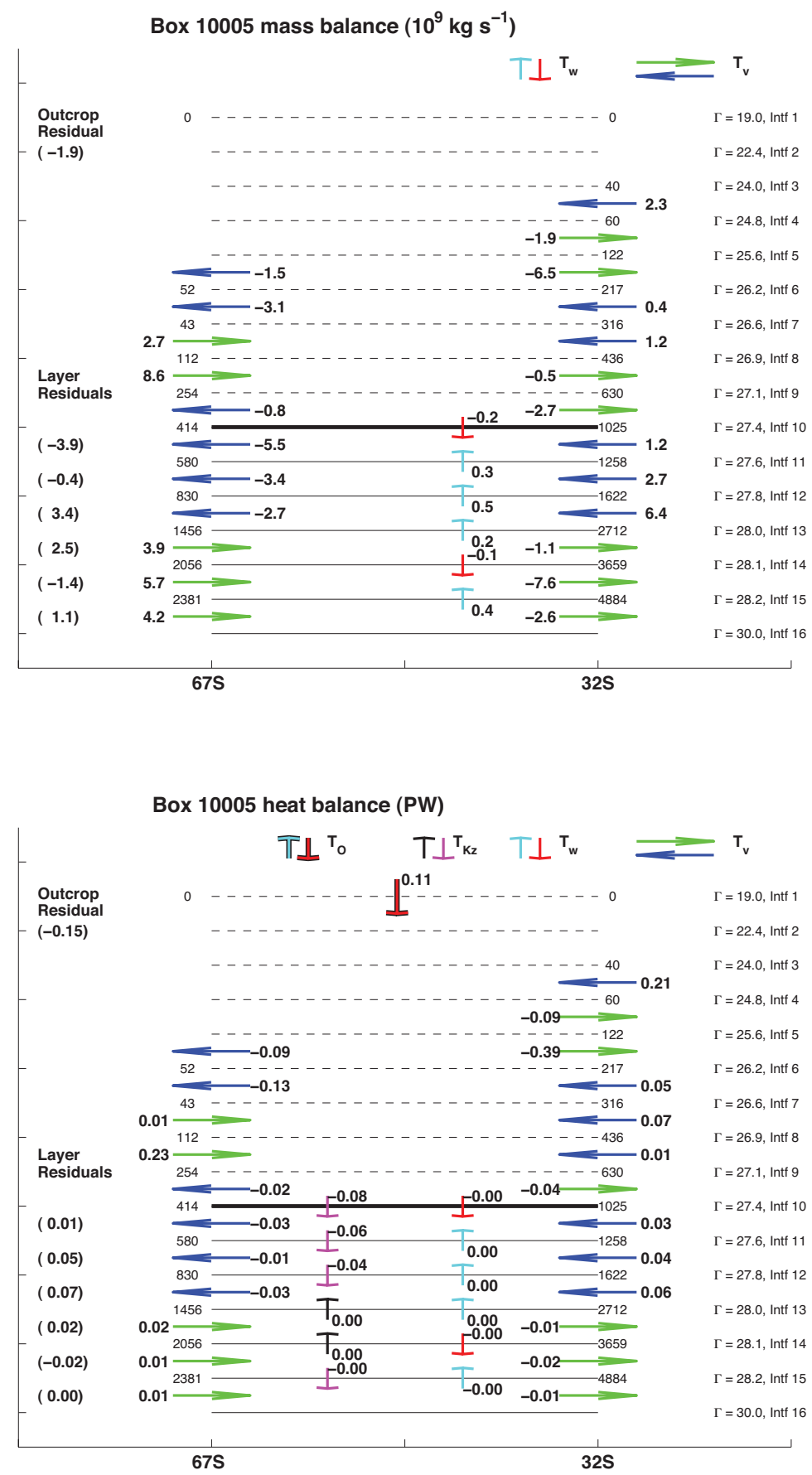

Fig. 12e.

Same as Fig. 12a for the box defined by the $67^{\circ} \mathrm{S}$ and $32^{\circ} \mathrm{S}$ transects. 

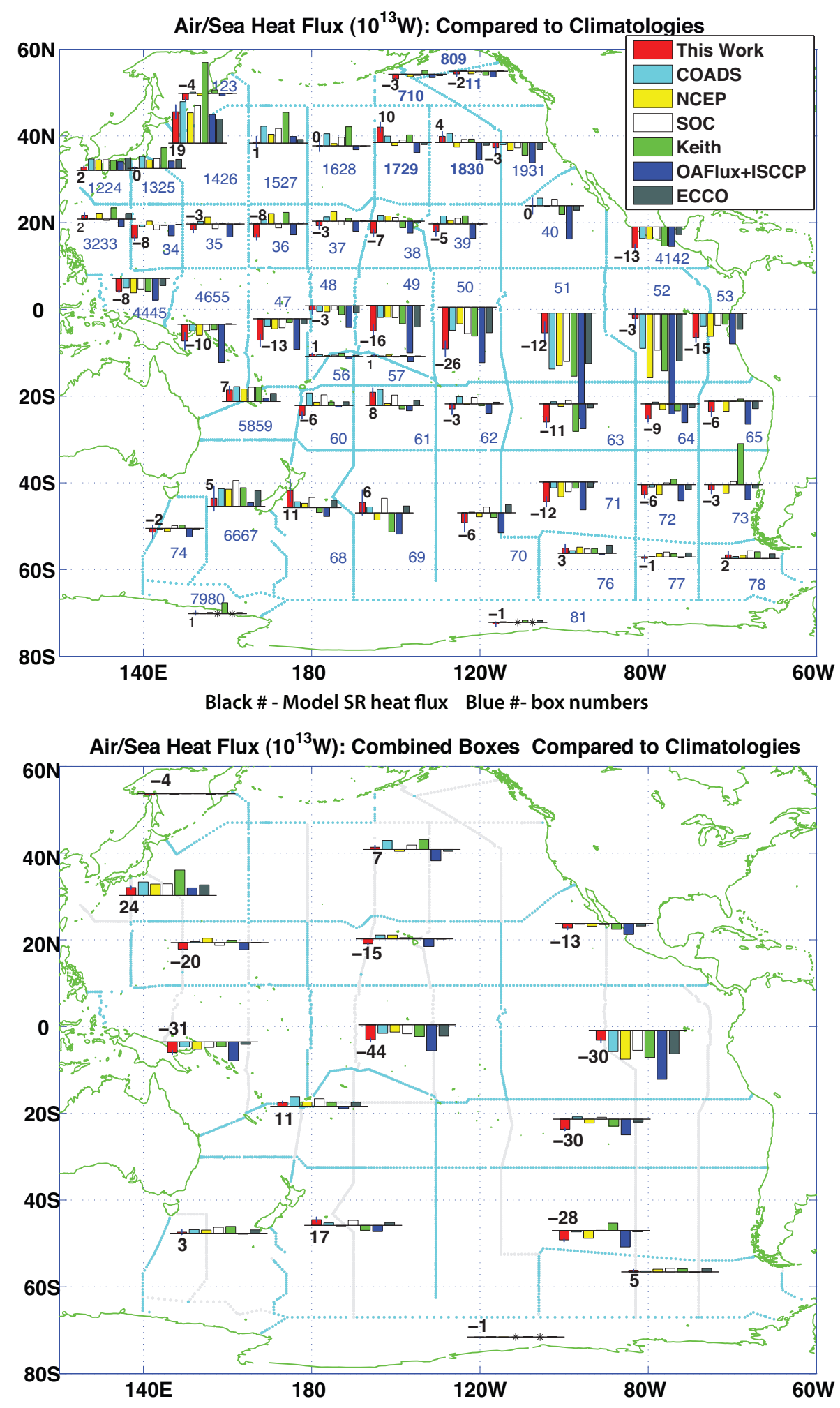

Fig. 13. Upper panel: inverse model air-sea exchange of heat (energy) flux. Inverse model results (shown in red) are compared to estimates from surface flux climatologies, in particular: (COADS) da Silva et al. (1994); (NCEP) Kalnay et al. (1996); (SOC) Grist and Josey (2003); Keith (1995); (OAFlux+ISCCP) latent and sensible heat Yu and Weller (2007) combined with radiation Rossow and Schiffer (1999); and (ECCO) Stammer et al. (2002). Asterisks indicate a lack of data within the climatology for comparison. Lower panel: small boxes have been grouped together to increase the signal to noise ratio. 


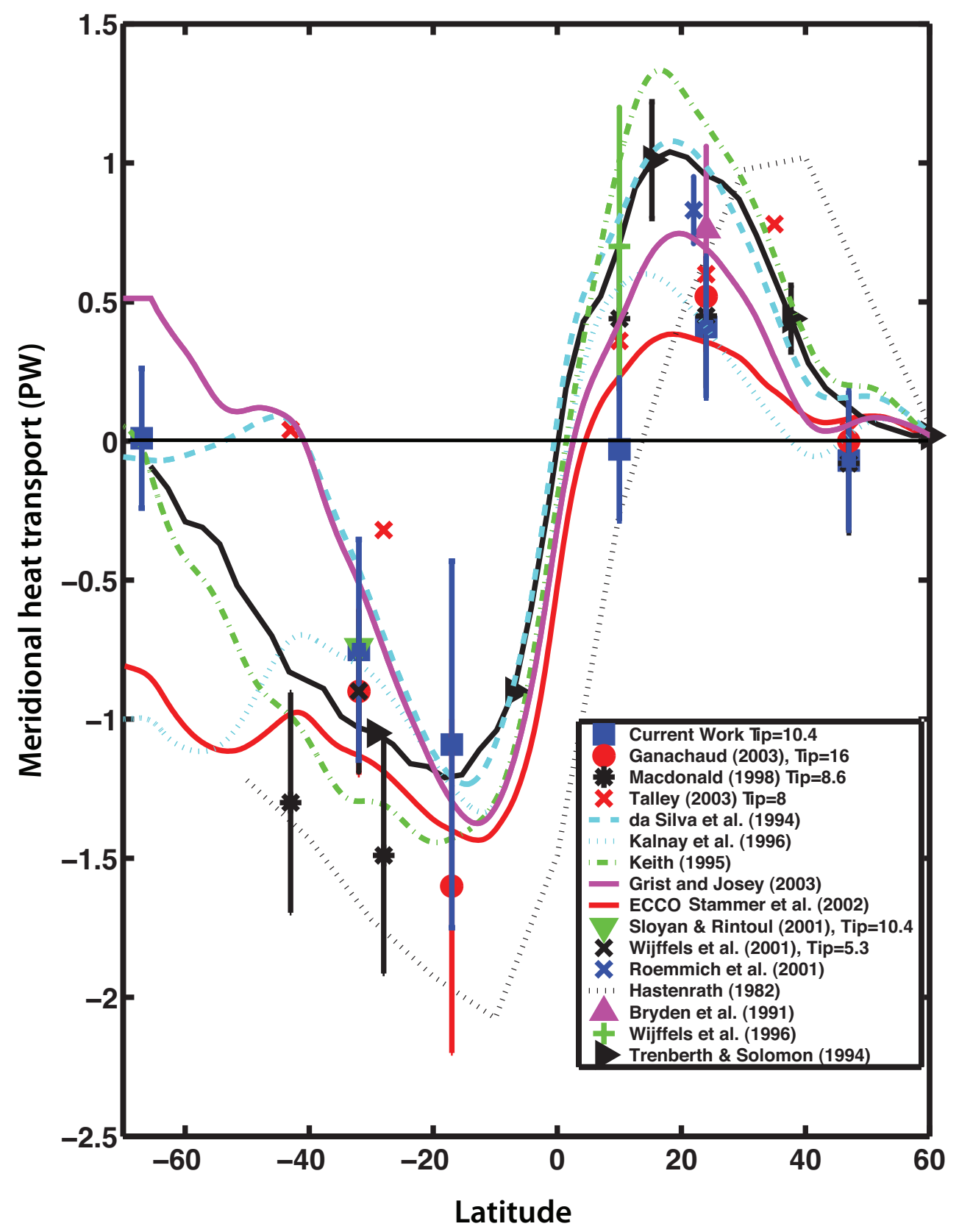

Fig. 14. Estimates of Indo-Pacific meridional transport of heat. In the legend " $T_{i p}$ " indicates where an estimate of mass transport through the Indonesian Archipelago has been calculated or assumed in the process of estimating heat transport. South of the equator, our estimates for the Pacific have been added to the Indian Ocean temperature transport estimates of Ganachaud and Wunsch (2000) which have been scaled for the difference in $T_{i p}$ temperature transport. Individual estimates north of the equator are for the Pacific only. Units are PW. 

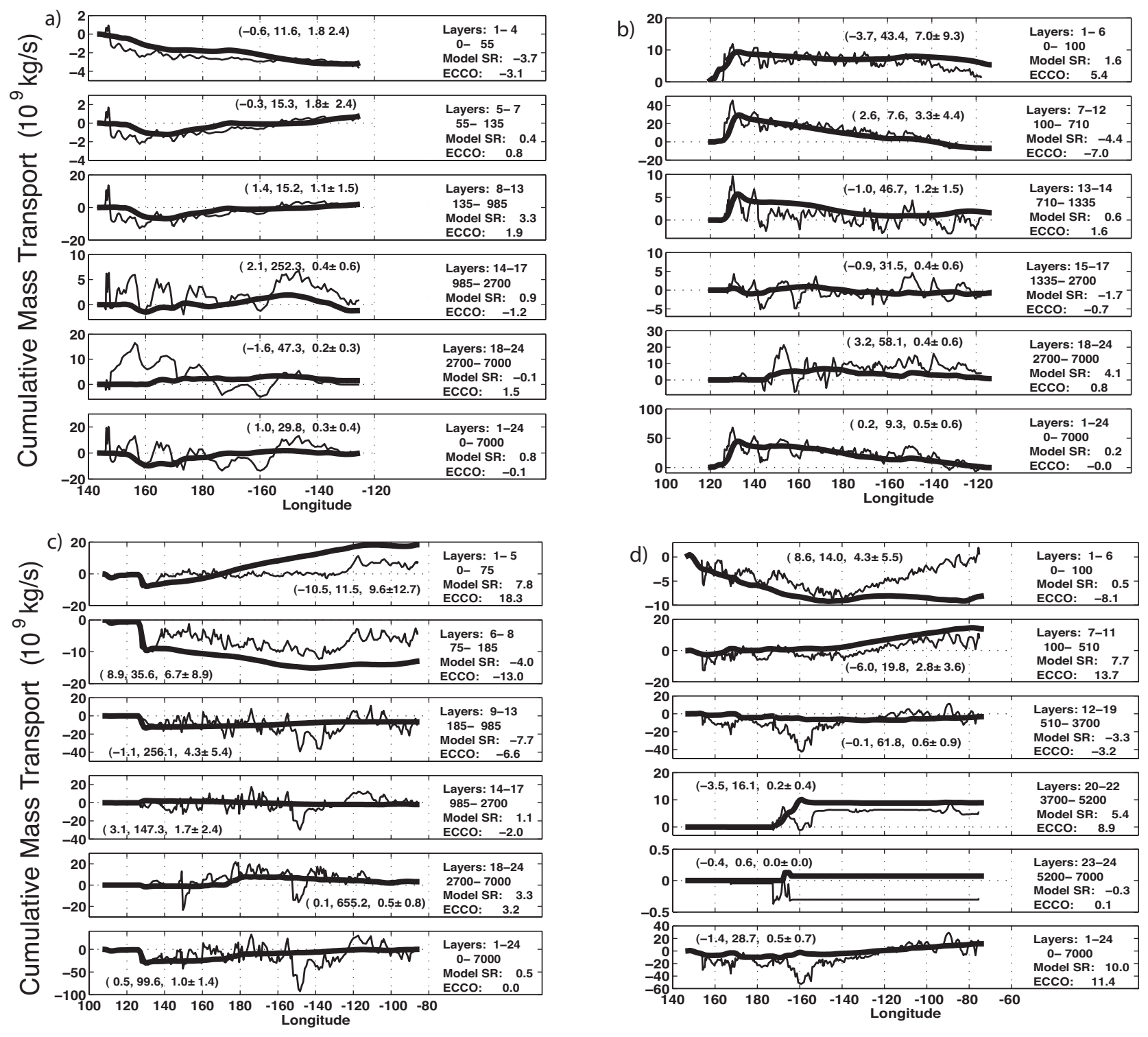

Fig. 15. a)Integrated absolute mass transport across $\mathrm{P} 01,47^{\circ} \mathrm{N}$ for Model SR (thin line) and ECCO-GODAE (thick line). Values to the right indicate: ECCO-GODAE model layers included in the integration, chosen to best illustrate changes in net vertical transport and similarities between the two models; depth of the interfaces bounding the layer sets; and net layer set transport. Integration is performed from west to east. The three values in parentheses in upper left are the net difference in transport, mean absolute value of the ratio of Model SR to ECCO-GODAE transport, and mean absolute value of transport difference per kilometer. Positive values indicate northward flow. b)Same as Fig. 15a for P03, $24^{\circ}$ N. c)Same as Fig. 15a for P04, $10^{\circ}$ N. d)Same as Fig. 15a for $\mathrm{P} 21,17^{\circ} \mathrm{S}$. 


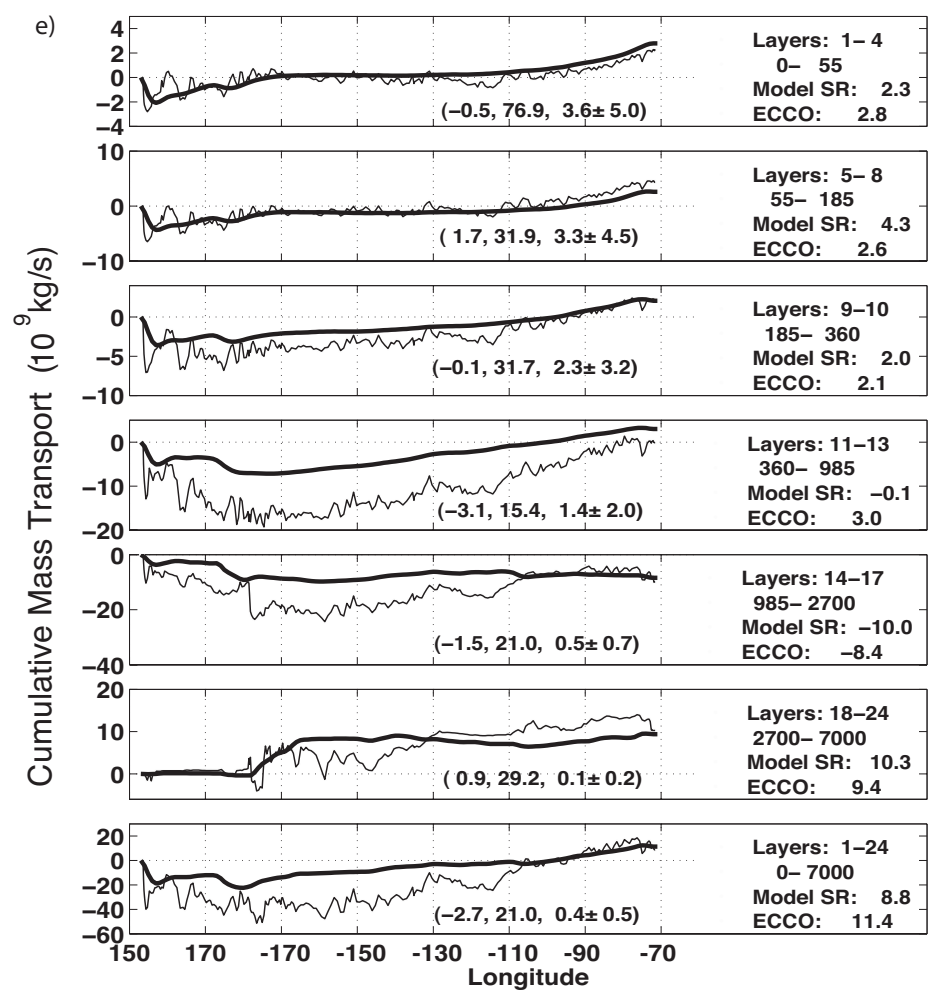

Fig. 15e. Same as Fig. 15a for P06, $32^{\circ} \mathrm{S}$.

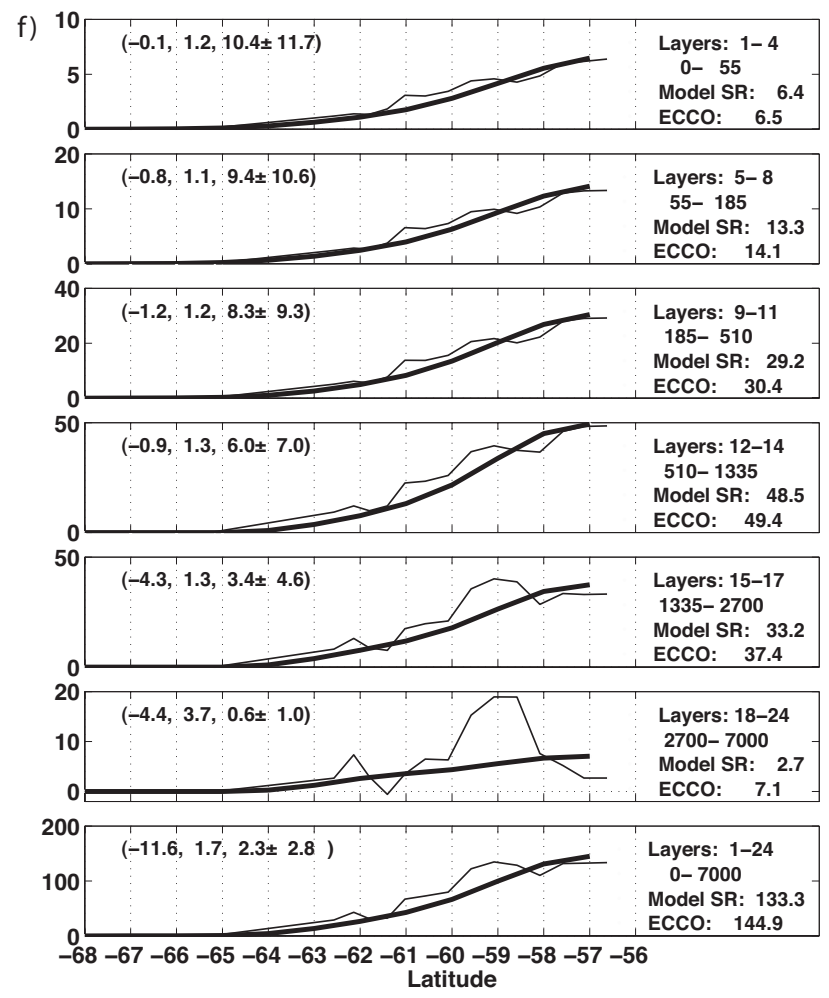

Fig. 15f. Same as Fig. 15a for Drake Passage, $88^{\circ} \mathrm{W}$. 

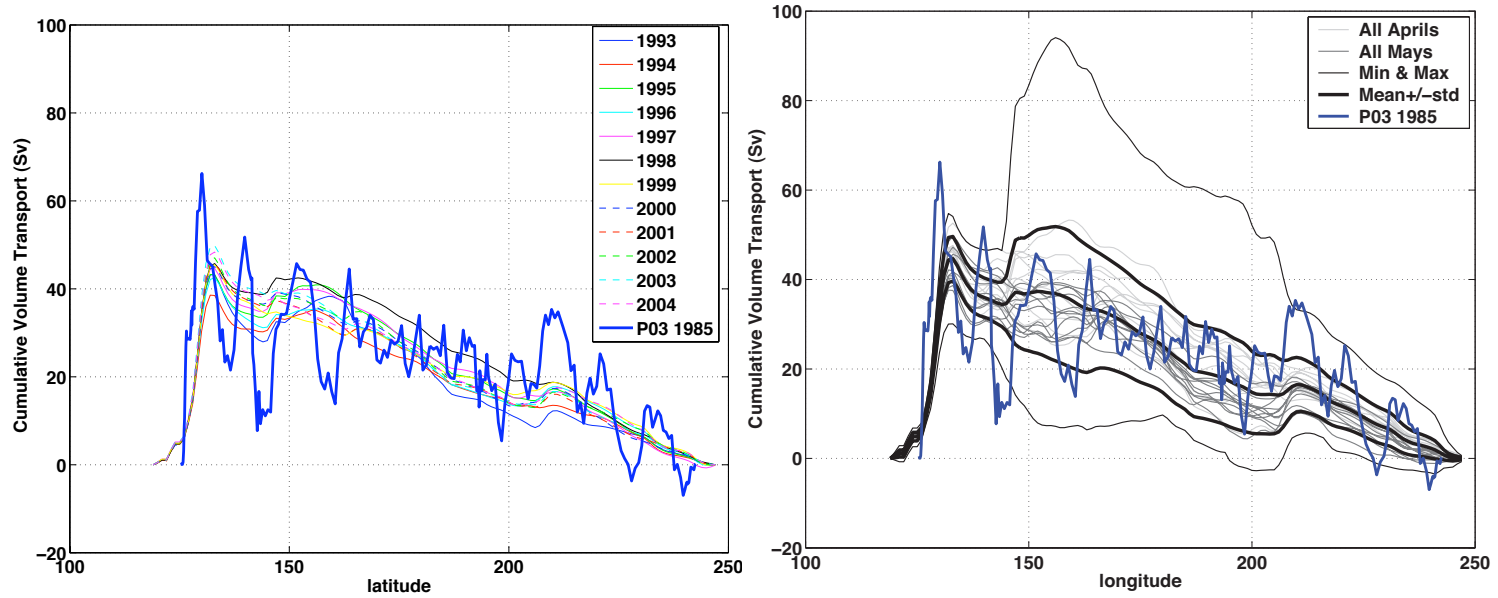

Fig. 16a. Mass transport stream function in- Fig. 16b. Same as right panel, here illustegrated from west to east along $\mathrm{P} 03,24^{\circ} \mathrm{N}$ trating the monthly variation with the minin both ECCO-GODAE and Model SR illus- imum, maximum, mean and standard deviatrating the year to year variation according to tion taken over all ECCO Aprils and Mays ECCO. The thick solid blue line is the same compared to P03, which was carried out duras the thin line in the lowest panel of Fig 15b. ing April and May of 1985. 


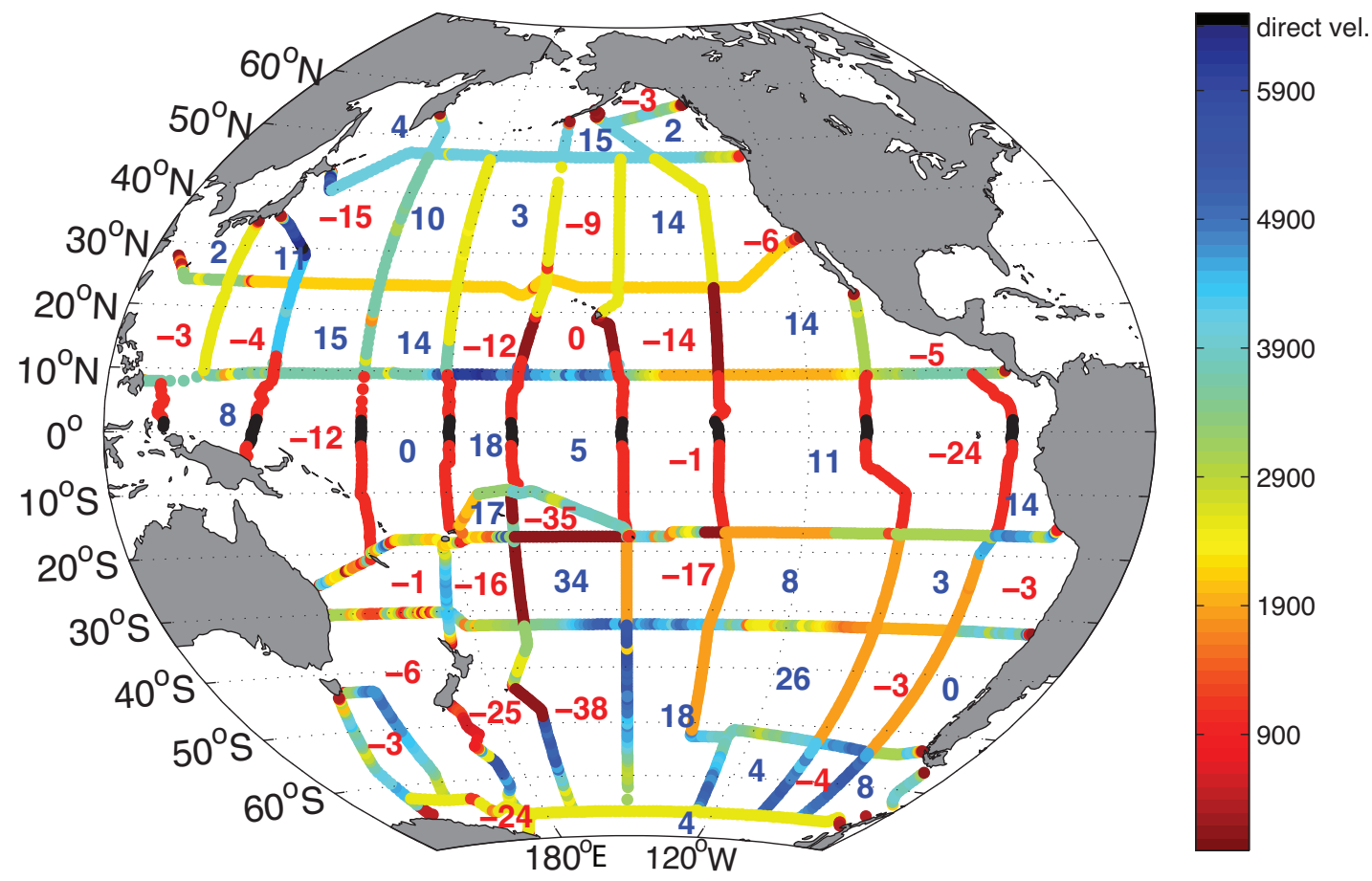

Fig. B.1. Pressure of initial geostrophic velocity reference surfaces (dbars) for Pacific station pairs. Velocities at station pairs within $2^{\circ}$ of the equator are based on absolute velocity estimates, and therefore, do not require reference surfaces. The values in blue and red are the initial top to bottom convergences and divergences in the boxes, respectively. Units $10^{9} \times 10^{9} \mathrm{~kg} \mathrm{~s}^{-1}$. 
Table 1

Hydrographic sections used in the analysis. Data are available from CCHDO (2009).

\begin{tabular}{|c|c|c|c|c|c|}
\hline $\begin{array}{l}\text { WOCE } \\
\text { Desig. }\end{array}$ & Expocode & $\begin{array}{l}\text { Nominal } \\
\text { Lat./Long. }\end{array}$ & $\begin{array}{l}\text { Ship (RV) \& } \\
\text { Chief Scientist }\end{array}$ & Date & $\begin{array}{l}\text { \# Stations } \\
\text { Used/Total }\end{array}$ \\
\hline P01 & 31TTTPS47 & $47^{\circ} \mathrm{N}$ & T G Thompson, L. Talley & $08 / 04 / 85-09 / 07 / 85$ & $113 / 115$ \\
\hline P03_1 & 31TTTPS24_1 & $24^{\circ} \mathrm{N}$ & T G Thompson, J. Swift & $03 / 30 / 85-4 / 30 / 85$ & $101 / 106$ \\
\hline P03_2 & 31TTTPS24_2 & $24^{\circ} \mathrm{N}$ & T G Thompson, D. Roemmich & $05 / 04 / 85-06 / 03 / 85$ & $97 / 110$ \\
\hline P04W & $32 \mathrm{MW} 893$ & $10^{\circ} \mathrm{N}$ & Moana Wave, J. Toole & $02 / 06 / 89-03 / 09 / 89$ & $68 / 83$ \\
\hline $\mathrm{P} 04 \mathrm{C}$ & $32 \mathrm{MW} 893$ & $10^{\circ} \mathrm{N}$ & Moana Wave, E. Brady & $03 / 09 / 89-03 / 24 / 89$ & $35 / 35$ \\
\hline P04E & $32 \mathrm{MW} 893$ & $10^{\circ} \mathrm{N}$ & Moana Wave, H. Bryden & $04 / 02 / 89-05 / 19 / 89$ & $100 / 102$ \\
\hline P06W & 316N138_5 & $30.5^{\circ} \mathrm{S}$ & Knorr, J. Toole & $07 / 13 / 92-07 / 30 / 92$ & $78 / 78$ \\
\hline $\mathrm{P} 06 \mathrm{C}$ & 316N138_4 & $32.5^{\circ} \mathrm{S}$ & Knorr, M. McCartney & $05 / 30 / 92-07 / 04 / 92$ & $113 / 113$ \\
\hline P06E & 316N138_3 & $32.5^{\circ} \mathrm{S}$ & Knorr, H. Bryden & $05 / 02 / 92-05 / 24 / 92$ & $68 / 68$ \\
\hline P08S & $49 X K 9605$ & $130^{\circ} \mathrm{E}$ & Kaiyo, N. Yoshioka & $6 / 17 / 96-07 / 02 / 96$ & $16 / 27$ \\
\hline P09 & 49RY9407 & $137^{\circ} \mathrm{E}$ & Ryofu Maru, I. Kaneko & $07 / 07 / 94-08 / 25 / 94$ & $103 / 105$ \\
\hline $\mathrm{P} 10$ & $3250 \mathrm{TN} 26$ & $149^{\circ} \mathrm{E}$ & T G Thompson, M. Hall & $10 / 05 / 93-11 / 10 / 93$ & $94 / 101$ \\
\hline $\mathrm{P} 11 \mathrm{~S}$ & 09FA693 & $155^{\circ} \mathrm{E}$ & Franklin, J. Church & $06 / 24 / 93-07 / 17 / 93$ & $43 / 80$ \\
\hline $\mathrm{P} 11 \mathrm{~A}$ & 3209AR9391_2 & $155^{\circ} \mathrm{E}$ & Aurora Australis, S. Rintoul & 04/04/93-05/9/93 & $55 / 64$ \\
\hline $\mathrm{P} 13$ & 3220CGC92 & $165^{\circ} \mathrm{E}$ & John V. Vickers, J. Bullister & $08 / 04 / 92-10 / 21 / 92$ & $59 / 86$ \\
\hline $\mathrm{P} 13 \mathrm{C}$ & 49НН915 & $165^{\circ} \mathrm{E}$ & Hakuho Maru, K. Taira & $08 / 13 / 91-10 / 02 / 91$ & $21 / 73$ \\
\hline P13J & 49HН932 & $165^{\circ} \mathrm{E}$ & Hakuho Maru, K. Taira & $05 / 13 / 93-05 / 30 / 93$ & $11 / 22$ \\
\hline $\mathrm{P} 14 \mathrm{C}$ & 3216N138_7 & $176^{\circ} \mathrm{E}$ & Knorr, D. Roemmich & $09 / 01 / 92-09 / 15 / 92$ & $57 / 52$ \\
\hline $\mathrm{P} 14 \mathrm{~N}$ & $325023 / 24$ & $179^{\circ} \mathrm{E}$ & T G Thompson, G. Roden & $07 / 05 / 93-09 / 02 / 93$ & $183 / 185$ \\
\hline $\mathrm{P} 14 \mathrm{~S}$ & 31DSCG96_1 & $172^{\circ} \mathrm{E}$ & Discoverer, J. Bullister & $01 / 05 / 96-02 / 04 / 96$ & $27 / 29$ \\
\hline $\mathrm{P} 15 \mathrm{~S}$ & 31DSCG96_2 & $170^{\circ} \mathrm{W}$ & Discoverer, R. Feely & $02 / 12 / 96-03 / 10 / 96$ & $137 / 150$ \\
\hline \multirow[t]{2}{*}{$\mathrm{P} 15 \mathrm{~N}$} & 18DD9403_1 & $165^{\circ} \mathrm{W}$ & J P Tully, J. Garrett & 09/06/94-10/10/94 & $54 / 177$ \\
\hline & 18DD9403_2 & $165^{\circ} \mathrm{W}$ & J P Tully, H. Freeland & $10 / 18 / 94-10 / 28 / 94$ & $52 / 191$ \\
\hline
\end{tabular}


Table 1 continued

Hydrographic sections used in the analysis. Data are available from CCHDO (2009).

\begin{tabular}{|c|c|c|c|c|c|}
\hline $\begin{array}{l}\text { WOCE } \\
\text { Desig. }\end{array}$ & Expocode & $\begin{array}{l}\text { Nominal } \\
\text { Lat./Long. }\end{array}$ & $\begin{array}{l}\text { Ship (RV) \& } \\
\text { Chief Scientist }\end{array}$ & Date & $\begin{array}{l}\text { \# Stations } \\
\text { Used/Total }\end{array}$ \\
\hline $\mathrm{P} 16 \mathrm{~A}$ & 31N138_9 & $150^{\circ} \mathrm{W}$ & Knorr, J. Reid & $10 / 06 / 92-11 / 25 / 92$ & $50 / 71$ \\
\hline P16S & 31WTTUNES_2 & $150.5^{\circ} \mathrm{W}$ & T. Washington, J. Swift & 08/12/91-08/25/91 & $41 / 41$ \\
\hline $\mathrm{P} 16 \mathrm{C}$ & 31WTTUNES_3 & $150.5^{\circ} \mathrm{W}$ & T. Washington, L. Talley & 08/31/91-10/01/91 & $77 / 148$ \\
\hline $\mathrm{P} 16 \mathrm{~N}$ & 31DSCGC91_3 & $152^{\circ} \mathrm{W}$ & Discoverer, J. Bullister & 02/14/91-04/08/91 & $41 / 80$ \\
\hline $\mathrm{P} 17 \mathrm{E}$ & 316N138_10 & $135^{\circ} \mathrm{W}$ & Knorr, J. Swift & $12 / 04 / 92-01 / 10 / 93$ & $79 / 79$ \\
\hline P17S & 31WTTUNES_2 & $135^{\circ} \mathrm{W}$ & T. Washington, J. Swift & $07 / 16 / 91-08 / 08 / 91$ & $55 / 56$ \\
\hline $\mathrm{P} 17 \mathrm{~A}$ & 316N138_9 & $135^{\circ} \mathrm{W}$ & Knorr, J. Reid & $10 / 06 / 92-11 / 25 / 92$ & $40 / 56$ \\
\hline $\mathrm{P} 17 \mathrm{C}$ & 31WTTUNES_1 & $135^{\circ} \mathrm{W}$ & T. Washington, M. Tsuchiya & $05 / 31 / 91-07 / 11 / 91$ & $82 / 123$ \\
\hline $\mathrm{P} 17 \mathrm{~N}$ & 325021_1 & $24^{\circ} \mathrm{N}, 145^{\circ} \mathrm{W}$ & T G Thompson, D. Musgrave & $05 / 15 / 93-06 / 26 / 93$ & $130 / 202$ \\
\hline $\mathrm{P} 18 \mathrm{~S}$ & 31DSCG94_2 & $110^{\circ} \mathrm{W}$ & Discoverer, B. Taft & $01 / 26 / 94-04 / 27 / 94$ & $77 / 78$ \\
\hline $\mathrm{P} 18 \mathrm{~N}$ & 31DSCG94_3 & $103^{\circ} \mathrm{W}$ & Discoverer, G. Johnson & $01 / 26 / 94-04 / 27 / 94$ & $107 / 107$ \\
\hline P19S & 316N138_10 & $88^{\circ} \mathrm{W}$ & Knorr, J. Swift & $01 / 18 / 93-01 / 22 / 93$ & $27 / 27$ \\
\hline $\mathrm{P} 19 \mathrm{C}$ & 316N138_12 & $88^{\circ} \mathrm{W}$ & Knorr, L. Talley & $02 / 22 / 93-04 / 13 / 93$ & $189 / 221$ \\
\hline $\mathrm{P} 21 \mathrm{E}$ & 318MWESTW_4 & $17^{\circ} \mathrm{S}$ & Melville, M. McCartney & $03 / 27 / 93-05 / 15 / 94$ & $161 / 161$ \\
\hline $\mathrm{P} 21 \mathrm{~W}$ & 318MWESTW_5 & $17^{\circ} \mathrm{S}$ & Melville, H. Bryden & $05 / 19 / 94-06 / 25 / 94$ & $141 / 133$ \\
\hline P31 & 3250031 & $14^{\circ} \mathrm{S}$ & T G Thompson, D. Roemmich & $01 / 25 / 94-02 / 19 / 94$ & $93 / 91$ \\
\hline S04/A21 & 06MT11_5 & $68^{\circ} \mathrm{W}$ & Meteor, W. Roether & $01 / 23 / 90-03 / 08 / 90$ & $15 / 79$ \\
\hline $\mathrm{S} 04 \mathrm{P}$ & 90KDIOFFE6_1 & $67^{\circ} \mathrm{S}$ & Akad. Ioffe, M. Koshlyakov & $02 / 14 / 92-04 / 06 / 92$ & $113 / 113$ \\
\hline S03 & 09AR9404_1 & $63^{\circ} \mathrm{S}, 140^{\circ} \mathrm{E}$ & Aurora Australis, S. Rintoul & $12 / 13 / 94-02 / 02 / 95$ & $19 / 54$ \\
\hline NIWA & Cambell Plateau & $49^{\circ} \mathrm{S}, 172^{\circ} \mathrm{E}$ & Morris et al. (2001) & $05 / 07 / 98-05 / 09 / 98$ & $14 / 26$ \\
\hline Mean & Tropics & $165^{\circ} \mathrm{E}-95^{\circ} \mathrm{W}$ & repeats & $09 / 96-11 / 98$ & $28 / 40$ \\
\hline
\end{tabular}


Table 2

Distance-averaged potential temperature and salinity on neutral density interfaces. Surface and bottom averages include values from every station in the transect, whereas neutral density averages only include values where the interfaces exist.

\begin{tabular}{|c|c|c|c|c|c|c|}
\hline Latitude & & $47^{\circ} \mathrm{N}$ & $24^{\circ} \mathrm{N}$ & $17^{\circ} \mathrm{S}$ & $32^{\circ} \mathrm{S}$ & $67^{\circ} \mathrm{S}$ \\
\hline $\begin{array}{l}\text { Interface } \\
\text { Number }\end{array}$ & $\begin{array}{l}\gamma^{n} \text { Surface } \\
\left(\mathrm{kg} \mathrm{m}^{-3}\right)\end{array}$ & $\bar{\Theta} \frac{\left({ }^{\circ} \mathrm{C}\right)}{S}$ & $\bar{\Theta} \frac{\left({ }^{\circ} \mathrm{C}\right)}{S}$ & $\bar{\Theta} \frac{\left({ }^{\circ} \mathrm{C}\right)}{S}$ & $\bar{\Theta} \frac{\left({ }^{\circ} \mathrm{C}\right)}{S}$ & $\bar{\Theta} \frac{\left({ }^{\circ} \mathrm{C}\right)}{S}$ \\
\hline 1 & surface & $\begin{array}{l}13.53 \\
32.72\end{array}$ & $\begin{array}{l}23.03 \\
34.86\end{array}$ & $\begin{array}{l}25.74 \\
35.70\end{array}$ & $\begin{array}{l}18.54 \\
35.23\end{array}$ & $\begin{array}{r}0.35 \\
33.72\end{array}$ \\
\hline 2 & 22.4 & $\begin{array}{l}- \\
-\end{array}$ & $\begin{array}{l}26.53 \\
34.60\end{array}$ & $\begin{array}{l}28.00 \\
35.22\end{array}$ & - & - \\
\hline 3 & 24.0 & $\begin{array}{l}15.00 \\
32.81\end{array}$ & $\begin{array}{l}22.88 \\
35.02\end{array}$ & $\begin{array}{l}25.15 \\
35.91\end{array}$ & $\begin{array}{l}19.96 \\
34.80\end{array}$ & - \\
\hline 4 & 24.8 & $\begin{array}{l}12.56 \\
32.78\end{array}$ & $\begin{array}{l}19.65 \\
34.90\end{array}$ & $\begin{array}{l}22.47 \\
35.93\end{array}$ & $\begin{array}{r}17.916 \\
34.55\end{array}$ & - \\
\hline 5 & 25.6 & $\begin{array}{r}8.57 \\
32.93\end{array}$ & $\begin{array}{l}15.12 \\
34.51\end{array}$ & $\begin{array}{l}18.29 \\
35.48\end{array}$ & $\begin{array}{l}16.69 \\
34.99\end{array}$ & - \\
\hline 6 & 26.2 & $\begin{array}{r}6.20 \\
33.15\end{array}$ & $\begin{array}{l}11.24 \\
34.24\end{array}$ & $\begin{array}{l}14.24 \\
35.02\end{array}$ & $\begin{array}{l}14.03 \\
34.98\end{array}$ & - \\
\hline 7 & 26.6 & $\begin{array}{r}4.28 \\
33.43\end{array}$ & $\begin{array}{r}8.54 \\
34.13\end{array}$ & $\begin{array}{l}11.34 \\
34.77\end{array}$ & $\begin{array}{l}11.42 \\
34.80\end{array}$ & $\begin{array}{l}-0.44 \\
33.38\end{array}$ \\
\hline 8 & 26.9 & $\begin{array}{r}3.68 \\
33.67\end{array}$ & $\begin{array}{r}6.54 \\
34.11\end{array}$ & $\begin{array}{r}8.91 \\
34.58\end{array}$ & $\begin{array}{r}8.77 \\
34.56\end{array}$ & $\begin{array}{r}0.53 \\
33.59\end{array}$ \\
\hline 9 & 27.1 & $\begin{array}{r}3.62 \\
33.88\end{array}$ & $\begin{array}{r}5.50 \\
34.16\end{array}$ & $\begin{array}{r}7.15 \\
34.47\end{array}$ & $\begin{array}{r}6.77 \\
34.41\end{array}$ & $\begin{array}{r}0.04 \\
33.66\end{array}$ \\
\hline 10 & 27.4 & $\begin{array}{r}3.38 \\
34.20\end{array}$ & $\begin{array}{r}4.28 \\
34.34\end{array}$ & $\begin{array}{r}5.03 \\
34.46\end{array}$ & $\begin{array}{r}4.46 \\
34.36\end{array}$ & $\begin{array}{l}-0.34 \\
33.86\end{array}$ \\
\hline 11 & 27.6 & $\begin{array}{r}2.85 \\
34.37\end{array}$ & $\begin{array}{r}3.48 \\
34.46\end{array}$ & $\begin{array}{r}3.81 \\
34.52\end{array}$ & $\begin{array}{r}3.44 \\
34.46\end{array}$ & $\begin{array}{l}-0.76 \\
34.03\end{array}$ \\
\hline 12 & 27.8 & $\begin{array}{r}2.19 \\
34.51\end{array}$ & $\begin{array}{r}2.50 \\
34.56\end{array}$ & $\begin{array}{r}2.69 \\
34.59\end{array}$ & $\begin{array}{r}2.59 \\
34.57\end{array}$ & $\begin{array}{r}0.15 \\
34.31\end{array}$ \\
\hline 13 & 28.0 & $\begin{array}{r}1.49 \\
34.64\end{array}$ & $\begin{array}{r}1.54 \\
34.65\end{array}$ & $\begin{array}{r}1.64 \\
34.67\end{array}$ & $\begin{array}{r}1.64 \\
34.67\end{array}$ & $\begin{array}{r}1.31 \\
34.65\end{array}$ \\
\hline 14 & 28.1 & $\begin{array}{r}1.11 \\
34.69\end{array}$ & $\begin{array}{r}1.11 \\
34.69\end{array}$ & $\begin{array}{r}1.14 \\
34.70\end{array}$ & $\begin{array}{r}1.20 \\
34.71\end{array}$ & $\begin{array}{r}1.21 \\
34.72\end{array}$ \\
\hline 15 & 28.2 & $\begin{array}{l}- \\
- \\
-\end{array}$ & $\begin{array}{l}- \\
- \\
-\end{array}$ & $\begin{array}{r}0.63 \\
34.71\end{array}$ & $\begin{array}{r}0.63 \\
34.71\end{array}$ & $\begin{array}{r}0.58 \\
34.71\end{array}$ \\
\hline 16 & bottom & $\begin{array}{r}1.07 \\
34.69\end{array}$ & $\begin{array}{r}1.20 \\
34.68\end{array}$ & $\begin{array}{r}1.32 \\
34.69\end{array}$ & $\begin{array}{r}0.58 \\
34.71\end{array}$ & $\begin{array}{l}-0.02 \\
34.70\end{array}$ \\
\hline
\end{tabular}


Table 3

Pacific Ocean water mass definitions.

\begin{tabular}{lllll}
\hline Water Mass & Water Mass & $\begin{array}{l}\text { Neutral Density } \\
\text { Limits }\left(\mathrm{kg} \mathrm{m}^{-3}\right)\end{array}$ & $\begin{array}{l}\text { Model } \\
\text { Layers }\end{array}$ & $\begin{array}{l}\text { Geographic } \\
\text { Limits }\end{array}$ \\
\hline NPSW & Name & below mixed layer -25.5 & 4 & Outcrops $\sim 30^{\circ} \mathrm{N}$ \\
SPSW & S. Pac. Subtropical & below mixed layer -25.5 & 4 & S. Pac. western gyre \\
NPCW & N. Pac. Central & $25.5-26.2$ & 5 & Subducted at $\sim 40^{\circ} \mathrm{N}$ \\
SPCW & S. Pac. Central & $25.5-26.2$ & 5 & Subducted at $\sim 40^{\circ} \mathrm{S}$ \\
SAMW & Subantarctic Mode & $26.2-27.15$ & $6-8$ & S. Pac. gyre \\
NPIW & N. Pac. Intermediate & $26.25-27.15$ & $6-8$ & N. Pac. gyre \\
AAIW & Antarctic Intermediate & $27.15-27.70$ & $9-10$ & \\
NPDW & North Pac. Deep & $27.70-28.01$ & $11-12$ & \\
UCDW & Upper Circumpolar Deep & $28.01-28.10$ & 13 & \\
LCDW & Lower Circumpolar Deep & $28.10-28.16$ & 14 & \\
AABW & Antarctic Bottom & Below 28.16 & 15 & \\
\hline
\end{tabular}


Table 4

Initial estimates of the Ekman transport (column 3) across long lines based on NCEP reanalysis winds (Kalnay et al., 1996) along with the mean (column 4) and standard deviation (column 5) of the Ekman transport integrated along the same long lines (column 5) from five wind products: NCEP; Hellerman and Rosenstein (1983); SOC (Josey et al., 1996, 2002); Trenberth et al. (1989); and ERS. Column 6 shows the Model SR final estimates of Ekman transport. Units: $10^{9} \mathrm{~kg} \mathrm{~s}^{-1}$. Positive is northward on the zonal transects (above the middle line). Positive is eastward on the meridional transects (below the middle line). ${ }^{\dagger}$ Only 3 wind products are included in estimate of mean and standard deviation for S04/A21. ${ }^{\ddagger}$ Only 4 wind products are included in estimate of mean and standard deviation for S03.

\begin{tabular}{|c|c|c|c|c|c|}
\hline WOCE & Nominal & NCEP Ekman & Wind & Product & Model \\
\hline Desig. & Lon/Lat & Mass Flux & Average & Std. Dev. & Estimate \\
\hline P01 & $45^{\circ} \mathrm{N}$ & -4.3 & -5.1 & 1.4 & -4.3 \\
\hline P03 & $24^{\circ} \mathrm{N}$ & 8.4 & 10.1 & 2.0 & 8.5 \\
\hline P04 & $10^{\circ} \mathrm{N}$ & 30.8 & 30.4 & 7.7 & 30.6 \\
\hline $\mathrm{P} 21$ & $17^{\circ} \mathrm{S}$ & -19.0 & -18.7 & 1.5 & -10.2 \\
\hline P06 & $32^{\circ} \mathrm{S}$ & 1.3 & 1.1 & 1.0 & 1.2 \\
\hline $\mathrm{S}_{0} 4 \mathrm{P}^{\dagger}$ & $67^{\circ} \mathrm{S}$ & 5.0 & 5.0 & 1.6 & 4.9 \\
\hline P09 & $137^{\circ} \mathrm{E}$ & -1.0 & -1.0 & 0.1 & -0.9 \\
\hline $\mathrm{S} 03^{\ddagger}$ & $142^{\circ} \mathrm{E}$ & -0.2 & 0.0 & 0.2 & -0.1 \\
\hline P10 & $149^{\circ} \mathrm{E}$ & -1.3 & -2.4 & 3.9 & -1.4 \\
\hline P11 & $154^{\circ} \mathrm{E}$ & 0.8 & 0.5 & 0.3 & 0.8 \\
\hline $\mathrm{P} 13$ & $165^{\circ} \mathrm{E}$ & -2.4 & -1.8 & 1.9 & -3.7 \\
\hline P14 & $176^{\circ} \mathrm{E}$ & -1.4 & -2.0 & 0.9 & -0.4 \\
\hline $\mathrm{P} 15$ & $170^{\circ} \mathrm{W}$ & -2.3 & -3.8 & 1.5 & -3.3 \\
\hline P16 & $152^{\circ} \mathrm{W}$ & -0.7 & -1.1 & 2.2 & -0.7 \\
\hline $\mathrm{P} 17$ & $135^{\circ} \mathrm{W}$ & -2.7 & -3.8 & 1.4 & -2.3 \\
\hline P18 & $103^{\circ} \mathrm{W}$ & -4.1 & -4.3 & 1.6 & 3.2 \\
\hline P19 & $88^{\circ} \mathrm{W}$ & -2.6 & -6.4 & 2.9 & -3.9 \\
\hline S04/A21 & $68^{\circ} \mathrm{W}$ & 0.5 & 0.3 & 0.2 & 0.5 \\
\hline
\end{tabular}


Table 5

Model constraints. ${ }^{\dagger}$ See text for source of constraint.

Type Constraint and Initial Estimate of Uncertainty

\section{Conservation Constraints}

Mass

Silicate

Volume

Heat Anomaly

Oxygen Anomaly

Phosphate Anomaly

Salinity Anomaly
Top to bottom in all boxes $\left( \pm 1 \times 10^{9} \mathrm{~kg} \mathrm{~s}^{-1}\right)$

Top to bottom in all boxes, except Southern Ocean $\left( \pm 50 \mathrm{kmol} \mathrm{s}^{-1}\right)$

In bulk outcropping layers \& each non-outcropping layer $\left( \pm 2 \times 10^{6} \mathrm{~m}^{3} \mathrm{~s}^{-1}\right)$

In bulk outcropping layers and each non-outcropping layer

In bulk outcropping layers and each non-outcropping layer

In bulk outcropping layers and each non-outcropping layer

In bulk outcropping layers and each non-outcropping layer

\section{Surface and Transect Flux Constraints}

Freshwater Fluxes: Baumgartner and Reichel (1975) with an integration reference point at

Bering Strait included in net across each zonal line

Bering Strait: $\quad 0.83 \pm 0.66 \times 10^{6} \mathrm{~m}^{3} \mathrm{~s}^{-1}$ (Roach et al., 1995) included in net across each zonal line

Net Meridional Mass: Bering Strait + Freshwater

$\left(32^{\circ} \mathrm{S} 0.4,17^{\circ} \mathrm{S} 0.2,10^{\circ} \mathrm{N} 0.7,24^{\circ} \mathrm{N} 0.6,47^{\circ} \mathrm{N} 0.6\right.$, uncertainty \pm 0.7$)$

Indonesian Passage: $\quad 10 \pm 5 \times 10^{9} \mathrm{~kg} \mathrm{~s}^{-1}$ included in net across $17^{\circ} \mathrm{S}$ and $32^{\circ} \mathrm{S}^{\dagger}$

ACC: $\quad 138.7 \pm 10.7 \times 10^{9} \mathrm{~kg} \mathrm{~s}^{-1}$ placed at Drake Passage ${ }^{\dagger}$

$148.7 \pm 10.7 \times 10^{9} \mathrm{~kg} \mathrm{~s}^{-1}$ placed across Tasamania-Antarctica section ${ }^{\dagger}$

On each long meridional line, the flux is set as appropriate to match the Drake

Passage, Tasmania-Antarctica and/or Indonesian Passage Throughflow transports

Ekman Fluxes: $\quad$ NCEP Re-analysis winds (Kalnay et al., 1996)

Initial uncertainty from variance in 5 wind products (Table 4)

Ekman convergence/divergence within each box $=$ net top to bottom geostrophic outflow/inflow.

Geostrophic + Ekman flux across each long zonal line $=$ net inflow/outflow.

\section{Notes}

Outcrops: $\quad$ Conservation in outcropping layers is achieved through air-sea exchange terms. Anomalies Calculation of initial estimate of anomaly constraint uncertainty is discussed in Appendix A 
Table 6

Topographic and mass flux model constraints.

\begin{tabular}{|c|c|c|c|}
\hline $\begin{array}{l}\text { Met* } \\
(\mathrm{Y} / \mathrm{N})\end{array}$ & $\begin{array}{l}\text { Input Estimate } \\
\left(10^{9} \mathrm{~kg} \mathrm{~s}^{-1}\right)\end{array}$ & $\begin{array}{l}\text { SR Result } \\
\left(10^{9} \mathrm{~kg} \mathrm{~s}^{-1}\right)\end{array}$ & $\begin{array}{l}\text { Constraint Description and Source } \\
\text { R96=Roemmich et al. (1996), JT93=Johnson and Toole (1993) }\end{array}$ \\
\hline \multicolumn{4}{|c|}{ Station Pair Specific Mass Flux Constraints } \\
\hline $\mathrm{Y}$ & $12.0 \pm 1.0$ & $9.9 \pm 0.8$ & P06 Net northward abyssal flow $\gamma^{n}>28.1 \mathrm{~kg} \mathrm{~m}^{-3}$ \\
\hline $\mathrm{N}$ & $10.6 \pm 1.7$ & $5.7 \pm 0.8$ & P21 Net northward abyssal flow $\gamma^{n}>28.1$, R96 \\
\hline $\mathrm{N}$ & $10.6 \pm 1.7$ & $6.3 \pm 1.1$ & P31 Net northward abyssal flow $\gamma^{n}>28.1$, R96 \\
\hline $\mathrm{Y}$ & $8.0 \pm 1.0$ & $7.3 \pm 0.9$ & P31 Samoan Passage $\gamma^{n}>28.1$, R96 \\
\hline $\mathrm{Y}$ & $1.1 \pm 1.0$ & $0.8 \pm 0.6$ & P31 Robbie Ridge $\gamma^{n}>28.1$, R96 \\
\hline $\mathrm{Y}$ & $2.9 \pm 1.0$ & $2.4 \pm 0.9$ & P31 East of Manihiki Plateau $\gamma^{n}>28.1$, R96 \\
\hline $\mathrm{Y}$ & $0.0 \pm 0.5$ & $0.2 \pm 0.5$ & P31 Between Samoan Pass. \& Manihiki Plat. $\gamma^{n}>28.1$, R96 \\
\hline $\mathrm{Y}$ & $5.0 \pm 3.0$ & $3.4 \pm 1.3$ & P03 Northward abyssal flow $\gamma^{n}>28.0$ \\
\hline $\mathrm{Y}$ & $0.0 \pm 1.0$ & $0.9 \pm 0.8$ & P01 Disallow creation of bottom water $\gamma^{n}>28.1$ \\
\hline $\mathrm{Y}$ & $0.4 \pm 0.4$ & $0.0 \pm 0.1$ & P04 Yap Trench, JT93 \\
\hline $\mathrm{Y}$ & $6.0 \pm 2.0$ & $3.5 \pm 1.4$ & P04 East Marianna, JT93 \\
\hline $\mathrm{Y}$ & $8.5 \pm 2.0$ & $6.6 \pm 1.6$ & P04 Central Basin, DWBC, JT93 \\
\hline $\mathrm{Y}$ & $-4.9 \pm 2.0$ & $-6.2 \pm 1.6$ & P04 Northeast Pacific Basin, JT93 \\
\hline \multicolumn{4}{|c|}{ Station Pair Specific Mass Flux Divergence Constraints from Ganachaud (1999) } \\
\hline $\mathrm{Y}$ & $0.0 \pm 0.5$ & $0.1 \pm 0.5$ & P21 - P06 New Caledonia Trough $\gamma^{n}>27.8$ \\
\hline $\mathrm{Y}$ & $0.0 \pm 0.5$ & $0.1 \pm 0.5$ & P21 - P06 South Fiji Basin $\gamma^{n}>28.0$ \\
\hline \multicolumn{4}{|c|}{ Station Pair Specific Topographic Constraints from Ganachaud (1999) } \\
\hline $\mathrm{Y}$ & $0.0 \pm 1.0$ & $0.8 \pm 0.7$ & P06 Tasman Basin $\gamma^{n}>28.1$ \\
\hline $\mathrm{Y}$ & $0.0 \pm 1.0$ & $0.1 \pm 0.5$ & P21 North Tasman Basin $\gamma^{n}>28.1$ \\
\hline $\mathrm{Y}$ & $0.0 \pm 1.0$ & $0.1 \pm 0.6$ & P06 New Caledonia Trough $\gamma^{n}>27.8$ \\
\hline $\mathrm{Y}$ & $0.0 \pm 1.0$ & $0.0 \pm 0.9$ & P21 Yupanqui Basin $\gamma^{n}>28.0$ \\
\hline $\mathrm{Y}$ & $0.0 \pm 1.0$ & $0.1 \pm 0.9$ & P21 North Peru Basin $\gamma^{n}>28.0$ \\
\hline $\mathrm{Y}$ & $0.0 \pm 1.0$ & $0.1 \pm 1.0$ & P21 Bauer Basin $\gamma^{n}>28.0$ \\
\hline $\mathrm{Y}$ & $0.0 \pm 0.5$ & $0.0 \pm 0.4$ & P03 Okinawa Trough $\gamma^{n}>27.6$ \\
\hline $\mathrm{Y}$ & $0.0 \pm 0.5$ & $0.0 \pm 0.5$ & P03 North Philippine Basin $\gamma^{n}>28.0$ \\
\hline $\mathrm{Y}$ & $0.0 \pm 0.5$ & $0.0 \pm 0.5$ & P01 Kuril Trench $\gamma^{n}>28.1$ \\
\hline
\end{tabular}


Table 7

Initial estimates of uncertainties for model unknowns.

\begin{tabular}{|c|c|c|}
\hline Jnknown & Model & Initial Estimate of Square Root Solution (Co)Variance \\
\hline \multirow[t]{4}{*}{$\mathbf{v}_{R}$} & LR\& SR & Based on velocity shear in the region of the reference surface \\
\hline & & Not less than $5 \mathrm{~cm} \mathrm{~s}^{-1}$ above $1000 \mathrm{dbar}$, not less than $2 \mathrm{~cm} \mathrm{~s}^{-1}$ below $1000 \mathrm{dbar}$ \\
\hline & & $10 \mathrm{~cm} \mathrm{~s}^{-1}$ within the ACC \\
\hline & & $6 \mathrm{~cm} \mathrm{~s}^{-1}$ for absolute velocity corrections near the equator (Johnson et al., 2002) \\
\hline \multirow[t]{3}{*}{$\mathbf{E}_{m}$} & LR\& SR & Based on the variance among 7 wind products including, where available: \\
\hline & & ERS, Hellerman and Rosenstein, NCEP, Oberhuber, SOC, SSMI and Trenberth. \\
\hline & & On average approximately $20 \%$ of the NCEP Ekman transport value. \\
\hline \multirow[t]{2}{*}{$\mathbf{w}$} & LR & $2 \times 10^{-5} \mathrm{~cm} \mathrm{~s}^{-1}$ \\
\hline & $\mathrm{SR}$ & Set to the final solution covariance of model LR \\
\hline \multirow[t]{2}{*}{$\mathbf{k}_{z}$} & LR & $1 \mathrm{~cm}^{2} \mathrm{~s}^{-1}$ \\
\hline & $\mathrm{SR}$ & Set to the final solution covariance of model LR \\
\hline $\mathbf{J}_{\text {phosphate }}$ & $\mathrm{LR} \& \mathrm{SR}$ & $0.04 \mu \mathrm{mol} \mathrm{kg}^{-1} \mathrm{yr}^{-1}$ in interior layer \\
\hline $\mathbf{J}_{\text {heat }}$ & LR \& SR & $30 \mathrm{~W} \mathrm{~m}^{2}$, within bulk outcropping layers representing an air-sea exchange \\
\hline $\mathbf{J}_{\text {salt }}$ & LR \& SR & $2000 \mathrm{~mm} \mathrm{yr}^{-1}$, E-P within bulk outcropping layers, air-sea exchange \\
\hline $\mathbf{J}_{\text {oxygen }}$ & $\mathrm{LR} \& \mathrm{SR}$ & $200 \mathrm{~mol} \mathrm{~m}^{2} \mathrm{yr}^{-1}$, within outcropping layers, air-sea exchange \\
\hline
\end{tabular}


Table 8

Model estimates of equatorial current transport. See text for definitions designed to match those of Johnson et al. (2002).

\begin{tabular}{|c|c|c|c|c|c|c|}
\hline WOCE & Nominal & $\mathrm{SEC}(\mathrm{S})$ & $\mathrm{SEC}(\mathrm{N})$ & NECC & EUC & NEC \\
\hline Desig. & Lat. & $10^{9} \mathrm{~kg} \mathrm{~s}^{-1}$ & $10^{9} \mathrm{~kg} \mathrm{~s}^{-1}$ & $10^{9} \mathrm{~kg} \mathrm{~s}^{-1}$ & $10^{9} \mathrm{~kg} \mathrm{~s}^{-1}$ & $10^{9} \mathrm{~kg} \mathrm{~s}^{-1}$ \\
\hline P10 & $149^{\circ} \mathrm{E}$ & -14 & -4 & 25 & 12 & -36 \\
\hline $\mathrm{P} 13$ & $165^{\circ} \mathrm{E}$ & -10 & 0 & 14 & 14 & -20 \\
\hline $\mathrm{P} 14$ & $179^{\circ} \mathrm{E}$ & -27 & -1 & 26 & 15 & -32 \\
\hline $\mathrm{P} 15$ & $170^{\circ} \mathrm{W}$ & -21 & 0 & 30 & 18 & -27 \\
\hline P16 & $152^{\circ} \mathrm{W}$ & -35 & -1 & 14 & 29 & -35 \\
\hline $\mathrm{P} 17$ & $135^{\circ} \mathrm{W}$ & -19 & -2 & 24 & 26 & -26 \\
\hline P18 & $103^{\circ} \mathrm{W}$ & -8 & -1 & 5 & 16 & -25 \\
\hline P19 & $88^{\circ} \mathrm{W}$ & -2 & -3 & 11 & 6 & -9 \\
\hline
\end{tabular}


Table 9

Model estimates of mass transport for major currents.

\begin{tabular}{lrr}
\hline Name & $\begin{array}{r}\text { Section } \\
\text { Position }\end{array}$ & $\begin{array}{r}\text { Mass Transport } \\
10^{9} \mathrm{~kg} \mathrm{~s}^{-1}\end{array}$ \\
\hline East Australia Current & $17^{\circ} \mathrm{S}$ & $-27.5 \pm 8.3$ \\
East Australia Current & $32^{\circ} \mathrm{S}$ & $-39.9 \pm 7.8$ \\
Kuroshio & $24^{\circ} \mathrm{N}$ & $31.1 \pm 1.7$ \\
Kuroshio & $137^{\circ} \mathrm{E}$ & $78.9 \pm 11.0$ \\
Kuroshio & $143^{\circ} \mathrm{E}$ & $88.3 \pm 8.1$ \\
Mindanao & $10^{\circ} \mathrm{N}$ & $-30.5 \pm 11.2$ \\
Antarctic Circumpolar Current & $142^{\circ} \mathrm{E}$ & $141.1 \pm 5.0$ \\
Antarctic Circumpolar Current & $68^{\circ} \mathrm{W}$ & $133.5 \pm 4.8$ \\
Pacific Indian Throughflow & $\sim 130^{\circ} \mathrm{E}$ & $-10.4 \pm 1.5$ \\
& & \\
\hline
\end{tabular}

Table 10

Estimates of deep western boundary current transport in the northwest Pacific.

\begin{tabular}{lrrrrrrrr}
\hline WOCE & \multicolumn{2}{c}{ Nominal } & Cont. & Inshore & Offshore & Beyond & $\gamma^{n}$ & Interface \\
Desig. & Lat. & Lon. & Slope & side of Trench & $\begin{array}{r}\text { Trench } \\
\text { Layers }\end{array}$ & Pressure \\
& ${ }^{\circ} \mathrm{N}$ & ${ }^{\circ} \mathrm{E}$ & $10^{9} \mathrm{~kg} \mathrm{~s}^{-1}$ & $10^{9} \mathrm{~kg} \mathrm{~s}^{-1}$ & $10^{9} \mathrm{~kg} \mathrm{~s}^{-1}$ & $10^{9} \mathrm{~kg} \mathrm{~s}^{-1}$ & dbars & \\
\hline P13 & 53.3 & 162.4 & $3.2 \pm 1.3$ & $-1.5 \pm 4.1$ & $8.7 \pm 7.6$ & $\mathrm{~N} / \mathrm{A}$ & $12-14$ & 1450 -bot. \\
P01 & 42.3 & 146.0 & $-3.2 \pm 4.0$ & $8.0 \pm 5.9$ & $-5.0 \pm 4.7$ & $5.7 \pm 10.6$ & $12-14$ & 1575 -bot. \\
P10 & 34.1 & 142.6 & $-1.9 \pm 1.6$ & $1.2 \pm 1.2$ & $-31.5 \pm 12.1$ & $34.5 \pm 14.2$ & $12-14$ & 1650 -bot. \\
P03 & 25.4 & 129.2 & $0.1 \pm 5.1$ & $3.2 \pm 6.8$ & $-4.1 \pm 6.9$ & $-0.9 \pm 5.7$ & $12-13$ & 1575 -bot. \\
P03 & 25.2 & 144.4 & $-2.6 \pm 2.8$ & $-7.7 \pm 8.1$ & $9.3 \pm 7.7$ & $8.8 \pm 9.4$ & $12-14$ & 1550 -bot. \\
\hline
\end{tabular}


Table 11

Comparison to Ganachaud and Wunsch (2000) Pacific basin-averaged $\mathbf{w}$ and $\mathbf{k}_{\mathbf{z}}$.

\begin{tabular}{lllll}
\hline Source & \multicolumn{2}{c}{$\gamma^{n}$ Interfaces } & $\begin{array}{l}\overline{\mathbf{w}} \\
10^{-5} \mathrm{~cm} \mathrm{~s}^{-1}\end{array}$ & $\begin{array}{l}\overline{\mathrm{k}_{\mathrm{z}}} \\
\mathrm{cm}^{2} \mathrm{~s}^{-1}\end{array}$ \\
\hline GW2000 & Deep & $27.96-28.07$ & $1.0 \pm 0.3$ & $4 \pm 1$ \\
Current Work & Deep & $27.8-28.0$ & $0.5 \pm 0.6$ & $0.9 \pm 0.1$ \\
GW2000 & Bottom & $28.1-28.2$ & $4 \pm 1$ & $9 \pm 2$ \\
Current Work & Bottom & $28.1-28.2$ & $1.0 \pm 0.5$ & $0.8 \pm 0.1$ \\
\hline
\end{tabular}


Table 12

Transport estimates for major Pacific currents from ECCO-GODAE monthly means (Olson, 2006) compared to Model SR results. ECCO uncertainty estimates are based on standard deviations of monthly mean values over the period of the run. Cross-basin Equatorial Current errorbars are based on the standard deviation of the Model SR meridional section estimates. Positive: eastward and northward.

\begin{tabular}{|c|c|c|c|c|c|}
\hline \multirow[t]{2}{*}{ Current } & Source & Latitude & Longitude & Above & ECCO/Model SR \\
\hline & & & & Depth (m) & $10^{6} \mathrm{~m}^{3} \mathrm{~s}^{-1} / 10^{9} \mathrm{~kg} \mathrm{~s}^{-1}$ \\
\hline \multirow[t]{3}{*}{ Oyashio } & Olson (2006) & $48^{\circ} \mathrm{N}$ & $155.0-166.0^{\circ} \mathrm{E}$ & 1750 & $-11.4 \pm 3.7$ \\
\hline & This work & $47^{\circ} \mathrm{N}$ & $152.3-158.7^{\circ} \mathrm{E}$ & 1550 & $-11.0 \pm 3.4$ \\
\hline & This work & $47^{\circ} \mathrm{N}$ & $152.3-158.7^{\circ} \mathrm{E}$ & bottom & $-24.1 \pm 11.7$ \\
\hline \multirow[t]{4}{*}{ Kuroshio } & Olson (2006) & $26^{\circ} \mathrm{N}$ & $121.0-134.0^{\circ} \mathrm{E}$ & 1750 & $48.3 \pm 3.2$ \\
\hline & This work & $27^{\circ} \mathrm{N}$ & $125.8-126.6^{\circ} \mathrm{E}$ & bottom & $31.0 \pm 1.7$ \\
\hline & This work & $31.8-33.4^{\circ} \mathrm{N}$ & $137^{\circ} \mathrm{E}$ & bottom & $78.0 \pm 11.0$ \\
\hline & This work & $34.8-32.5^{\circ} \mathrm{N}$ & $141.5-145.2^{\circ} \mathrm{E}$ & 4300 & $88.3 \pm 8.1$ \\
\hline \multirow[t]{3}{*}{ EAC } & Olson (2006) & $30^{\circ} \mathrm{S}$ & $145.0-158.0^{\circ} \mathrm{E}$ & 2200 & $-22.9 \pm 2.6$ \\
\hline & This work & $30.1^{\circ} \mathrm{S}$ & $153.5-154.5^{\circ} \mathrm{E}$ & bottom & $-39.7 \pm 7.9$ \\
\hline & This work & $24.8^{\circ} \mathrm{S}$ & $153.7-155.3^{\circ} \mathrm{E}$ & bottom & $-26.1 \pm 8.2$ \\
\hline \multirow[t]{3}{*}{ SECS } & Olson (2006) & $20-3^{\circ} \mathrm{S}$ & $140.0^{\circ} \mathrm{W}$ & 360 & $-21.9 \pm 10.9$ \\
\hline & This work & $8-0^{\circ} \mathrm{S}$ & $149^{\circ} \mathrm{E}-88^{\circ} \mathrm{W}$ & $\sigma_{\theta}<26.0$ & $-17.0 \pm 10.7$ \\
\hline & This work & $8-0^{\circ} \mathrm{S}$ & $135^{\circ} \mathrm{W}$ & $180 \pm 40$ & $-19.0 \pm 1.0$ \\
\hline \multirow[t]{3}{*}{ NEC } & Olson (2006) & $11-27^{\circ} \mathrm{N}$ & $140.0^{\circ} \mathrm{W}$ & 360 & $-18.9 \pm 2.7$ \\
\hline & This work & $2-15^{\circ} \mathrm{N}$ & $149^{\circ} \mathrm{E}-88^{\circ} \mathrm{W}$ & $\sigma_{\theta}<26.0$ & $-26.3 \pm 8.8$ \\
\hline & This work & $2-15^{\circ} \mathrm{N}$ & $135^{\circ} \mathrm{W}$ & $140 \pm 25$ & $-25.0 \pm 2.0$ \\
\hline \multirow[t]{3}{*}{ NECC } & Olson (2006) & $2^{\circ} \mathrm{S}-10^{\circ} \mathrm{N}$ & $140.0^{\circ} \mathrm{W}$ & 360 & $14.8 \pm 5.4$ \\
\hline & This work & $2-8^{\circ} \mathrm{N}$ & $149^{\circ} \mathrm{E}-88^{\circ} \mathrm{W}$ & $\sigma_{\theta}<26.0$ & $18.8 \pm 8.8$ \\
\hline & This work & $2-8^{\circ} \mathrm{N}$ & $135^{\circ} \mathrm{W}$ & $155 \pm 15$ & $24.0 \pm 2.0$ \\
\hline \multirow[t]{2}{*}{$\mathrm{ACC}$} & Olson (2006) & $50-60^{\circ} \mathrm{S}$ & $73^{\circ} \mathrm{W}$ & bottom & $146.1 \pm 4.9$ \\
\hline & This work & $57-57^{\circ} \mathrm{S}$ & $68^{\circ} \mathrm{W}$ & bottom & $133.3 \pm 4.8$ \\
\hline
\end{tabular}




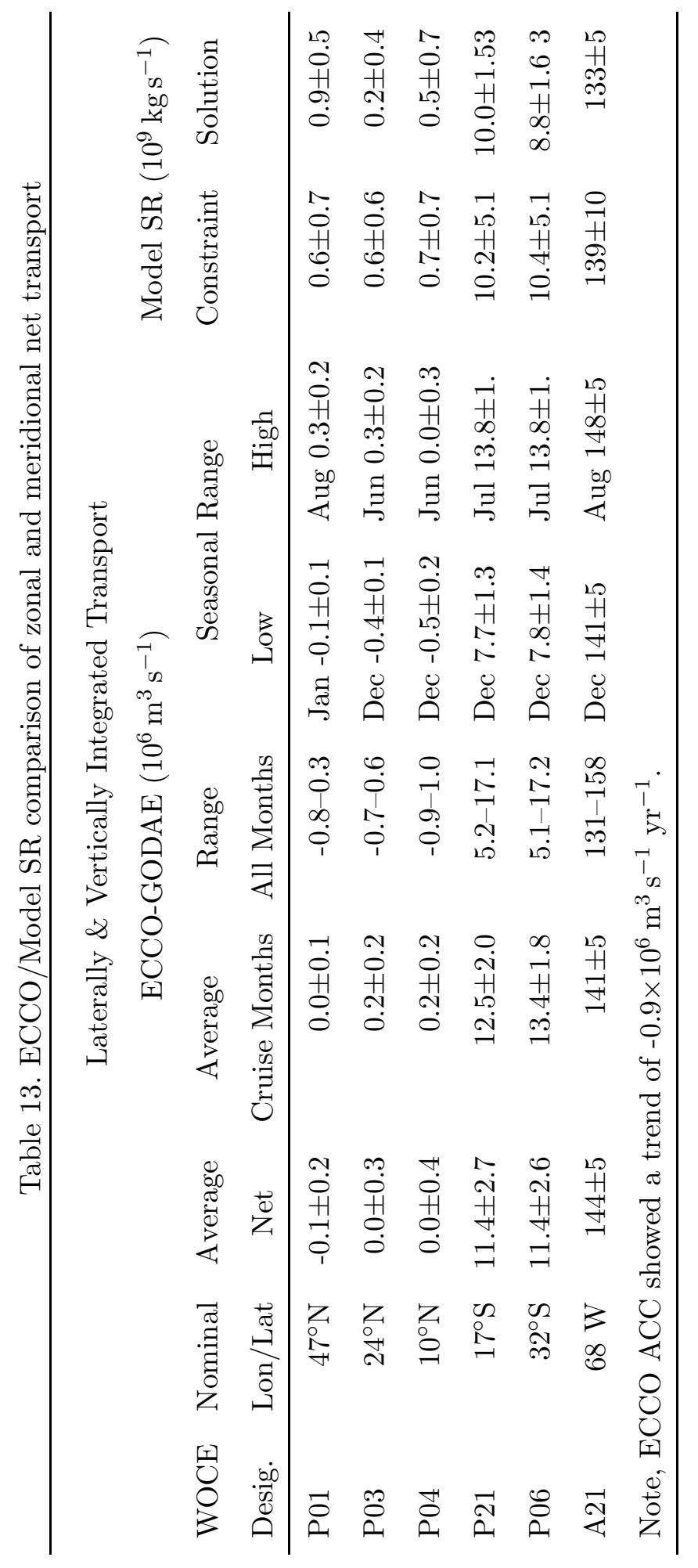


Table A.1

The Model SR twenty constraints that are least well met.

\begin{tabular}{|c|c|c|c|c|c|c|c|c|}
\hline Constraint & Description & & Layer/ & Residual/ & Residual & Input & RHS & Output \\
\hline Box & Property & Type & Interface & Uncertainty & & Estimate & & Estimate \\
\hline 10003 & heat & $\mathrm{A}$ & 15 & 6.3 & 0.32 & $0.00 \pm 0.05$ & 0.00 & $0.32 \pm 0.03$ \\
\hline 10007 & volume & $\mathrm{W}$ & 14 & 6.2 & 2.1 & $0.0 \pm 0.3$ & $(1.4)$ & $2.1 \pm 0.3$ \\
\hline 10006 & volume & W & 14 & 5.0 & 1.7 & $0.0 \pm 0.3$ & $(2.1)$ & $1.7 \pm 0.2$ \\
\hline 10002 & volume & W & 13 & 3.8 & 1.3 & $0.0 \pm 0.3$ & $(0.5)$ & $1.3 \pm 0.3$ \\
\hline 10007 & heat & $\mathrm{A}$ & 15 & 3.6 & 0.13 & $0.00 \pm 0.04$ & 0.00 & $0.13 \pm 0.03$ \\
\hline 39 & phspht & $\mathrm{A}$ & 10 & 3.2 & -0.6 & $0.0 \pm 0.2$ & 1.0 & $-0.6 \pm 0.1$ \\
\hline 78 & phspht & $\mathrm{A}$ & 12 & 3.1 & -1.0 & $0.0 \pm 0.3$ & 3.4 & $-1.0 \pm 0.2$ \\
\hline 10007 & volume & $\mathrm{W}$ & 15 & 3.1 & 1.0 & $0.0 \pm 0.3$ & $(-0.8)$ & $1.0 \pm 0.1$ \\
\hline 10003 & heat & $\mathrm{A}$ & 14 & 3.1 & -3.7 & $0.0 \pm 1.2$ & 14.5 & $-3.7 \pm 0.8$ \\
\hline 10003 & heat & $\mathrm{A}$ & 9 & 3.0 & 107 & $0 \pm 36$ & 3 & $107 \pm 26$ \\
\hline 52 & heat & $\mathrm{A}$ & 6 & 2.9 & 71 & $0 \pm 24$ & 4.3 & $71 \pm 14$ \\
\hline $\mathrm{P} 21-17^{\circ} \mathrm{S}$ & mass & $\mathrm{T}$ & $14-15$ & 2.9 & 4.9 & $-10.6 \pm 1.7$ & 1.1 & $-5.7 \pm 0.8$ \\
\hline 39 & phspht & $\mathrm{A}$ & 9 & 2.9 & -0.7 & $0.0 \pm 0.2$ & 0.8 & $0.7 \pm 0.2$ \\
\hline 10007 & volume & $\mathrm{A}$ & 5 & 2.8 & 5.5 & $0.0 \pm 2.0$ & -11.8 & $5.5 \pm 0.9$ \\
\hline Samoan & mass & $\mathrm{T}$ & 14 & 2.7 & -4.6 & $10.9 \pm 1.7$ & 2.2 & $6.3 \pm 1.1$ \\
\hline 10003 & volume & W & 15 & 2.7 & 0.4 & $0.0 \pm 0.3$ & $(-0.8)$ & $0.9 \pm 0.2$ \\
\hline 51 & volume & $\mathrm{A}$ & 4 & 2.7 & 0.5 & $0.0 \pm 2.0$ & -6.5 & $5.4 \pm 0.8$ \\
\hline 4142 & heat & $\mathrm{A}$ & 6 & 2.7 & 20 & $0 \pm 7$ & -3 & $20 \pm 5$ \\
\hline 50 & heat & $\mathrm{A}$ & 6 & 2.7 & 61 & $0 \pm 23$ & -2.3 & $61 \pm 15$ \\
\hline 50 & heat & $\mathrm{A}$ & 9 & 2.6 & 11.1 & $0.0 \pm 4.2$ & -2.2 & $11.1 \pm 3.0$ \\
\hline
\end{tabular}

Units: mass $10^{9} \mathrm{~kg} \mathrm{~s}^{-1}$, volume $10^{6} \mathrm{~m}^{3} \mathrm{~s}^{-1}$, nutrients $\mathrm{kmol} \mathrm{s}^{-1}$, heat $1 \mathrm{x} 10^{12} \mathrm{~W}$

$\mathrm{A}$-anomaly, $\mathrm{T}$-transport, $\mathrm{W}$ - matching vertical transports $\sum \mathrm{Tw}_{S R}=\mathrm{Tw}_{L R}$

For the $\mathrm{W}$ constraints, $\mathrm{Tw}_{L R}$ is given in parenthesis in column 8, "RHS".

RHS stands for the right handside of Equation 1. 